Portland State University

PDXScholar

8-1-1967

\title{
Das satirische Element in den Werken Nestroys
}

Walter Pauler

Portland State University

Follow this and additional works at: https://pdxscholar.library.pdx.edu/open_access_etds

Part of the German Language and Literature Commons Let us know how access to this document benefits you.

\section{Recommended Citation}

Pauler, Walter, "Das satirische Element in den Werken Nestroys" (1967). Dissertations and Theses. Paper 708.

https://doi.org/10.15760/etd.708

This Thesis is brought to you for free and open access. It has been accepted for inclusion in Dissertations and Theses by an authorized administrator of PDXScholar. Please contact us if we can make this document more accessible: pdxscholar@pdx.edu. 
Walter Pauler for the Master of Arts in German Date thesis is presented: August 1, 1967

TITLE: DAS SATIRISCHE ELEMENT IN DEN WERKEN NESTROYS. Abstract approved:

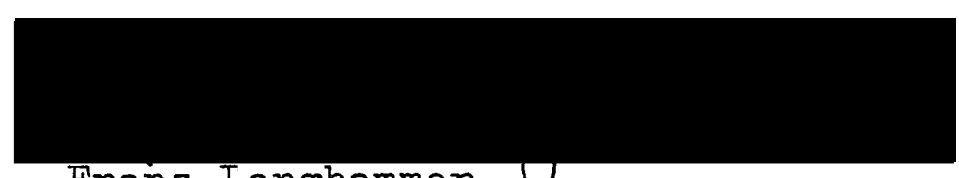

Franz Langhammer $O$

Associate Professor of German

This thesis proposes to show the satirical element in the works of Nestroy. Nestroy was playwright and actor, producer and director. His dramatic art represents the highest development in the three hundred year tradition of the "Wiener Volkstheater". For this reason, the thesis begins with a summary of the evolution of the "Wiener Volkstheater".

Following a brief chapter appraising comedy, various definitions of satire have been summarized. The theories have been examined with the intention of finding a general definition of the genre. It has been concluded that each author of satire has an individualized style and use of satire, based on his selection of models and their subsequent interpretation by him. Thus diverse definitions of satire must be incorporated in evaluating Nestroy's 
works, as his satire ranges from fine irony to invective. As the satiric element in Nestroy's plays evolves out of familiar comic conventions, it represents an unusual blend in the history of the "Wiener Volkstheater" (satirical farce).

For Nestroy the stage was not a means of transforming a poetic vision into reality, but for reflecting with satiric wit upon man's caricatured image. The hilarious framework of his plots are a concession to the audience, as is the reference to local institutions, topography and habits.

Despite a surprising variety of language technique, which he inherited from the "Wiener Volkstheater", he created new forms of language usage. In his satirical attacks, he exposes the shortcomings of his contemporaries through deliberately unpoetic dialogues, witty antithesis, vivid figures of ironic speech, provocative aphorisms and series of questions and definitions that reveal the weaknesses of his characters. By interweaving technical terminology in his dialogues, Nestroy achieved comic and parodistic effects; through these hilarious incongruities he satirized various professions. Nestroy's dramatic satire originates in his hyperbolic portrayal of human shortcomings.

Behind a gay facade, the sceptic views presented in Nestroy's plays are not immediately obvious. However, a 
pessimistic outlook dominates Nestroy's satire. His satirical contrasts demonstrate the imperfection of man, and reveal Nestroy's doubt about the validity of ideals. Nestroy recognized, perhaps intuitively, that measuring reality against the ideal on the stage might create a "Schaubühne als moralische Anstalt." As a result, Nestroy often refers to transcendence through intellect. Nestroy found it sufficient to portray human shortcomings, often in hyperbolic manner, without reference to an acceptable ideal. He leaves the interpretation of his satirical attack to his audience.

All of the elements of stage technique heighten the masterly dialogue in Nestroy's plays, making his unique satirical farces among the most admirable within the German tradition of comedy. 
DAS SATIRTSCHF ELEMENTI

IN DEN WERHEN NESTROYS

\author{
by \\ Waltex Paules
}

\begin{abstract}
A THESIS
Presented to the Department of Foreign Languages and the Graduate Council of Portland State Coljege in partial fulfillment of the requirements for the degree of Master of Arts in German June 1968
\end{abstract}


APPROVED:

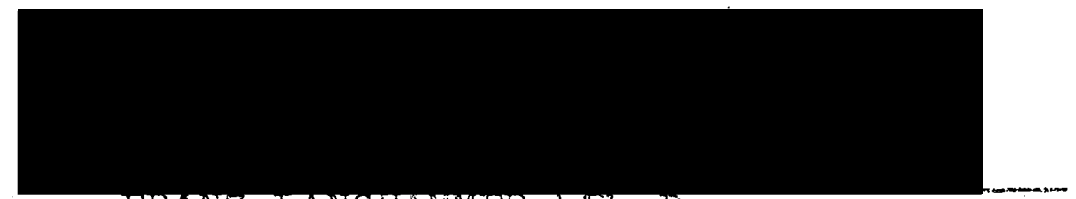

FRANZ LANGHAMNER, Wh.D.

Associate Professor of German

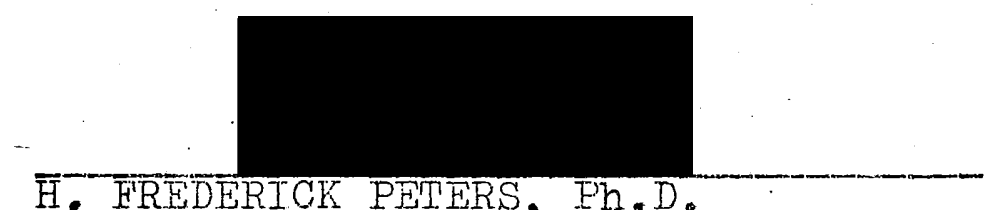

H. FREDERICK PETERS, Eh.D.

Administrative Officer

Department of Foreign Languages

FREDERICK J. COX, Qh.D.

Dean of Graduate School

Date thesis is presented: August 1, 1967 


\section{INHAIT}

\section{Einleitung}

I. Die Entwicklung der Wiener Volkskomödie vor Nestroy

II. Das Komische

36

III. Die Satire
a) Definitionen
b). Theorien
c) Anwerdung der Theorien

43

53

58

IV. Der Inhalt der Satiren Nestroys

63

a) Mensch

b) Gesellschaft

c) Geld

d) Folitik

e) Schicksal

AbschluR

Bibliographie 


\section{ETNLEITUNG}

Mit dem Eissay "Nestroy und die Nachwelt"l und der Interpretation von Nestroys Sticker leitete Karl Kraus eine Neubewextung Nestroys ejn. Und heute, bemerkt $\mathrm{F} . \mathrm{H}$. Maut-.. ner, "versammeln sechs deutsche Universitäten ${ }^{2}$ ejnen Hörerkreis, um der Kunst Nestroys zu gedenken-wahrlich keines Unbekannten mehr, wenn auch eines Verwjrrenden und vielen noch Fragwürdigen, der instande ist, den streit der Meinungen zu erregen". 3

E. Castle bezeichnet Nestroy als "kalustischen Menschenverächter"4 -während. J. Wiegand uber die "eigentümliche Sonderform des Humors der österreichischen Dichter von Grillparzer, Raimund, Nestroy kis zu Hofmannsthal und

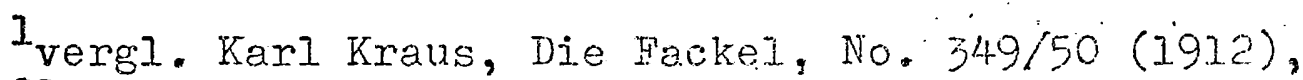
p. I-23.

2aie Universitäten München, Köln, Heidelberg, Freiburg, Bonn und Berlin; (Reden anläplich Nestroys 100. Todestag, 1962).

Franz M. Mautner, "Nestroys Kunst und unsere Zeit"., Schiller Jahrbuch 1963 (Stuttgart: KIett Verlag; 1953), p. 3937394.

4E.Castle, "Österreichische Iiteratur", Reallexikon der deutschen Iiteratureschichte, 2 . Auflage, Bd. II F.747. 
Rilke" schreibt. Er nent diesen Humor "zugieich gekonnten Realismus wie romantische Schwermut und Veltanest, die in z.T. sehr kuItivierten Fomen gebänigt wird "r otto Forst de Battaglia kommt in seinem Axtikel "Micht Philosoph, sondern Moralist" zu dem SchluB, Nestroy sei "wahrhaft groß und originell" nur in "einem Bezirk, wo Prilosophie und Iiteratur einander begegnen: als Moralist". ${ }^{2}$ Dagegen sieht J. Gregor in Nestroy "eine Abklärung nach der Seite der Philosophie". 3

$\mathrm{Zu}$ einem besonderen Urtedl kommt $\mathbb{N}$, Fuerst in seinem 1966 erschienenen Werk The Victorian Age of German Iiterature:

Nestroy does not exist apart from the stage, although the twentietr century has endeavored to wake him a literany classic. . And he actually had as much "genius" as Grillparzer: as much inteliect, verve and wealth-only in an inferior genre: twice inferior, first because it was 'ancilla theatri', subservient to the theatre, and second because it was the parasitic genre of parody. 4

Die Feststellung, daß Nestroy nicht ohne Bïhne exjstiert, kann man mit $W$. Kaysers Ausfïrungen beantworten:

Bei der Interpretation des Dramas besteht immer die Gefahr, daß Iiteraturhistoriker und Kritiker Buchphilosophie betreiber und aber dem lesbaren

IJ. Wiegand, "Humor", Reallexikon, Bd. Is p. 733.

20tto Forst de Battaglia, "Nicht Philosoph sondern Moralist", Forum IX (Mai 1962), 208-210.

3Joseph Gregor, Geschichte des österreichischen Theaters (Wien: Donau Verlag: 1.148): 1.16.

${ }^{4}$ Norbert Euerst, The Vjctorian Age of German Iiterature (University Park \& London: The Eennsylvania State University Press, 1966), p. 21. 
Wort vergessen, daß ein Drama foür die Auführung gedacht ist und nur in der Auffuhrung volles Leben hat.1

Utberhaupt ist ein Teil der dramatischen Technik von dem Umstand des gleichzeitigen Theaters abhän... gig; der Iiteramistoriker, der bei der Untersuchung eines Dramas nicht die dazugehörige Bühne kennt, gerät leicht auf Irrwege. ${ }^{2}$

Uber die Stellung Nestroys in der Komödienliteratur. führt F.H. Nautner folgendes aus:

Schlagen wir Angst]ichkeit vor traditionellen Vorurteilen in den Wind, so möchten wir, nach nüchterner Uberlegung, sagen: Fr ist der größte deutsche Komödiendichter, ganz gewiß, wenn man Komödiendichter jenen nennt, dem Komödie nicht Nebenleistung ist--ein Einmaliges oder Gelegentliches--sondern Hauptwerk, Leben und Zwang wie einem Goldoni oder Molìere.3

Die Geschichte der Wiener VoJkskomödie ist exst in zweiter Iinie eine Dramengeschichte, in erster Iinie wohl eine Geschichte von Gebrauchsformen ${ }^{4}$ des Theaters. Diese Gebrauchsdramatik steigert sich bei Philipp Hafner, Raimund und Nestroy zur Dichtung. Hafners geniale Iustspielbegabung bezeichnet $E$. Alker als "vielleicht einzigartig in Deutschland".5 F. Sengle sieht in Nestroy (zusammen mit Schiller, Goldoni und Grillparzer) "einen dex großen

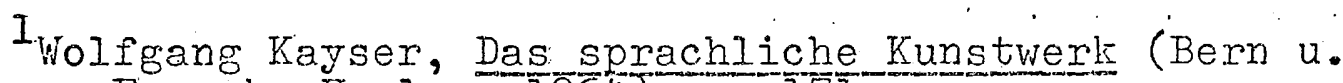
München: Francke Verlag, 1964), p. 171.

I Ibid. p. 196.

3 Mautner, p. 384 .

4.vergl. Klaus Ziegler, Deutsche Philologie im Aufriß, Herausgeber H. Stammler (Berlin-Bielefeld: Erich Schmidt Verlag, 1954) Bd. II, Spalte 1067/68.

5 Ernst Alker, Die deutsche Titeratur im 19. Jahrhundert (Stuttgart: A. Króner Verlag, 1961), p. 136. 
Nieister der theatralischen Barocktradition" I Sengle führt weiter aus, man solle die Zweckliteratur des Bie.. dermeier anerkennen und hochiajten "wo sje innerhalb der begrenzten ästhetischen Möglichkeiten der Zweckform zur Meisterschaft gelangt". ${ }^{2}$

Gute Satiren, Briefe, Eipigramme oder Reisebeschreibungen sind besser als mittelmäBige Dramen, Epen, Elegien oder Oden. Im Widerspruch zu diesem eigentich doch selbstverstänlichen Prinzip hat die neuere Germanistik, wenjgstens in Deutschiand, die Geschichte der Gebrauchsformen kaum noch erforscht. 3

Das Standardwerk über die Wiener Volkskomödie ist otto Rommels Geschichte der Alt-Wiener-Volkskomödie--Thre Geschichte vom barocken Weltheater bis zun Tode Nestroys. 4

Während N. Fuerst Nestroy beschäftigt sieht mit dem "parasitic genre of parody", bezeichnete K. Kraus Nestroy als "den ersten deutschen Satiriker in dem sich die Spram che Gedanken macht über die Dinge", 5 wobei der Begriff "parody" bei Fuerst etwas unbestimmt gemeint sein ma.g. "It is a well known fact, that in their wider application, the words 'parody", "burlesque", 'caricature" and "travesty' are often used interchangeably." 6 Ergänzen könnte

$I_{\text {Friedrich Sengle, Arbeiten zur deutschen Iiteratur }}$ 1720-1850 (Stuttgart: Metz1erscher Verlag, 1965) p. 117 .

Iㅁid. p. 165.

3. Ibid. p. 166.

${ }^{4}$ Ot to Rommel, Die Alt-Wiener-Volkskomödie (Wien: Schroli Verlag, 1952)

5 Karl Kraus, Auswahl aus dem Werk (Munchen: Kösel Verlag, 1957) p. 171.

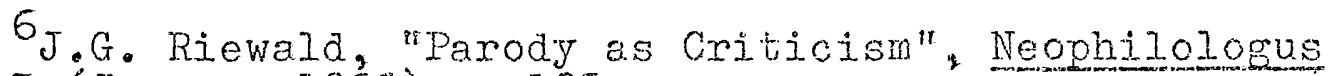
vol. I. (January 1966) p. I.25. 
man vorstehende Abgrenzung noch àuch diese Fieststeliung: "So selbstverständich das Wort 'Parodie' verwendet wird, so wenig ist der Begriff in Sinnberejch zwischen Nachahmung und Satire geklärt."I "Parody . is not merely a craft, but also an art, and that the perfect parodist must be a finished and experienced craftsman and artist. The highest kind of this art form is both critical and creative by nature." 2

Vor allem muß festgestellt werden, daß nur ein kleiner Teil der 83 Stücke Nestroys Earodien sind. Das parodistische Element ist fast in allen stücken vorhanden. 0 . Rommel bezeichnet zum Bejspiel Nestroys Parodie Juaith und Holofernes als "eine der berühmtesten Parodien un. serer Literatur". 3

Die Charakterisierungen; die ästhetischen und moraJischen Urteile über Nestroys Werk und seine Person, erreichen ein beachtiches Volumen. Darunter befinden sich Aussprüche von Hebbel, F. Th. Vischer, Gutzkow, Richard Wagner, den Fürsten Metternich und Schwarzenberg--bis zu. Brecht und Dürrenmatt. Verwirrend sind die sich oft widersprechenden Darstellungen in den Iiteraturgeschichten.

Die Grundlage jeder Arbeit über Nestroy bildet die

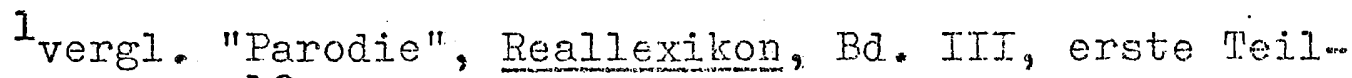
lieferung, p. 12 .

$2_{\text {Riewald, } p .128 .}$

3 Fritz Bruckner und otto Romel (Herausgeber) Johann Nestroy, Sämtliche Werke (Wien: Schrol] Verlag, 1924-1930) B. . IV, .364 . 
historisch-kritische Gesantausgabe, Johann Nestroys sämtliche Werke, in fünfzehn Bänden, herausgegeben von Fritz Bruckner und Otto Rommel (1924-1930). Eine Auswahl von 47 der insgesamt 83 Stïcke Nestroys, enthält die von Otto Rommel nach den Handschriften und Erstdrucken revidierte sechsbändige Ausgabe Johann Nestroy: Gesammelte Werke (1948). Der sechste Band dieser Edition ist für das gesante Coupletwerk und die Aphorismen Nestroys maßgebend.

Bei der Beschëftigung mit dem dramatischen Werk Nestroys bjetet sich zunächst ein Bild verwirrender vielfalt, in Bezug auf Form, Stoff und Gehalt. Rommel ordnete diese Stücke, indem er sie in der historisch-kritischen Ausgabe in fünf Hauptgruppen aufteilte: 1) Zauberspiele

2) Parodien 3) Politische Komödien 4) Volksstücke 5) Possen. Im Gegensatz zur Rommelschen Einteilung bezeichnet F.H. Mautner alle Stücke als "satirische Possen", und Nestroy als den Schöpfer dieser neven Gattung. 1

Einer eingehenden Analyse der dramatischen Form Nestroys käme nach Rommel "der Darlegung einer exschöpfenden Theorie der Komik gleich". ${ }^{2}$ Tatsächlich steht eine zusammenfassende Darstellung von Nestroys Satire noch aus. In Nestroy sind Satiriker und Theaterkomiker in einer Person vereint. Die vielschichtige Bindung des

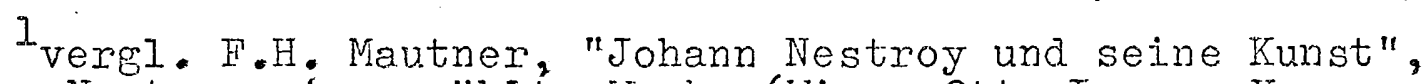
Johann Nestroy. AusgewähIte Werke (Wien: Otto Iorenz Ver-.." Iag 0.J.) p. 36 .

2 vergl. Otto Rommel (Herausgeber) Johann Nestroy: Ge... sammelte Werke (Wien: Schroli Verlag, 1948), Bd.I, p.107. 
satirischen Elementes an Komik, Parodie, Tronie, Grotesm ke und Karjkatur stellt einer eingehenden Untersuchung Schwierigkeiten entgegen.

Ein weiterer Faktor im komischen Theater sird die überlieferten Motive, Figuren und strukturmodelle, die durch die Tradition der europäiscken Komödie und der Wiener Volkskomödie auf Nestroy einwirkten. AuBerdem sind die Personen und Handlungen der Komödiemweit stärker als die der Tragödie-an soziale Zusammerhänge gebunden. Geschichtliche Elemente und die üblicher Stilmittel der Zeit sind demnach von Bedeutung. Wine Be-. schränkung auf das Einzelwerk, auf die werkimanente Interpretation, würde der eigentichen Ieistung Nestroy: nicht gerecht werden.

In der vorliegenden Arbeit soll versucht werden, durch die Auswertung der vielfältigen Vorbedingungen, eine Deutung der Satire im dramatischen Werk Nestroys zu geben. 
I. DTE ENTWICKIUNG DER WIENER VOLKSKOMÖDTE,

VOR NESTROY

Die Entwicklung des Wiener Volkstheaters von der Mitte des 17. bis zur Mitte des 19. Jahrhunderts steht an Umfang und Reichtum ebenbürtig neben dem Londons des 16., Venedigs des 17. und Paris des 18. Jahrhunderts. Das Wiener Volkstheater ist die einzige organische Weiterentwicklung des Theaters der Wandertruppen des 17. und 18. Jahrhunderts. Doch kann seine BIüte nur durch die barocke Oper, barocken Kaiserspiele und die barocken Hauptund Staatsaktionen verstanden werden. Commedia dell'arte und Thêatre italien spielen besonders nach Stranitzky eine entscheidende Rolle.

Eine vollendete Wechselwirkung zwischen Bühne und Zuschauer wird nur innerhalb eines geographisch, kulturell und soziologisch begrenzten Bereichs erreicht. C.P. Magill führt dazu folgendes aus:

In Austria, ${ }^{I}$ there existed a homogeneous culture and code of manners, a long and unbroken tradition, a cultural centre where comedy has flourished for centuries and which is itself a fathomless reservoir of comic material.?

Es kann nicht Aufgabe dieser Darstellung sein, die allmähliche Entwicklung des Barockdramas aus dem mittelal(Magill)

I"Austrian cornedy means, of course, Viennese comedy." ${ }^{2}$ C.P. Magill, "Austrian Comedy", German Life and Letters IV (October 1950), p. 33 . 
terlichen geistichen Schauspiel und dem Renassancedrama zu verfolgen. Die Wurzeln der Wiener Volkskomödie liegen in der zweiten Hälfe des 17. Jahrhunders, der Glanzzeit des Barockdramas. Die prunkvolle Oper des Kaiser. hofes und die aufwendiger Kajserspiele (Iudi caesarei.) der Jesuiten wurden das Vorbijd der "großen Aktionen" der Wan dertruppen.

Der Einfluß des barocken Universaldramas macht sich in Geist und Form durch die ganze Wener Volkskomödie-über Grillparzer bis zu Hofmannsthal bemerkbar. Es ist das, für die Bühne und von der Bühne bestinmte, scha-u-und geschehnisfreudige Theater.

Es will den Blick auf dexs Ganze des Lebens vermitteln und gibt daher gerne neben der Tragik auch der Komik Raum . . Mit dem mittelalterlichen geistlichen Schauspiel ist nicht nur dem Ordensdrama, sondern dem gesamten Barockdrama überhaupt, auch in seiner weitgehenden Säkularisierung auf der Opernbühne, der weltanschauliche Drang gemeinsam, das: Irdische stets in seine Determinierung durch metaphysische Potenzen zu sehen, und, dem Forntrieb des "Schau-Spieles" gehorchend, diesen Zusammenhang theatralisch schaubar zu machen.1

R. Alewyn nennt den "so schwer zu fassenden, unserer di.rekten Anschauung entzogenen Gejst des Barocktheaters" . . das "zugleich geistjgste . . aber ebensosehr das sjunlichste theater das jemals existiert hat"?

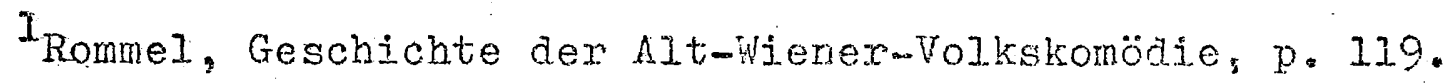

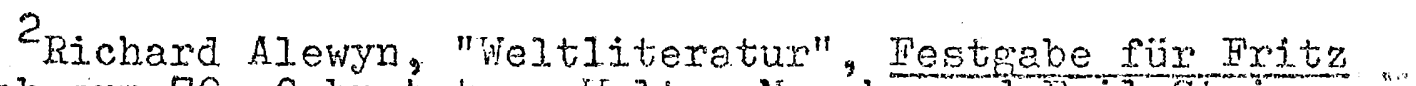
Strich zum 70, Geburtstan, Walter Muschg und Fini staiger (Herausgeber) (Bern: Francke Verlag, 1952) p. 150-38. 
Die ältesten Dokumente der Wiener Volkskomödie sind Bearbeitungen von Operntexten der Wiener Hofoper, die sogenannten "Wiener Haupt- und Staatsaktionen" Anton Stranitzkys. Eine direkte stoffliche Beeinflussung der Volkskomödie durch die pathetische Barocktheatralik von Oper und Ordensdrama läßt sich mit Sicherheit nicht feststellen.

Von Bedeutung jedoch ist das Schein - Sein Problem des Barockdramas für das Wiener Volkstheater. Dieses "sinnlichste und geistigste Theater" (Alewgn) neigt zur Derbheit, zur Drastik, Großartiges rückt neben direkte Nichtigkeit. Das Publikum vergiBt aber auch im Lachen nicht die Verpflichtung tragender Werte--es fordert das 'ridendo dicere verum', also einen Gehalt.

Die barocke Komik beruht auf "der Spannung zwischen sich blähendem Schein und dem werthaltigen Sein". 1 schein und Sein also werden sichtbar nebeneinander gestellt. Es ist die Freude der Barockzeit an der Antithese. Die "Inkongruenz des Werthaften" jedoch will man nicht satirisch angreifen. So erklärt sich auch, daß Hanswurst das barocke Heldenideal nicht angreift--er versucht nur durch. sein Narrenprivileg bis an die äuBerste Grenze zu gelangen. Auch ist die Intermedienkomik des Barock- und Jesuitendramas keine Satire auf den Gehalt des Hauptteils. Die Auseinandersetzung mit dem barocken Schein - Sein Problem 
läßt sich in der Wüener Volkskomödie bis zu Nestroy verfolgen.

Von besonderer Bedeutung sind die Beviehungen zirischen der Wiener Volkskomödie und der Intermedienkomik von Oper und Ordensdrama. Bereits 1588 erhîelt die Provinz Österreich die Genehnigung, bej. den Intermeäien die Iandessprache zu verwenden. Wahrscheinlich machten diese allegorisch-komischen Zwischenspiele fur das Volk den Haupt.reiz der in lateinischer sprache gegebenen Jesuitendramen aus. Im Gegensatz zu den sonst üblichen Nachspielen, den Pickelherring-Possen und Hanswurstspielen im Anschlus an die Haupt- und Staatsaktionen, gestaltet man in Osterrejch hëufiger das Zwischenspiel possenhaft. Die Jesuiten Iernten von der Gewandtheit der "buffoni" der Commedia dell' arte, doch ebenso durch den Wettbewerb nit den englischen Komödianten und deren burlesk-derben Tragikoinöajen ( $z \cdot B$. Wettbewerb mit der Truppe des Tohn Green in Graz 1607/08).

AlIe diese Elemente führten zur Ausbilaung dex Wiew ner Jesuitenkomödie; in manchem gewissermaBen eine Vorwegnahme der Synthese verschiedener Kräfte, die später, nur auf anderer Fbene, zur Wiener Volkskonödie führten. Daß das vielfältige Barockerbe auf das volkstümljche Theater und auf die Phantasie des Volkes ejnwirken mußte. ist selbstverständ]ich. Direkter jedoch war der EinfluB, der seit Ende des 16. Jahrhunderts, vorwiegend in Wien spielenden italienischen Polcinellspielex, spanischen Sänger-aund seit Anfang des 17. Jahrhunderts auch engilischer 
Kornödianten. 1649 hielten sich auch deutsche Truppen in Osterreich auf. Nach Rommel trugen die Vandertruppen "im 17. Jahrhundert die Tradition des deutschen Thesters und wurden geschichtich zu einem ganz unentbehrlichen Bindeglied zwischen den in drückender Enge lebenden breiten Schichten des Volkes und den traumbaft phantastischen, aber romanisch überfremdeten Barocktheater der Hofe" "I

Um das Volk mit der Welt des Hofes "vertraut" zu machen, führten die Wandertruppen die sogenannten: "Hauptund Staatsaktionen" auf: Diese "Aktionen" waren zurechtgenachte Schauspielerstücke nach Iiterarischen Vorlagen (oftmals Gryphius, Iohenstein, Shakespeare, mit starken Motiven und krassen Effekten. Unter dem Pinfluß des romantisch-abenteuerlicher Typus der spanisch-italienischen "Commedia per aventura" treten die Greueldramen zurück. Di.e grellen Motive werden am Ende, des glücklichen Ausganges wegen, meistens widerrufen. Das Gebilde, das man anfangs des 18. Jahrbunderts als "Haupt- und Staatsaktion" bezeichnet, setzt sich aus den verschiedensten Flementen zusammen. Fürstenhöfe, große Impfänge, kriegerische Aufzüge, Einkerkerungen, "Großmütigkeit" in allen Formen und Liebe, als schäferisches Milieu, bilden den gropartigfeierlichen Hintergrund.

Unter den Wandertruppen taucht 1705 J. A. Stranitzky (1676-1726) in Wien auf. Uber die Prinzipale Elenson und HiJverding fuhrt sein Weg zum Wiener Volkstbeater.

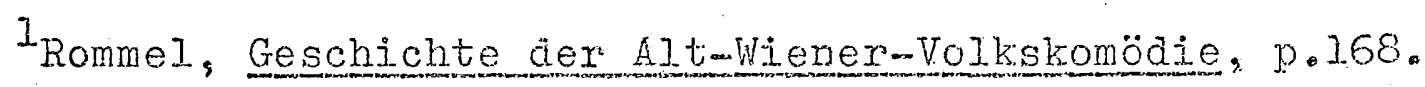


Uber aie Neubersche Truppe aggegen fubrt der Weg zum deutschen Bildungstheater.

Beim Volkstheater handelt es sich stets um ein komisches Spiel; wesentlich ist die zentrale stellung der komischen Figur. Einfache dramatische Vorfühungen nach der Art des Fastnachtspiels, lassen sich in Österreich schon in der zweiten Hälfte des 13. Jahrhunderts nachweisen. In dem Spiel aus St. Paul "Neidhart mit dem Veilchen", nach E. Castle "das erste weltiche Iustspiel urserer Literatur" ${ }^{1}$ und besonders in Nejdharts "interliedern" verbinden sich Spott, Humor, Parodie und Bauernsatire.? G. Ehrismann sieht in der Zeitspanne vom 13 . bis zum 15. Jahrhundert, "für die Zeitsatire in Ossterreich einen günstigen Boden, hier herrschte eine rege Teilnahme an den Vorgängen des wirklichen Lebens" ${ }^{3}$

Im mittelalterlichen Passionsspiel findet sich die komische Person als "Rubin", des Gehjlfen des Salbenkrämers. Die "erste politische Satire in deutscher sprache die sich der dramatischen Form bedient "t ${ }^{4}$ ist Des Antichrist Fastnacht (1354), der Verfasser ist ein Schweizer.

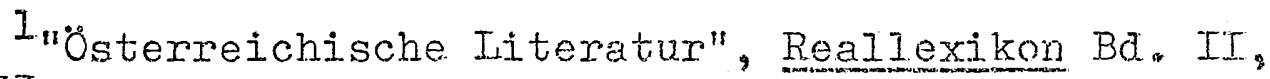
p. 733 .

2 vergl. Julius Schwietering, Die deutsche Dichtung des Mittelalters (Darmstadt: Herman Gentner Verlag, 1957) p.258.

3 vergl. Gustav Ehrismann, Geschichte der deutschen Iiteratur bis zum Ausgange des MittelaIters Bd. IV, p.336. ...

${ }^{4}$ vergl. Annalen der deutschen Literatur, Heinz otto
} Burger (Herausgeber), Frste Lieferung (Stuttgart: T. B. Metzlersche Verlagsbuchhandlung, 0.J.) p. 232. 
In den vielfältigsten Formen tritt der Narr aur Die metaphysische Auffassung der Reforation, Mer Mersch sei. dem Teufel verfaljen", ersetzte den Narr duroh den Teufel. Eine "Hitut von peufeln ängstigte das Volk, in Prosa, Verm sen und sogar in aramatischer Form" "l

Eine weitere Form des Narren ist der bäueriche Schalksnarr 'EulenspiegeI', er gehört zur Tradition des "weisen" Narren. Rommel leitet den "wienerischen" Hans. wurst Stranitzky aus dieser Jinie ab Die Narrenfigur des Fastnachtspiels wird vom Hanswurst verdrängt. Als komische Figur des Dramas, (als derber und geiler Bauentölpel) erscheint der Name 'Hans Wurst' zueast in einem Nirn-. berger Fastmachtspiel (1553). E. Castle hebt die osterreichischen Fastnachtspiele, die Sterzinger SpjeIe und drei Stïcke aus einer Monseet Handschrift (Ende des 15. Jahrhunderts) in dramatischer und stilistischer Hinsicht von den Nürnberger Fastnachtspielen ab. "Die Hejterkeit dieser spiele beruht mehr auf dem der österreichischen Volksart eigenen harmlosen Spaß, als auf der in Nirnberg beliebten Zote. "2 Jedenfalls ist die Figur des Hanswurst der Wanderbühnen und damit auch die Gestalti von Stranjtzkys wienerischem Hanswurst von elementarer Derbheit und Drastik.

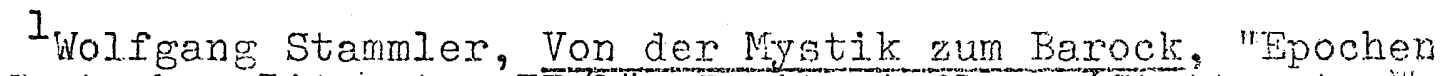
der deutschen Iiteratur IJ7I" Zwejte AufJage (Stuttgart: J.B. Metzlersche Verlagsbuchhandlung, 1950) p. 446. 2E. Castile, "Osterreichjsche Jiteratur", Reajlexixon Bd. IJ, p. 734 . 
Iiür das Verständnis der Sexulkomik und der damit verbundenen Parodie und Satire in der Hener Volkskomödie sind folgende Ausfühungen aufschjukreich. Bereits F. Martini hat gezeigt, "daß der Bauer in der mittelalterlichen Iiteratur als Sinnbild und mimischer Typus verstanden werden muß, nicht aber als realistisches Abbild". I.

Nach P. Böckmann ist in Neidhart von Reuentals parodistischsatirischer Haltung "der Realismus und die Drastik der Schilderung nicht Selbstzweck, sondern steigert sich zur Satire und bedient sich deshalo parodistischer pormen".? E. Catholy äuBert sich ausführlicher zu diesem Thena:

Der Versuch, sich einer Bildsprache zu bediem. ner, in der charakteristische Terrini des Geschlechtslebens durch harmlose Wörter ersetzt werden, ist freilich kein besonderes rierkmal. der Fastnachtspiele, sondern kennzeichnet jede komische Dichtung im Bereiche des Erotischen. Mit der Absicht, durch diese Bilder das Fubljkum stärker am Spiel zu beteiligen, verbinaet sich auch hier wieder das Bestreben, Anschlus an die literarische Tradition zu finden.3

Jie Obszönitäten wirken in erster Iinie als Formen eines spiels. 4

Wie stark die Sphäre des. Irdischen und damit auch die Triebwelt auf dje Sphëre der Transzendenz bezogen war und von dort her ihren Rang und ihre Stellung zugewiesen erhielt, zeigt sich übrigens auch im realen Leben der Zeit. . Die Fastnacht.

IFritz Martini, "Das Baverntum im deutschen Schrifttum, vor den Anfängen bis zum 16. Jahrhundert, (Deutsche Vierteljahrsschrift für Iiteratur und Gejstes-Geschichte, Bत. 27, 1944) zitiert nach: Eckehard Catholy Das Fastnachtspiel des spätmittelalters (Gestalt und Funktjon) (Tübingen: Nax Niemeyer Veriag, 1961) p. 259.

${ }^{2}$ Paul Böckmann, Formgeschichte der deutschen Dichtung . (Hamburg: Hof fmann un Campe Veriag, 1949) Ba. Is p. 176.

Eickehard Catholy, Das Festnachtepiel des Spätmittel-alters, $p .246$.

${ }^{4}$ Ibid. p. 252. 
spiele konnten sich somjt teilwejse auf eine selbst verständliche Betonung der sexuellen Sphäre im städtischen AlItag berufen .....

Stranitzky übernahm demnach bei der schaffurgg des "Wiener" Hanswurst eine lange Sexualkomik-..Tradition. Diese Richtung ist bei den Vaganten, der mittelhochdeutschen Kleinepik, bei Neidhart und der Nachfolge der wrechten Nejdhart-Lieder, Oswald von Wolkenstein, der Narren- und Teufelsliteratur, vorgebildet. Ahnlicher Drastik bedienen sich etwa die Barockkomödien eines Gryphius, Iohenstein und Chr. Weise, die Auffürungen der Hamburger oper (um 1690, mit Ansätzen zu einer plattdeutschen Volkskomödie) und zur zeit Stranitrkys, die "Sächsische Komödie". (Henrici, König). Diese Feststeliungen sind für diese Untersuchung insofern von Wichtigkeit, als Nestroy stärker als seine unmittelbaren Vorgänger, die Modelle der Hanswurst. Tradition und Commedia dell'arte verwendet. Es erklärt außerdem die Haltlosigkeit der vielfachen Angxiffe wegen seiner "Laszivität"--durch parodistisch-satirische Verwendung sexueller Komik--mit Bezug auf die damalige Umwelt. Mit der Ubernahme des Kärntnertortheaters (Ende 17lo) begründete Stranitzky das erste stehende deutsche Sprechtheater. Für den Spielbetrieb verfaßte ex die sogenannten "Wiener Haupt- und Staatsaktionen", insgesamt 14, durchwegs nach jtalienischen Operntexten der Wiener Hofopex. Die Komik dieser umgearbeiteten Stücke ist ron elementa- ".

\section{Ibid. p.256.}


rer Derbheit, ebenso die đer Incermezzi, die in aie "Aktionen" eingeschajtet sind. Wie beiri Pickelhering neigt diese Komik zum Burlesk-Grotesken und verwendet ebenso die in barocken Stücken übliche Sexual- und F̈äkalkomik. C.P. Magill berichtet über einen Besuch von Lady Mary Wortley Montagu im Theater am Kärntnertor (1716). Lady Mary schrieb über eine Aufrïhrung von Stranitzkys "Amphitryon" an Eope:

"I could not easily pardon the liberty the poet has taken of larding his play with not only indecent expressions, but such gross words as I don't think our mob would suffer from a mountebenk." It was not so much the gross antics of the players which shocked her as the fact that they performed them "in the direct view of the boxes, which were full. of people of the first rank, they seemed very well pleased with their entertain.ment". With agreeable frankness she confesses: "I never laughed so much in my Iiffe."I

Die reichste Quelle Stranitzkys Hanswretkomik leitet sich aus der Unzulänglichkeit an dem heldischen Ideal der Barockwelt ab. Die Furchtsamkeit wird durch unsinniges Prablen und Brambarasieren kompensiert. Parodie und Satire werden selten verwendet, es ist naive, drastische Komik die Situationen sucht. Stranitzky gab seiner Hanswurst Gestalt, trotz aller Bindung an die jahrhundertealte Tradition der Hanswurstimigur, individuelle Züge. Hier gelang erstmalig die Vemittlung zwischen den englischen Spielformen des Pickelhering und den italienischen Typen der Commedia dell'

$$
\text { I.C.P. Magil1, "Austrian Comedy", German Iife and Iet- }
$$
ters vol. IV (October 1950) no.l, p. 35 . 
arte. Aus dieser Synthese entstand der "Wjenerische" Hanswurst (nach Rommel der "Wiener Ur-Fianswurst"). Stram nitzky wurde damit zum Begründer der Wiener Volkskomödie.

Es fällt nicht in den Rahmen dieser Arbeit, die vielfältigen Einflüsse der Masken (Typen) der Commedia dell' arte auf die Wiener Volkskomödie aufzuzejgen; ebenso die in Frankreich zur Comédie italienne bzw. zun Théătre ita.Iien umgeformte Commedia dell'arte.

Bedeutsam für die Entwicklung wird Stranitakys Kenstnis der Gherardischen Singspiel-Sammlung des Théâtre itaIien. Der Iiterarische Einfiuß der Commedia deli "arte anf a die Wiener Volkskomödie erfolgt somit über Frankreich. Die ebengenanten Singspiele stehen in enger Beziehung zum Théâtre de Ia Foire. Es sind Stücke aus Prosadialogen mit eingebauten Gassenliedern (Vaudevilles) die wir. kungsvoll Komik, Satire und Groteske verbinden. Bezeichnender Weise, formt Stranitzky die "witzig-pointierten Dialoge ins volkstümich Drastische um, ebenso beschneidet er die satirischen Zusätze"I (Standessatire) des Théâtre italien. Aus heimischen Elementen, aus Motiven des Picariscben Romans, ${ }^{2}$ Szenen der Gherardischen Sammlung und Textstelien und Einfëlien aus Abraham a Santa Claras Werken entsteht die sogenannte "Ollapatrida des

Ivergl. Walter Hinck, Das deutsche Lustspiel des 17. und 18. Jahrhunderts und die italienische Komodie (stuttgart: J.B. Netzlersche VeriagsbuchnandIung, 1965) p.143/44.

2 verwiesen sei auf den Artikel "Wiederkehr der Schelme" Willy Schumann, PMTA Vol. IXXXI (December 1966) No.7, bes. p. 467. 
durchtriebenen Fuchsmundi". Gottsched schliekt in der "Critischen Dichtkunst" bei seiner erbjtierten Polemik gegen die "Geburten der italienjschen Schaubuhne" Btranitzkys "Ol lapatrida" mit ein.

Der StraBburger Theologe Johann Geiler ron Kaisersberg (1445-1510) brachte die deutsche Predigt in enge Berühung mit der weltichen Dichtung. Er verwendet die sprachlichen Mittel der zeitgenössischen Satixe, burleske Wortspiele und derbe Komik. Abraham a Santa Clara (1644-1709) bereicherte diesen stil poch mit barocken Mitteln. Es entstand damit, "die saitigmgroteske Drastik h der sinnlich ausmalenden Bilder, Metapher und Vergleiche, überall eine Freude am Burlesken, die in der Heimat des Hanswursts verständlich ist".

Die barocken Stilmittel der Antithese waren die Wiederholungen von Einzelworten oder ganzen Sätzen, unterstrichen durch Parallelismus und Synonymhäufungen; noch Nestroy macht davon ausgiebiger Gebrauch. Geblie. ben ist auch der Hang zu Hyperbolik und Wortverärehun. gen, zu Wortketten, Klangwitz und dem verkehrten Gebrach von Fremdwörtern nach dem Vorbild eines Gryphius. Fs ist bezeichnend für Nestroy, daß er trotz allex Verpflichtung zur Barocktradition des Wiener Volkstheaters, "Barockgegner" ist. J.H. Scholte sjeht die Satjiker der Barock-

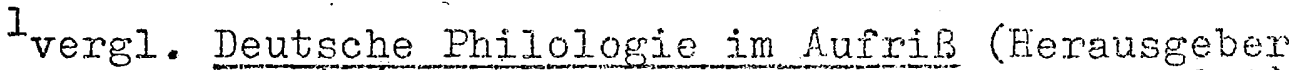
Wolfgang Stamier) (Berlin: Erjch Schmiat Verlag, 1952) Bd. I. $I_{2} .1134$. 
zeit (Logau, Lauremberg, Moscherosch, Schupp, Chr. Weise) ebenfalls als Barockgegner, weil sie "dex ejgenex zeit den Spiegel. vorhalten". I Wenn Nestroy etwa aie aus der Barockzeit stammenden Phrasen "Fuer Gnaden" und "Buer Wohlgeboren" satirjsch verwendet, oder wenn er barocke Worthäufungen konstruiert, wie zum Beispiel "Oberpremierpolizeikommissärdirektionsdirektor"; um damit aie Titel w sucht komisch-satirisch zu beleuchten. Die "Barockgegnerschaft" Nestroys entspringt jedoch, zum Unterschied der Satiriker des Barock, nicht erster Iinie moralischer Absicht.

Nachfolger Stranitzkys wird Gottfried Prehaluer (1699-1769). Er ist weit großstädtischer als der als "Salzburger Bauer" agierende Stranitzky. An Stelle der barocken "Haupt - und Staatsaktionen" tritt die zlis Grow teske neigende Burleske. Die pompöse Welt der Fürstenhöfe wird abgelöst durch die Filguren der Großstadt. Neu war die Gesellschaftssatire des Théâtre itolien für die abgeschlossenen Adelskreise des barocken Wien. Wârend der Hanswurst vom Typ Stranitzkys ein Solist war, ist Prehauser gewandter Alles-Spieler nach Art der Conmedia. dell"arte. Der Kontakt mit italienischen Pinflissen unả eine kaiser]iche Verfügung (1741) bestimmte dje Vermjschung der "teutschen Comödien" mit "dermalen italienischen Operetten" (Kurzopern). Nach Rommel wurde dadurch die Wjener

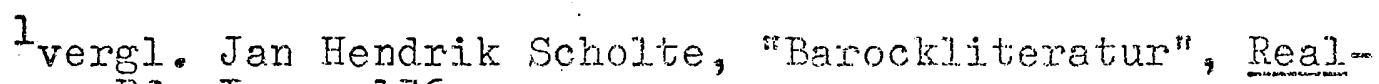
lexikon, Bd. I, $p .136$. 
Volkskomödie "für alle Zukunft zum singspiel oder wenigstens zur Posse mit Musik". I

Josef Felix von Kurz (1717-1783), genant Bernardor, (nach einer Type die er schuf), war der letzte Repräsentant des barocken Universalismus in der Wiener Volkskomödie. Er schrieb Dutzende "Ambigue comique", entstanden aus der jahrhundertealten Tradition der Zwischenspiele; sie vereinigen eine Komödie, eine Pantomime und eine Operette. Burlesk-Komik und Farodie verschmelzen die beliebten "Teufelskomödjen" "Die von Italien übernommenen Teufels- und Unterweltskomo̊dien gehen auf die seit der Renaissance übliche Form der Totengespräche (nach Lukian) für Zwecke der Satire zurück. Die Anwerdung in der Wiener Volkskomödie brachte eine Parodierung der mythologischen Vorstellungen nach Wiener Nuster mit sich. Schließlich war Kurz-Bernardon auch noch der Schöpfer der dramatischen Parodie in der Volkskomödie. Seine Parodien auf die "Haupt- und Staatsaktionen" hielten sich fast ein hal w bes Jahrhundert auf dem Spielplan.

Mit dem aufkommenden Rationalismus geht der Einfluß der Barocktradition vorübergehend zurück. Auf' Betreiben des "Wiener Gottsched", Joseph von Sonnenfels, muß der Hanswurst die Bühne verlassen (1769).

Erst die Aufklärung--in Deutschland Lessing und in Wien Sonnenfels--hat den rheater, das bisher nur Scherz war, seine tiefere Bedeutung gegeben;

Ivergl. Otto Rommel, Geschichte der AltwilienerVolkskomödie, p. 352. 
die sovie] verlästerte Zensur owies sich als hejl w sam, denn sie entthronte die sterile Diktatur des Schauspielers und fuhrte die wie uberal] hej.lsame Zweiheit Dichter-Schauspieler ein; diese fïhrte im nächsten Jahrhundert zu der grandiosen Fintwicklurg des Wiener Volkstheaters.

Die Pflege der Volkskomödie fiel-w wie vor Stranitzky -. wieder den Wandertruppen zu. Bei den Wandertruppen wurde Hanswurst als lustige Person von Kaspar (Hanskasper) abgeDie Figur des "Wiener Kasperl" schuf Johanr Laroche. Die Hauptmasse der für Kasperl geschriebenen Stücke sind Burlesken.

Die Vertreibung des Hanswurst hatte in Wien jedoch keineswegs eine Unterbrechung der romanischen Einfüusse zur FoIge. In Deutschland dauerte die Wirkung der Commedia dell'arte nur bis gegen 1770, auch fand besonders die Richtung der Pariser Conédie italienne keine Ent.sprechung in den Kleinstädten Deutschlands. Während man aus der Tradition der Wiener Volkskomöaie die wertereie Sphäre der Commedia dell'arte als Spiel auffaßte, sah Gottsched in der Komödie ein Mittel satixischer Verspottung des Lächerlichen zur moralischen Belehrung. IJessing unterstellt der Komödie die Wirkung eines "Preservatifs" für J. Möser wird der Harlekin zu einem "Controleur der Sitten". Den Hanswurst wollten weder Iessing, Möser noch Krüger wieder auf die Bïhne bringen.

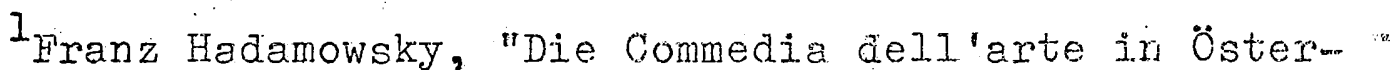
reich und ihre Wirkung auf das Wienes Volkstheater" , Maske und Kothurn (Viertel jahrsschrift für Theaterwissenschaft), Jg. 1957, Heft 4, p. 3]2. 
A] le drei verfochten die Sache eines zwar lustigen, frechwitzigen, ausgelassenen und satirischen, gelegentlich auch empfindsamei aber in jedem Falie "ge-m sitteten" Harlekins, eines Iarlekins, der in seiner. komischen Substanz eberso "gereinigt" sein sollte, wie es die unter Gottscheäs Herrschaft entstandene deutsche Komödie war. 1 .

In der Komödie eine "Schule der Sitten" zu sehen Iehnte bereits Ph. Hafner ab. Der satirisch-parodistische Gehalt in den Stücken der Wisener Volkskomödie ist weitgehend dex moralisch-didaktischen Tendenz enthoben. Die satirischen Angriffe sind Teil des theatralischen Spiels und nur begrenzt Ausdruck eines konkxeten geselIschaftichen Zustands. Erst bei Nestroy wird die Satire vielschichtiger. Philipp Hafner $(1735-1.764)$ studierte die Komödien Molières, Goldonis und Holbergs. Fo Alker weist auf die "organische Verbindung zwischen dem teilweise literarischen Theater des Spätbarock (Stranitzky--Kurz-Bernardon) und đern Bühnenschrjfttum der Aufklärung" durch Hafner hin. 2 Hafner gab der Parodie und der Burleske, vor allen aber dem volkstümlichen Sittenstück (Wiener Lokalstück) neue Richtung. Die fortschreitende Auflösung der barok-ken ständeordnung betrachtet Hafner schon von einem rationalistisch-bürgerlichen standpunkt. Er bringt scharfgezeichnete Typen des Wiener. Alltags auf aie Bühne und.

I Horst Steinmetz, "Der Harlekin, seine Rolle in aer deutschen Komödientheorie und Dichtung des 18. Jahrhunderts" Neophilologus Ji, no. I (January I966) p. 97.

$$
\text { 2.1ker; p: } 136 \text { : }
$$


rückt damit von der Hanswuretfigur ab; der Barocktradition bleibt er trotzden verbunden. Im wiener Hanswurststreit" schrieb er eine "Verteidigung der Wienerischen . Schaubühne" (I76I).

Die Zeit der Stegreifkonödie war mit Prehausers Tod. (1769) abgelaufen. Sie war noch reines Spiel, eine Spiegelung der Ganzheit des Iebens, im Sinn des barocken Universaldramas: Der Rationalismus verlangte von jedem Kunstwerk eine "vernüntige Nachahmung der Natur", und eine "moralische Perspektive". Dieser EinfluB macht sich teilweise bei Hafner, stärker jedoch bei Ferdinand Kringsteiner (1775-1810) und im josephinischen Iokalstück bemerk bar. Kringsteiner geht vom bürgerlichen Schauspiel aus. Eine scharfe Konstrastierung von Gut und Böse, sozialkritische Tendenzen vermischt mit burlesken Episoden, kennzeichnet seine Stücke. Die Komik stand über der moralischerzieherischen Tendenz. Das josephinische Lokalstück hatte enge Beziehungen zur zeitgenössischen Journalistik. In den "Eipeldauer Briefen" gibt $J$. Richter in der Form satirischer Briefe Berichte zu Wiener Zuständen und Ereignissen. G. Schildbach und $K$. Gewey schrieben satirische Stücke die das "lockere moralische Leben" der Zeit angriffen. Der Komödiengehalt nimmt zugunsten "moralischer Aktualitäten" ab.

Um dem wachsenden Unterhaltungsbedirfois der bjener zu genügen, gründete man die sogenannten "Vorstadtheater" (1781 Theater in der Leopoldstadt, 1786 Theater an der Wien, 
1787 in der Josefstadt). Durch neue Zensurvorschriften (1784) und verschärfte Polizei- und Zensurmaßregeln ausgelöst, und als Gegenströmung gegen die rationalistischen Bestrebungen setzte eine starke Wiederbelebung der Barocktheatralik ein. Die Wandlung des Volksgeschmacks nach đem "Wunderbaren" traf sich mit dem Einfluß von Feenmärchen und Ritterromanen aus Frankreich. Der in Wien beliebte Wieland, hat mit seinen Märchensammlungen unmittelbar auf das Alt-Wiener-Volkstheater eingewirkt.

Emanuel Schikaneder stellte die Barocktheatralik wieder in den Dienst des Volkes. Neben effektvollen Motiven ging es ihm um den großen Gedanken des Jahrhunderts, Weisheit und Menschenliebe. Die "Zauberflöte" (1791) wurde sein Haupterfolg und Text zu Mozarts Oper. Joachim Perinet formte Hafners Stücke in burleske Singspiele um. Im Zusammenhang mit der Gottschedschen Komödienreform bemerkt $F$. Schneider in seinem 1948 erschienenen Buch, Die deutsche Dichtung der Aufklärungszeit, "wie lange sich dann die lustige Figur noch auf der. Bühne erhielt, besonders in Süddeutschland und hier wieder in Wien, . . entzieht sich im einzelnen unserer Kenntnis". I Für Einzelheiten sej hier auf Rommels Geschichte der Alt-Wiener Volkskomödie verwiesen, da in dieser Arbeit nur die auf

IFerdinand Schneider, Die deutsche Dichtung der Aufklärungszejt 2. Aurlage ('́tuttgart: J.B.Metzlersche Verlagsbuchhādiung, 194.8) p. 102. 
Nestroy weisenden Richtungen herausgearbejtet wexden können. Anton Hasenhut fïhrte die komische Gestalt des Thaddädl ein, der Typus kommt von "Taddeo" der Commedia dell'arte. Diese Gestalt beeinflußte noch Nestroys geistreiche Dümmlingsroljen.

Das neue Großstadtbewußtsein und ein Zug zum Mondänen wird von wesentlichem Einfluß auf die Volkskomödie der Kongreßzeit. Die drei Beherrscher der Bühne vor Raimund und Nestroy sind Josef A. Gleich (1772--184.I), KaxI Meissl (1775-1853) und Adolf Bëuerle (1786-1859).

Meissl schreibt Komödien in der Tradition des jose-w phinischen Sittenstückes. Erfolgreicher sind seine Parodien in Form des Lokalstückes; für die Satire hatte er besondere Begabung. Dje grotesk übersteigerten "mythologischen Karikaturen" schufen die Voraussetzung fur die parodistischen Zauberspiele Nestroys. Bäuerle war eine der repräsentativsten Persönlichkeiten des Wiener Vormärz. Er verlangte eine radikale Modernisiexung des "Kasper]" Theaters, und forderte die Erneverung des Iokalstijcks. Die von Bäuerle geschaffene Figur des "Staberl" bildet eine Neuheit in der Wiener Volkskomödie, sie löste Kasperl und Thaddädl ab. Es ist der Wendepunkt in der Entwicklung. vom Typus zum Charakter. Nach der Figur des Staberl entwickelte sich die komische Person bei Raimund und Nestroy immer mehr zur Charakterfigur. Es gelang Bäuerle jedoch nicht, das ihm vorschwebende Lokalstück zu schaffen, viele seiner stücke blieben Burlesken und harmlose parodistim sche Zauberspiele. 
Das Verdienst, die Tradition des Zauberspiels für Raimund offengehalten zu habea, gebihrt, G]eich. Der cha.rakteristische Beitrag Gleichs sind die Zauber- und Geisterstücke, die man "Bekehrungs-- oder Besserungsstücke" genannt hat. Sie tragen in die Volkskomödie einen "tieferen weltanschaulichen Gehalt ohne ihr Wesensmerkmal, die schwerelose Heiterkeit einzubüßen" (RommeI). K. Goedecke neunt die "Großen Drei" (Meissl, Bäuerle und Gleich) "Meister der Schaubühne ohne ideale Ansprijche".

Ferdinand Raimund (1790-1836) überwand die Staberl. komik Bäuerles und die Dichtung erhob sich über die Schaubüne ohne j.deale Ansprüche". Rommel nennt Raimund den "letzten Meister barocker Theatralik". Anstelle des barocken Glaubenspathos aber tritt die Biedermejermentalität, daß wahres Glück und menschliche Größe nur in Selbstbescheiaung liegen könne. In Raimunds Zauberstücken vereinigen sich Märchenhaftigkeit und Wirklichkeit. Der aus der Barocktradition stammende Dualismus von Geisterreich und Menschenwelt kommt zu Versöhnung und Illusjon. Durch Raimund vollendet sich zwar das parodistische Zauberspiel, das echt parodistische Element darin spielt eine untergeordnete Rolle.

Zusammenfassend kann festgestellt werden, daß es bereits vor Nestroy Ansätze einer satirischen Literatur gab. Die vielfachen Strömungen innerhalb der Wjener Volkskomödie verwischen die Grenzen von der Satire zur Posse und Burleske, zum Singspjel und Zauberspiel. Stärker ausgem 
prägt ist der satirische Gehalt nur im Sittenstück (Wjener Volksstück) und der durch die josephinische Journalistik beeinfluBten Iiteratur. Das sonst notwendigerweise in der Parodie enthaltene satirische Element kommt durch den Charakter der wienex Farodien in besonderer Form zum Ausdruck. A. Iiede bezeichnet die Parodientradition der Wiener Volkskomödie als "die einzig bedeutende des deutschen Sprachgebietes"--das stimit sicher dem Umfang nach. Trotzdem ist diese Art der Parodien, mịt, wenigen Ausnabmen (etwa bei Kringsteiner) mehr eine Ar.. gelegenheit des volkstümichen iebens. Die Untertitel der Parodien sprechen daher oft von "Karikaturgemälden" oder "parodierenden Possen". "Die Utberbetonung von Utberspanntheiten und Empfindungen führt mehr zur GroteskKomik, denn zur Satire. Eine Angelegenheit der Literatur werden Satire und Parodie erst unter Nestroy.

Johann N. Nestroy (1801-1862) ist an ererbter und erworbener Bildung reicher als seine Vorgänger. Der Vater Nestroys war Rechtsanwalt und ernöglichte ihm eine humanistische Erziehung, sowie den Besuch der Universität. 1822 gab Nestroy das juristische Studium auf; um als Solist ein Engagement an der Hofoper anzunehmen. Es folgten Anstellungen am Deutschen Theater in Amsterdam, in Brünn, Lemberg, PreBburg und Graz. Die Sprechstücke in Nestroys Repertoire nehmen immer breiteren Raum ejn; das erste Stück schrieb er 1827. Von besonderer Bedeutung für die Entwicklung als Dramatiker und Schauspiejer wurde 
der Vertrag mit Direktor CarI (Theater an der Wien, 1831). Für sechs Jahre (1854-1860) war Nestroy Direktor des Carl Theaters, $a b$ Ende 1860 bis 1862 trat ex nur noch in Gastspielen auf. Sein 83. Stück schrieb Nestroy 1862.

Rommels Monographien ${ }^{2}$ haben jeder weiteren Arbeit über Biographie, Theaterverhältnisse, schauspielerische Eigenart und Psychologie vorgebaut. Die Zeitbezogenheit der Satire macht es notwendig, kurz auf die sozialen und politischen Verhältnisse von Nestroys Umwelt zu verweisen. Wir sind nicht der Meinung, daß Nestroys Stücke "humoristisch getarnte sozialkritische Sittenstücke" sind.? Weit zutreffender ist Hugo V. Hofmannsthals Bezeichnung des dramatischen Charakters als "einer Verengung des Wirklichen". Besonders der Charakter der Hauptperson in Nestroys Stücken ist durch die satirische Richtung notwendigerweise bis zur Karikatur verzeichnet. Auch können wir uns nur zum Teil der Ansicht anschließen, im Biedermeier "eine Zeit des Geruhigen, des stiljen GIücks, des behaglichen Familienlebens" 3 zu sehen. B. Emrich verweist auf die "resignative Haltung" die oft nur gespielt wird und "besonders in Österreich-mu fast maskenhaften Seelenanlagen führt", während Nestroy durch "seine

IJohann Nestroy, Sämtliche Werke, Bd. XV; Johann Nestroy, Gesammelte Werke, Bd. I.

${ }^{2}$ vergl. Alker, p. 159.

3 vergl. Julius Wiegand, "Komische Dichtung", Reallexikon. Bd. I, p. 873 . 
Resignation und durch seinen Zug zur Bitterkeit vorn bie-đermeieriichen Gelassenheitsideal abweicht".I

Auf die Problematik der Biedermejer Forschurg und die von ihr vorgenommene Einreihurg Nestroys kann hier nicht näher eingegangen werden. W. Bietak betrachtet die biedermeierliche Resignation, als "Ausgleichserlebnis eines Spannungsvorganges, dessen Polrichtungen Ideal und Wirklichkeit anstreben". Bei Nestroy will Bjetak alle Stücke als "unbiedermeierlich" ausgeschlossen wissen, die sich in jhrem "zersetzend-pessjnistischen Charakter dem jungdeutschen Geist nähern" ${ }^{2}$

P. Kluckhohn meint als Bjedermeier nur eine "literam rische Epochenbezeichnung . . in cer die Itteratur eine Richtung auf den gesellschaftlichen Gebrauch bekommt" 3 W. Flemming sieht ein "beträchtiches Durcheinander innerhalb der Literaturgeschichte und der Verwendung der Bew zeichnung "Biedermeier". Auch die "Verallgemeinerung des Biedermeier $z u$ einem in sich beruhenden zeitraum der sich durch eine besondere KuItur auszeichne" sei irrefith. rend. 4.

Ivergl. Berthold Emrich, "Biedermeier", Reallexikon, Bd. I, p. I7I/72.

2 vergl. Wilhelm Bietak, Das Lebensgefüh des Biedermeier in der österreichischen Dichtung (Wien-Jeipzig: 1931) p. 141 .

${ }^{3}$ Paul Kluckhohn, Deutsche Vierteljahrschrift für Literatur und Geistesgeschichte, Bd. I3 (1935736) zitiert pach: Wilí Flemming, "Die Problematik der Bezeichnung 'Bie-' dermejer" Germanisch-Romanische Monatsschrift (1958) Bd. 39, Heft 4. p. 38I.

I Ibi.d., p. 384. 
Im Ganzen aber zeigt sich keine besinnliche Ge... mütlichkeit à la Biedermeier, sondern das aufgeregte Getriebe einer Ubergangsituation. Die Zeit der Romantik und des Idealismus ijberhaupt scheint vorbei. Romantisch wird meist mit verstiegen und idedijstisch mit illusorisch gleichgesetzt . . Was die Mehrzahl der literarisch beachteten Werke zwischen 1826 und 1850 zeigt, ist also durchaus nicht biedermejerlich im üblichen Sinn, weder in Haltung, Gesinnung noch Form - . Die Wirklichkeit dieser fjbergangszeit war weit unbehaglicher. . als Ganzes läBt sich diese Zeit nicht als "Biederneierzeit" charakterisieren. Vielmehr zeigt sie tatsächlich eine besonders auffällige Zerspaltenheit.I

Im Gegensatz zu früherer Auffassung, kommt man mit der von Flemming gezeigten Richtung zu einem besseren Verständnis Nestroys. Er benützt wohl überlieferte Formen, übernimnt jedoch nicht deren Gesinnung. Er ist Monarchist, protestiert aber in der satirischen Art eines Anastasius Grün. Sein Protest gegen übernommene Wertungen schließt ihn mit Büchner, Heine und Ienav zusammen. Jie Modeausdrücke "Zerrissen" und "Zerrissenheit" verspottet ex in der Posse Der Zerrissene. $2 u$ "erfassen" ist Nestroy als Dichter weder vom "Lebensgefühl" des Biedermeier, noch von der "Zerspaltenheit" her. Auch die Feststellung W. Muschg, "Alle großen Komödien der europäischen Bühne stammen von tragisch oder melancholisch gestimmten Dichtern: die Shakespeares, Molières und Corneilles so gut wie die Calderons und Lopes und wie die Kleists, Grillparzers,

\footnotetext{
I Ibid., p. $384 / 85$.

2 vergl. Deutsche Wortgeschichte, Herausgeber Friedrich
} Meurer und Friedrich Stroh (Ber]in: Ver]ag Walter de Gruy " ter \& Co, 1959) Bd. II, D. 346. 
Nestroys, Büchners" fügt nur eine weitere Komponente hinzu.

Auf die wesentichen Unterschiede der Periode des "Biedermeier" und "Vormärz" in der politischen Geschichte" kann hier nur verwiesen werden. Die Zeitspanne des Biedermeier in Österrejch ist beeinflußt von der Gejsteshaltung der josephinischen Aufklärung und von romantischem Gefühlsüberschwang. Iiteratur, Musik, und Kunst erleben ejne Blüte (Grillparzer, Raimund, Nestroy, Stifter--Beethoven, Schubert, Lanner; Strauk--Naldmüller, Schwind, Führich u.a.m.). Von Frankreich kommen neve Ideen einer sozialen und politischen Reform. Der österreichische Iim beralismus wird vom deutschen und westlichen Iiberalismus beeinflußt. Die wirtschaftichen Probleme der "industriellen" Revolution werden um 1830 auch in Osterreich wirksam. Verhaßt ist die Zensur, verhaßt aber auch die Bürokratie, die dem Volk gegenüber den staat repräsentiert-maurch Arrom ganz und beschränkten Geist des unteren Beamtentums. Der hohe Adel distanzierte sich vom niederen, GroBbürgertum und. Bankiers führten ein Leben großen Stils. Der Kleinbürger wird im allgemeinen vom Handwerk gestellt, der einfache Arbeiter lebt in Armut. Der Polizeiminister Sedjnitzky erm ließ Verordnungen gegen das "ausweislose Gesindel" von Bettlern und Vagabunden. Die satirischen Angriffe Nestroys auf die MiBstände

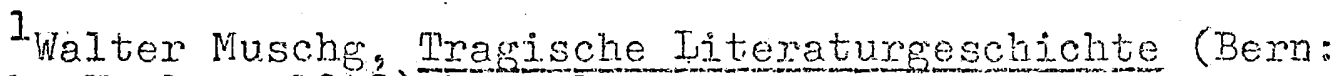
Francke Verlag, 1948) kap. 1. 
seiner Zeit, nahm die marxistische Literaturkritik zum Anlaß, in Nestroy eiren frühen Vorkämpfer des Kommunismus $\mathrm{zu}$ sehen. ${ }^{1}$ So stellt P. Reimann fest, Nestroy geißle in der Posse Freiheit in Krähwirkel die Feigheit der bürgerlichen Schichten und bringe die "Angst dex Bürger vor der Arbeiterklasse zum Ausdruck". 2 Uber das glejche Stück Nestroys kommt Reimann in einem anderen werk ${ }^{3}$ zu der Ansicht, Nestroy war "noch weit entfernt von sozialistischen Ideen ... und erkannte die Gefährichkeit der Bourgeoisie noch nicht im volien Umfang". Auch für die Posse Mäd. aus der Vorstadt bezeugte Reimann Nestroy, er war noch kein "ziepklarer bürgerlicher Revolutionär . . . und begriff das Wesen der sozialen Gegensätze noch nicht". ${ }^{5}$ Ir keiner der Auswahlgaben und Besprechungen ist jedoch Nestroys Stück Lady und Schneider erhalten. Dort heist es nämlich im Refrain eines Couplets "Ah, wenn a'Freiheit Kommunismus wixd, nein, Da hört es auf ein Vergnügen zu sein."16

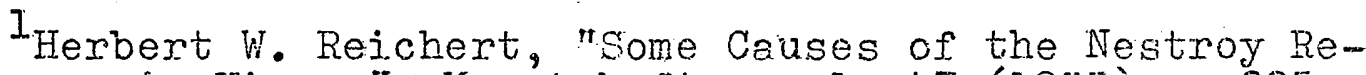
naissance in Vienna", Monatshefte, vol. 47 (1.955) p. 225.

${ }^{2}$ Johann Nestroy, Werke in zwei Bänden (Teilsaminlung) ausgewählt und eingeleitet vor Paul Reimann (Weimar: Volksverlag, 1962) Bd. I, Einleitung p. 21.

${ }^{3}$ Paul Reimann, Hauptströnungen der deutschen Literatur 1750-1848 (Beiträge zu ihrer Geschichte der Kritik) (Berìn: Dietz Verlag, 1963).

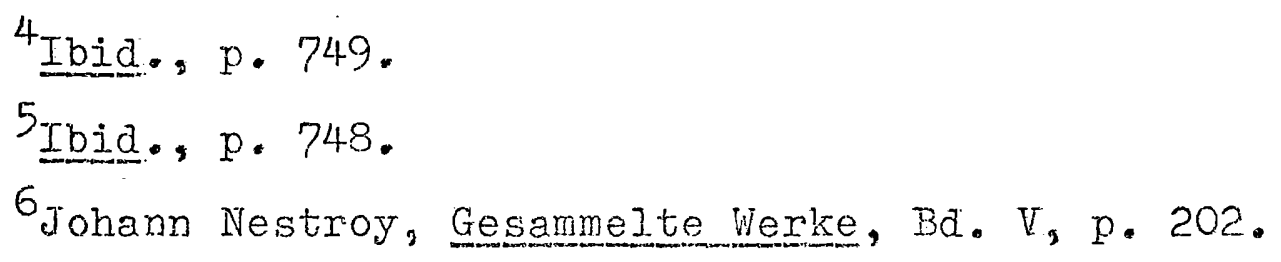


Ein Bericht der Weimares Beiträge ${ }^{1}$ über den III. Internationalen Germanisten-Kongreb in Amsterảam (1965) erwähnt einen Vortrag von W. Dietze (Leipzig) über "Tradition und Ursprünglichkeit in den Besserungsstücken des Wiener. Volkstheaters". In seinen Ausfüriangen entwickelte Dietze die Theorie "von der Funktion der Volkserziehung und Sozialkritik im 'Besserungsstück' . . der Entfaltung ironisch-parodistischer Züge aur die Struktur der Sozialerfakrung" von 1815-1848. Es wird weiter ausgefürt wie Dietze versuchte ${ }^{2}$ "durch konsequenten Historismus die Klassenbeziehungen zu exfassen". Lokalposse und Sittenkonödie lösten das "Modell des Besserungsstickes" ab, weil die"Kompliziertheit des gesellschaftlichen Gefüges nicht mehr hätte erfaßt werden können". ${ }^{3}$ Ohne den vollen Wortlaut, von Dietzes Vortrag zu kennen, weisen allein die ausgewählten Stellen einen starren Schematismus auf. Die Wertung wird zum erheblichen rejl nicht von der Sache, sondern vom sozialkritischen Standpunkt des Marxismus bestimnt.-offensichtlich um sich von der "reaktionären" Iiteraturwis-senschait abzuheben.

In Wirklichkeit sah Nestroy in den sozialen Rangstufen einen natürlichen Ausdruck der sozialen Ordnung. Dje Sa-

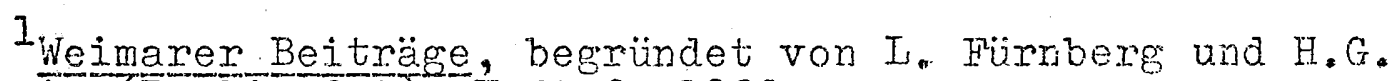
Thalheim (Beriin Ost), Heft $2,1966$.

${ }^{2}$ Ibid., p. 308.
${ }^{3}$ Ibid., p. 308. 
tire Nestroys ist aufs Allgemeine gerichtet, sie ist keine Fersonalsatire. Fr wollte nicht die "ejgenartige Poesie" der "Wiener Luft" schjldern, "sondern die Miasmer hatten es ihm angetan, die Krankheitskeime all der Neurosen und Agressionen die in ihr schwirrten".?

Die geistige Haltung Nestroys verbirgt sich hinter übernommenen Formen und Nodellen der Komik. Das Neue iru der Tradition der Viener Volkskomödie ist aber die besondere Art von Nestroys Satire.

IJohann Nestroy, Des wüsten Lebens flicht'ger Reiz, ausgewählt und mit einem Nachwort von Heinz Politzer? (Frankfurt/Main: Insel Verlag, 1961) p. 67. 


\section{DAS KONISCHE}

Tragödie una Komödie, die beiden großen Arten der dramatischen Dichtung haben in dem Konflikt von Sinn und Wirklichkeit ihren Grund, der Tragödie geht es um den Sinn, der Konödje um das Ubergewicht der Lebenswirklichkeit. 1

Die Tragödie will demnach in ihrer Froblematik an dem ungelöst bleibenden tragischen Konflikt mit der sittlichen Weltordnung verstanden werder. An dieser Problematik hat der Mensch sich zu bewähren. Die Komödie hat die Aufgabe, Komik, das heiBt menschliche Unzulänglichkeit, in Enscheinung treten zu lassen. Statt um Problematik geht es um die Lösung eines oft nur scheinbaren Konfliktes.

Während die Tragödie immer im Mittelpunkt der Betrachtung stand, sahen viele ihre Aufgabe erfüllt, wenn sie die "niedere" vor der "höheren" Komik abgehoben hatten.

Bis nach der deutschen Klassik galt das Komische im Bereich der literarischen Wertung als "niederer" stil. In der ethischen Einstufung der Philosophie, bei Spinoza zum Beispiel, galt es als Ausdruck der "Tierheit am Menschen".

O. Rommel weist darauf hin, daß über das wesen des Komischen "Philosophen, Ästhetiker, und Esychologen, seit dem 17. Jahrhundert--unter ihnen Männer wie Hobbes, Kant, Schlejermacher, Solger, F. Th. Vischer, Schopenhaver, Spencer, Iipps, Bergson, Freud, in nie abreiBender Gedankenar-

${ }^{1}$ Kurt Berger, "Die Dichtung im Zusammenhang der Künste" Deutsche Viertel jahrsschrift für Iiteraturwissenschaft und Geistesgeschichte: Bd. XXI (1943) p. 251. 
beit eine berghohe Iiteratur einander vielfach widersprechender Theorien aufgehäuft. " "I haben. Zu den deutschen Theorien der Komödie bemerkt G. Mijler, sie "interpretieren in mehr oder weniger pedantischer und schulmeisterlicher Weise den Aristoteles, sind von übertriebener Strenge und versuchen immer, eine moralische und belehrende, weltverbessernde Tendenz in das heitere Spiel des Theaters einzuschmuggeln". 2. Tieck ist der einzige-m-mit Einschränkungen auch Kant-.-der eine physiologische Erklärung der Komik gibt. Er erkennt, daß Komik sich wohl an den Intellekt wendet, die Aufnerksamkeit jedoch weitgehend an das Physische gebunden ist.

E. Staiger sieht das Wesen komischer Dichtung im "Antagonismus von dramatischer Spannung und komischer Entspannung", im ganzen stebt dies aber im "widerspruch zum dramatischen Zweck". Er führt weiter aus:

Je mehr ein Dichter zum Komischen neigt, desto eher wird er versucht sein, dramatische Sponnung nur als Ausgangslage des Lachens zu erzeugen und sich in lauter lächerlichen Einzelheiten zu verzetteln. Aristophanes, Plautus, Shakespeare in seinen derbsten Stücken, Molière in den Farcen, Gryphius, Raimund gebärden sich hier ganz hemmungsios. Doch immer wieder wird die Komödie hochlitexarisch reformiert. Dann setzt sich jener Typus durch, in dem die einheitliche spannung durchhält, das Lächer-

IOtto Rommel, Die Geschichte der Alt-Hiener-Volkskomödie, p. 154.

${ }^{2}$ Gottfried Müller, Die Theorie des Komischen, (Würburg: Konrad Triltsch Verlag, 1964) p. 39. 
liche aber nur nosh leise an den Rändern der Handlung spielt...

Die Gegnerschaft zur Komödie bildet sich noch heute zu einem großen Teil aus der Einstellung heraus, die Nietzsche als "ästhetischen Sokratismus in der Bühnenkunst" bezeichnet hat. Das Fehlen einer großen deutschen Lustspieltradition erklärt das zurückhaltende Interesse der literaturwissenschaftichen Forschung für die deutsche Komödie. So ist die Geschichte des deutschen Lustspiels von K. Holl (1923), noch immer die einzige Gesamtdarstel-Iung. ${ }^{2}$ Erst in jüngster Gegenwart scheint man dem Lustspiel vermehrte Aufmerksamkeit zu schenken, wie Teiluntersuchungen aus dem Gebiet der deutschen Iustspieltradition erkennen lassen. 3

Schon die Begriffe "Lustspiel" und Komödie" sind keineswegs von eindeutiger Bestimmtheit. In den meisten Theorien werden sie underschiedslos für alle Arten des heiteren Dramas gebraucht. Nach neveren Theorien ist die Komödie durch eine satirische Komik gekennzeichnet, während man dem Iustspiel eine zum Humor neigende, weniger agressive Komik zuspricht.

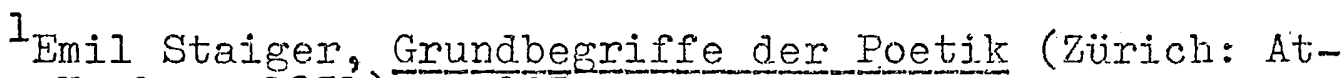
lantis Verlag, 1.951) p. 205.

${ }^{2}$ Karl Holl, Geschichte des deutschen Iustspiels (Leipzig, 1923).

${ }^{3}$ Catholy, Das Fastnachtspiel des Spätmittelalters. Hinck, Das deutsche Lustspiel des $17 \cdot$ u. 18. Jahrhunderts und die italjenische Komódie. Günter Wicke, Die Struktur des deutschen Lustspiels der Aufklërung (Bonn: H. Bouvier, 1965). 
0. Rommel unterscheidet in der Hauptsache zwei Formen der Komik: die Komik der Unzulänglichkeit und die Komik des übermütigen bzw. heiterüberlegenen Spjels. ${ }^{l}$ Die dramatische Ausformung der Unzulänglichkeitskomik ist die mimische Szene, die komische Figur. Von dieser Figur abgespalten, aber auf sie bezogen, ist der sogenannte "Lustigmacher", etwa wie die Narren Shakespeares oder der Grazioso des spanischen Dramas. Der "Lustigmacher" vertxitt den Geist, den Uitz, die Komik jst demnach agressiver. Neben diese "Unzulänglichkeitskomik" stel.t Rommel die Komik des "Kraftüberschwanges und des Ubermutes". Im Sprachliohen ist diese Konik durch Überfulle charakterisiert. "Diese Komik hyperbolischen Ubermutes ist der beste Nährboden für Parodie und Karikatur." ${ }^{2}$

Viele komische Erscheinungen werden ebenso oft dem Humor wie dem Witz zugeordnet. Der Witz ist vor allem an das Wort gebunden; die Form des Witzes könnte man dramatisch nennen. Sprachlich hängt Witz mit Wissen und Geist zusammen; der Intellekt ist daher stark beteiligt. Vielfach nimnt der Witz Klangglej.cheit oder ÄhnIichkeit bedeutungsverschiedener Mörter zum Anlaß. Nestroys Wortwitz etwa weist mit der Mehrdeutigkeit der wörter und der Iogisch-begrifflichen Grenze der Sprache, deren Unzulänglichkeit nach. Inhaltlich reicht die Skala von der Auf-

\section{p. $252 \mathrm{ff}$. Injid., p. 264.}

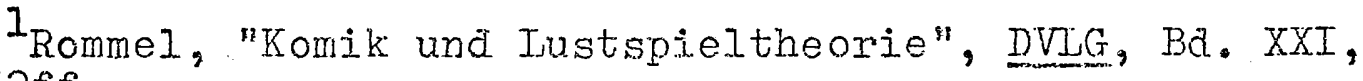


deckung von Unzulänglichkeit bis zum Ausdruck überlegenen Esprit. Wie bei aller Komik, darf auch der Witz nicht von der Bindung an das Normale und Wirkliche zu weit gelöst sein, um die komische Wirkung zu erreichen. Durch bewußte Konzentrierung auf einen Punkt (Pointe) und seinen meist satirischen Chargkter ist der witz ein Element der Satire.

Im Komischen setzt sich der "sinnliche" Mensch zur Wehr. Unzulänglichkeitskomik und die Kornik des überlegenen Spiels verbinden sich, um Dinge aus einer gewissen Entfernung zu sehen. Die dađurch entstehende geistige Freiheit empfinden wir als Iust, sie gibt uns ein Uoberm legenheitsgefühl, das die Relativität des "Absoluten" erkennt und die Bedingtheit auch des Normalen durchschaut. Eine solche Erkenntnis befreit zugleich von der Bindung an Vorschriften, Gebräuche oder etwa vom Druck der Autorität (z.B. bei Nestroy der Zensur). SchlieBlich setzt sich eine Komödie oder eine Posse aus "komischen Ejnheiten" zusammen, die mehr oder weniger fest verbunden sind. Verschieden ist auch der Grad der Komik, oder etwa die Bindung an Witz, Satire, Parodie und Groteske.

Im Ganzen gesehen ist das Phänomen des Komischen ein vielschichtiger Vorgang,

-.. eine komplexe Angelegenheit, in der verschiedene körperliche und geistige Funktionen zusammenarbeiten. Vielleicht geht man nicht fehl, wenn man in der Zusammenarbeit das Gedächtnis, das Gerühlsleben, den lillen, die kognitive Tätigkeit und vor allem das Triebleben erkennt. Keiner von diesen Faktoren läßt sich ganz ausscheiden, weder im Sinu für das Komische im 
einzeInen Nenschen noch im Sinn fir das Kornische bei einer bestimmten Gemeinschart. 1

In jedem Fall umsch]ieBt das Komische die Fülle des Lebens --auch der Ernst im Hintergrund behält seine Stelie.

Die Vielgestaltigkeit des Wortschatzes in "Sinnberejch des Komischen" hat W. Schmidt-Hidding in seiner Untersuchung $^{2}$ (nach Wortarten) in vier komische Grundhaltungen unterteilt: Witz--Humor--Spaß---Spott. Die sich in den Wortarten ausdrückenden Perspektiven versuchen eine Abgrenzung, wo die ästhetisch-literarische Terminj zu weitläufig und schwer zu überschauen wären.

1. Anlage, Begabung, Sinn für:

Witz: Witz, Geist, Esprit, Mutterwitz, Schlagfertigkeit

Humor: Selbstverspottung, Selbstironje

Spaß: Scherz

Spott: Verspottung, Spottsucht, Hohn, Ironie, Sarkasmus, Zynismus.

2. Eigenschaft:

Witz: witrig, geistreich, schlagfertig, spitz

Humor: humoristisch, launig, schälkhaft, ärollig, putzig

Spaß: spaßhaft, spassjg, scherzhaft, (possierlich), schelmisch, burlesk, grotesk.

Spott: spöttisch, spottlustig, spottsüchtig, lächerlich, beißend, schneioend, scharfzingig, schnippisch, höhnisch, hämisch, anzüglich, mokant, ironisch, satirisch, sarkastisch.

3. Nomina agentis:

Witz: Witzbold, witziger Kopf, Witzling (abschätzig) (ZotenreiBer)

Humor: Humorist, Schalk, Schelm, lachender Philosoph, Kauz, Till Eulenspiegel, (Büttenredner)

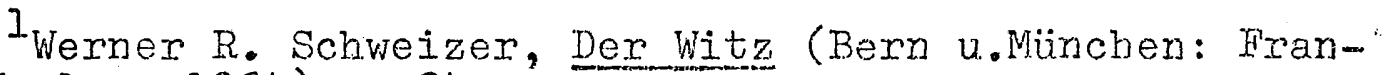
cke Verlag, 1964) p. 24.

${ }^{2}$ Wolfgang Schmidt-miditng, Europäische Schlüsselwör ter, $\mathrm{Bd}$. I. Humor und Witz (Wortvergleichende und wortgeschichtiche Studien) (Wünchen: Max. Hueber Verlag, 1.963). 
Spaß: Spaßvoge], SpaBmacher, Possenreißer, fideles Haus, vergnügtes Huhn, Schäker

Spott: Spötter, Satiriker, Ironiker, Sarkast Die Professionellen: Hofnari, Hausnarr, CIown, Kasper, Kasperle, Hanswurst, Harlekin, Pickeihering, Bajazzo, Dummer August, Hännesche.

4. Der verbale Bereich:

Witz: Witze reißen, witzeln, geistreicheln Humor: belächeln, necken, foppen, uzen

Spaß: Spaß machen, einen Possen, einen Streich spielen, hänseln, frotzeln, in den April schicken

Spott: spotten, spötteln, bespötteln, zum Narren halten, sich lustig machen, sticheln, herriehen über, anflaumen, durchhecheln, durch den Kakao ziehen, sich mokieren, zum Besten haben, zum Narren halten, hochnehmen, auf den Arm rehmen, verkohlen, verulken, auslachen, verlachen, ins Iächerliche ziehen, lächerlich machen, aach-. äffen, ironisieren, persiflieren, travestieren, karikieren, parodieren

5. Objektivierungen:

Witz: Witz, Pointe, Finfall, Wortspiel, Aphorismus, Bonmot

Humor: nur in Adjektivverbindungen: humorvolle Geschichte Spaß: Spaß, Streich, Jux, Ulk, Scherz, Narrenposse, Schnurre, Schnack, Posse, Possenspiel.

Spott: Spottrede, Spottlied, Spottname, Spitzname, Stich, Stichelei, Hieb, Hänselei, Anspielung, Satire Parodie, Travestje, Karikatur, Persiflage.

Diese Anordnung nach Wortarten gibt somit Auskunft ïber die angefuhrten Bezirke ("komische Grundhaltungen") und wie sie mit sinnverwandten wörtem besetzt sind. 


\section{DIE SATIRE}

\section{a. Definitionen}

"I can testify that it is a sobering experience to bave worked for years on a subject like satire and finally to realize that one cannot define strictly the central term of one's study "I "Eine heutigen wissenschaftlichen Ansprïchen genügende Geschjchte der deutschen Satire gibt es... nicht." ${ }^{2}$. Erst seit wenigen Jahren verfügen wir über eine Geschichte der deutschen Tragikomödie ${ }^{3}$ ura einer Darstellung über das Groteske. 4

Schon bei dem Versuch für den Begriff "Satire" eine befriedigende Definition zu finden, stößt man auf eine Unsicherheit in der Bewertung dieses Phänomens. Die Einleitungskapitel der meisten Werke über die Satire unterstreichen die Schwierigkeit einer einheitlichen Begriffs bestimmung. C.E. Vulliany schreibt:

Although satire is one of the most evident of qualities, both in literature and in life, there has never been agreement with regard to its precise definition,

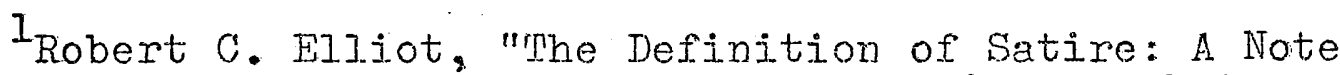
on a Method", Yearbook of Comparative and GeneraI Iiterature No. 11, 1.962 (Indiana University) p.22。

${ }^{2}$ Klaus Lazarowicz, Eerkehrte Velt, Vorstudien zu einer Geschichte der deutschen Satire (Tïbingen: Nax Nie-. meyer Verlag, 1963), p.X.

3 vergl. Karl S. Guthke, Geschichte und Poetik der deutschen Tragikomödie (Götitingen: Vandenhoeck und kuprecht, 1961).

4. Wolfang Kayser, Das Groteske. seine Gestaltung in Malerei und Dichtung (oldenbirg: Verlag Gerhard Staljng, 1957). 

or even with regard to the original meaning of the
word satura.

W.O.S. Sutherland setzt in gleicher Richting fort. "No one has much trouble in pointing out satire, but an attempt to describe or define it often arouses an uncomfortable feeling of inadequacy. "2 Auf eine kurze Formel bringt R.C. Elliot seine Ansicht, "Satire is notoriously a slippeny term, designating, as it does, a form of art and a spirit, a purpose and a tone--to say nothing of specific works of art whose resemblances may be highly remote. 3

Die Schwierigkeit, die Gattung Satire "wissenschaftlich zuetablieren", liegt darin, "daß es sich um eine unlösliche Einheit der Berührungspunkte mit Ironie, Humor, Witz, Parodie, Travestie, Pasquill etc. handelt. Hat schon jedes Phänomen für sich eine uferlose Diskussion über ihr jeweiliges Wesen hervorgerufen, so erst recht jener komplexe Begriff den man mit Satire bezeichnet". 4 Aus dieser Sicht werden die zum Teil sich widersprechenden Definitionen erklärlich. Uber das Zjel der Satire etwa

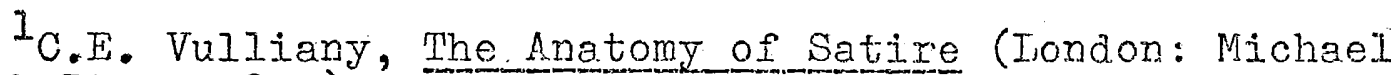
Joseph Itd., 1950) p. II.

2W.O.S. Sutherland, Jr., whe Art of the Satirist (The State University of Texas, i965) p. 9 .

3 Robert C. Flliot, The Power of Satire: Magic Ritual, Art (Princeton: Princeton University Press, 1960) p. VIII.

${ }^{4}$ Guthke, p. 12. 
gibt das Sachwörterbuch der Iiteratur folgence Auskunft, "stets ruft dje Satire durch Anprangerung der taster die Leser zu Richtern auf, mißt nach einem bewuBten Maßstab aas menschliche Treiben und hofft, durch Aufdeckung der Schäden eine Besserung zu bewirken". $Z_{u}$ anderer Ansicht gelangt G.E. Vulliany: "Thus, I think it must be aamitted that the primary intentions of satire are purely descriptive ana its pretence of moral improvement exceedingly frail. ${ }^{22}$ Nach W. Kayser kann sich das Satirische als "Kategorie der Perzeption" in nahezu allen Iiterarischen Formen zur Gel-. tung bringen. "Je mehr aber die Satire als 'Ginn-Ausspra.che' gemeint ist--durch gleichsam negierende Darstellung eines Negativen--desto weiter entfernt sie sich aus der Ijiteratur und begibt sich auf jenes Feld, das als didaktische Literatur bezeichnet wird. "3 Im Ganzen entsteht bei Kaysers Darstellung der Satire der Eindruck, als betrachte er die Satire nicht als eine vollwertige literarische Form. Darin, daß sich die Dichtung der Neuzeit von übernommenen Regeln und Formen befreite, sieht P. Böckmann in der Struktur eines Werkes das bestimmende Element. ${ }^{4}$

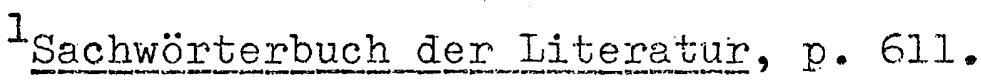
${ }^{2}$ C.E. VulIiany, p. II. Kayser, p. 380-383.

4 vergl. Paul Böckmann (in seinem Vortrag) stil-und
} Formprobleme in der Literatur, Vorträge des VII Kongress w ses der internationalen Vereinigung für modeme Sprachen und Iiteraturen in Heidelberg) Herausgeber Paul Böckmann (Heidelberg: Carl Winter Universitätsbuchindlung, 1959). 
Wir verstehen heute demach unter: "satirisch" eine be-.. stimmte Geisteshaltung. Wenn B.S. Guthke zum Pragikomi schen bemerkt, "Denn wir behandeln das Tragikomische ja nicht lediglich als ein ästhetisches Phänomen, sondern zúgleich als Chiffe einer Kategorie der Perzeption, eineI Auffassungsweise des Menschlichen, einer Möglichkeit, sich zur Welt und zu sich selbst zu verhalten ${ }^{l}$, so läBt sich diese Erweiterung ebenso auf das Satirische anwerden.

Eine "Erweiterung" der "ästhetischen Grundauffassungsart" (nach Wiegand) ${ }^{2}$ glaubt $H$. Arntzen zu geben, wenn ex zu der ästhetischen, noch aie "moralisch-ethische Auffas. sungsweise"3 hinzufügt. Arntzen steIlt zwar das "veränderte Weltverständnis seit der Aufk] ärung" fest, erachtet aber die Frage für wesentlich, wie sich das "Ästhetische mjt dem Kritisch-Moralischen verbinken lasse, "4 beaenkt jedoch nicht, daß es nicht unbedingt des "Kritischmorali-. schen" bedarf um Satiren zu schreiben. Es ist zu bedenken, daß sich die moralischen Werte in Umfang und Inhalt im Iaufe der Zeit ändern--selbst bei verschiedenen Bevölkerungsschichten der gleichen Zeit verschieden sind. Zur

\section{${ }^{I}$ Guthke, p. 23. \\ "Julius Wiegand, "Satire", Reallexjkon der deutschen} Iiteraturgeschichte (Berljn: Verlag Walter de Gruyter, 1928/29) Bd. III. p. 137. Nach viegand ist die satire eine "ästhetische Grundauffassungsart".

3 Arntzen, $\mathrm{p} .1 / 2$.

IIbid., p. 2 . 
Frage der "Moralität" führt I. Feinberg folgendes aus:

So the satirist, in choosing material which involves ethics and morality, is choosing waterial with which his particular audience is familiar. Because he chooses this socjally acceptable kind of critticism, his satire is likely to appear "moral", but morality is usually incidental to his aesthetic intentions, peripheral to it, and motivated to a large extent by purely technical requirementis. It is no more fair to assume that satirists have greater moral motivation than other writers...

Until we have a society in which there is considerably more agreement as to precisely what moraljty is, we will have to admit the possibility that there are satirists who are moral, satirists who are amoral, and satirists who are immoral.?

Man darf gerade bej der Bühnensatire Nestroys mit

Recht annehmen, daß der Autor jene Figuren und Modelle auswählt, die für das Sichtbamachen des Satirj.schen am besten geeignet sind. Der Versuch, die Satire und den Satiriker zu exfassen und zu deuten, führte dje Kritiker dazu, das Problem aus verschiedenen Perspektiven zu beleuchten. J. Pfeiffer nähert sich der Beziehung zwischen Satire und Satiriker wie folgt:

Satire drückt die Spannung aus, die zwischen der wahren Wirklichkeit und dem tatsächlichen Zustand der menschlichen Dinge besteht. Was auch immer ju einzelnen getroffen und bekämpft werden mag: es ist doch nur der stoffliche AnlaB, durch den das eigentliche Thema fühlbar wird, das den Satiriker jn Atem hält. Satire setzt also ein Unbedingtes und Unentstelltes als Hintergrund und Maßstab voraus. Sie lebt zwischen Verzweiflung und Hoffnung, dergestalt, daß diese, indem sie aus dem Verborgenen wirkt, das

I Teonard Feinberg, The Satirist, His Temperament, Motivation and Influence (Ames: Iowa State Unjuersity Press, 1963) p. 40 .

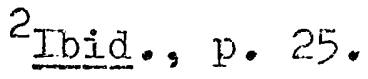


Abgleiten in skeptische oder gar zynische weltsjcht verhindert. 1

Hum vollen Verständnis wäre vorerst zu kJären, ob mit dem Begriff "wahre Wirkichkeit" die auBerdichterische Wirkichkeit, hier etwa in Ubereinstimmung mit dem ethischen Ideal (als Inbegriff der Volikommenheit) gemeint ist.

Eine philosophisch-theologische Auslegung gibt Th. Haecker in seinem "Dialog über die Satire". Danach "kann nicht einer Christ sein und ein Satiriker zugleich . . man kann nicht zwei Herren dienen, der tjebe und dem Haß"." Wobei es schon allein fraglich ist, ob man so allgernein im Haß eine treibende Kraft der Satjre sehen kann. Die Satire ist für Haecker "ein großer künstlerischer und ethischer Versuch, die Dinge wiederherzustellen, wiedereinzurenken vor der Erlösung". 3

Zu einer etwas anderen Festlegung des Satirischen kommt G. Highet, wenn er über die Beschaffenheit eines satirischen Textes sagt: "Most satiric writing contains cruel and dirty words; all satiric writing trivial and comic words; nearly all satiric writing contains colloquial antiliterary words. " Als weitere Kennzeichen ("typical weapons") des

IJohannes Pfeiffer, Utber das Dichterische und den Iichter (Hamburg: Richard Meiner Verlag, 1956) p. 122.

2 Theodor Haecker, Opuscula (München: 1949) p. 361. IIbid., p. 370 .

${ }^{4}$ Gilbert Fighet, The Anatomy of Satire (Princeton: Princeton University Press. 1962 p. 18. 
satirischen stils sieht Highet, "irony, paxadox, antitbesis, parody, colloquialism, anticlimax, topicality, obscenity, violence, vividness, exaggeration". " "The final test for satire is the typical emotion which the author feels, and wishes to evoke in his readers. It is a blend of amusement and contempt. ${ }^{2}$ Nach diesem "endgültigen Test" bleibt nur die Frage offen, wie der Autor die Resonanz bei dem Leser sichern kann.

Aus dem Bestreben fïr die deutsche Iiteratur eine gültige Definition der Satire zu erarbeiten, pruft und analysiert $K$. Lazarowic satirische Texte und Theorien des 18. Jahrhunderts. In dieser umfangrejchsten neveren Untersuchung über die deutsche Satire ${ }^{3}$ kornt der Autor zu folgenden Ergebnissen. Das Satirische ist nach Lazarowicz "eine dem satirischen Naturell eigentümiche Art der Welteriassung und Weltbeurteilung". 4

Im Unterschied zu anderen Erlebnisformen zielt die. satirische Welterfahrung auf die Uberwindung der reinen Passivität. Der Satiriker jst nicht bereit, die Welt hinzunehmen, wie sie ist. Er empört sich geger die Verunstaltung des Idealen oder Absoluten.5

Satirisches Schaffen gründet . . In der unbestreit--

I Ibid., p. 18 .

Ibid., p. 21 .

3K. Lazarowicz (Verkehrte Welt, Vorstudien zu einer Geschichte der deutschen Satire) siehe S. 43 dieser Arbeit.

${ }^{4}$ Ibid., p. 310.

5 Ibia., p. 310 . 
50

baren Erfahrung, daß die WeIt vor: dem Absoluten, dem Idealen und Normativen versagt. 1

Das Problem des moralischen Aspektes behandelt Lazarowicz nicht immer widerspruchslos. Danach gehört "allein das Problem der Iegitimation des Satirikers in die Zuständigkeit der Morala?

Indessen: moralische Integrität ist zwar eine unabdingbare Voraussetzung für die tulässigkeit des Satirisieren. Sie gewährleistet jedoch nich, daß die Ambitionen eines untadeligen Gelegenheitssatirikers auch satirische Gestalt annehmen. Anaererseits ist es durchaus möglich, daß einem moralisch zwielichtigen Autor (Liscow) satirische Meisterwerke gelingen. 3

"Qualität und Rang" einer Satire bemessen sich, nach Iazarowicz, "allein nach dem Grad der künstlerischen Perfektion"... auch die Frage nach dem "Besserungseffekt des satirischen Schaffens vermag dazu nichts beizutragen". 4 Wenn demnach "Qualität und Fang einer Satire allein durch . die künstlerische Perfektion" bestimmt werden, so sind damit Liscows "satirische Meisterwerke" gerechtfertigt--es bleibt jedoch die Frage offen, wie sich ein "moralischzwielichtiger" Autor (Iiscow) gleichzeitig gegen die "Verunstaltung des Idealen oder Absoluten empören" kann. Wir düren somit annehmen, daß "Moralität" und das "Versagen der WeIt vor dem Absoluten, dem Idealen und Normativen"

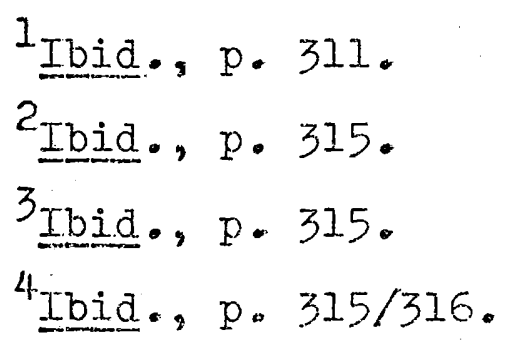


als Kriterium der Satire von untergeordneter Bedeutung sind.

Die "gestaltprägende ("strukturbildende") Energie" des Satirischen ist die Verkehrung. "Verkehrung, Ver. stellung, und Verzerrung stehen im Dienst der satirischen Negation. Diese drei Krärte wirken strukturbildend und integrationsfördernd, sie begrinden die 'verkehrte Welt"... ${ }^{\mathrm{mI}}$

Lazarowicz schlägt vor,

den Begriff Satire nur cort anzuwenden, wo der kïnst-lerische Aufbau einer verkehrten Welt angestrebt und wenigstens ansatzweise (auf jeden Fail ober deutich erkennbar) geleistet worden ist.?

Die Bezeichnung Satire oder das Beiwort satirisch soll "dem Verfasser einer Strafpredigt, eines politischen. Pamphlets, einer stachelschrift" (Straf-, Stachel- und Sittenschrif-. ten des späten Mittelalters und des Barock) "oder eines Lasterkatologs verweigert werden" ${ }^{3}$

Kennzeichnend für die Satire ist somit der Aufbau einer verkehrten Welt ("mundus perversus").

$\mathrm{Zu}$ den wichtigsten Medien des satirischen Welteufbaus gehören dje Ironie, die Parodie, die Travestie und die zur Karikatur tendierende Hyperbolik. Dazu tritt, vor allem das Mittel der indirekten Gestalten-Charakteristik (was in der Satire soviel wie Entlarvung bedeutet), die Sprachsatire. Kaum von der Stoffwabl, viel mehr von der sachgerechten und diskreten Verwendung dieser im Dienst der formalen wie materialen Dekompo--

\footnotetext{
I Ibja., p.71.

Ibid., p. 312 .

IIbid., p. 310 .
} 
sition stehenden MitteI wird die satirische Darstellung bestimmt. . . Der Satiriker bringt . . vor dem allenfalls angedeuteten Hintergrund des ordo die totale Verkehrtheit der Welt wur Anschauung. Das ist ein sehr ernsthaftes Geschät, auch da, wo es sich den Anschein gelassener Heiterkeit gibt, und auch dann, wenn wir durch die Verwendung komischer Darsteliungsmittel zum Lachen odex Lächeln gereizt werden.

Im Unterschied zum Humoristen und Komiker, ist der Satiriker ein Feind des Verkehrten. Nach Lazarowicz ist "das Problem der Abgrenzung der satirischen von der rein komischen Iiteratur unerledigt geblieben".?

Schließlich hat man noch versucht, den Satiriker gus biographischer, historischer und psychologischer Sicht zu bewerten. A. Kernan ${ }^{3}$ untersucht die biographischen und historischen Möglichkeiten. Bei der biographischen Annäherung glaubt man die Art der Satire aus körperlichen F'ehlern, psychischen Störungen und sozialen Schwierigkeiten ableiten zu können. Die historische Methode vergleicht die satirische Aussage eines Werkes mit dem nichtsatirischen Bild der gleichen Gesellschaft. I. Feinberg ${ }^{4}$ gruppiert die Ansichten verschiedener Psychologen, um aus psychologischen Aspekten (etwa neurotischen, sadistischen, masochjstischen Tendenzen) die satirische Weltsicht eines Autors zu erklären.

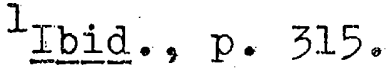 \\ Inid., p. 318.}

3 Alwin B. Kernan, The Plot of Satire (New Haven \& Iondon: Yale University Press, 1955) p. $4-6$.

${ }^{4}$ Feinberg, p. 211 ff. 
Die angeführten Definftionen und Ansichten über dje Satire haben deutlich gereigt, daß es eine allgemeingiltige Formel für die Satire nicht geben kann. Eine "Universal-FormeI" der Satire würde zu einem starren Schema führen und der Mannigfaltigkeit dieses Phänomens nicht gerecht werden. Auch wird notwendigerweise das Mischungsverhältnis in einer satire immer verschieden sein. So sind etwa Spott oder Ironie in Art und Intensitat des Ausdrucks vom jeweiligen Autor abhängjg. Man darf demnach annehmen, die Satire schafe sich fü jeden neuen Anlas neue Ausdrucksmittel. Die Tradition und die Umwelt geben wohl die Modelle, die satirische Kunst jedes Autors ist. jedoch speziftsch einmalig. Aus djesem Grund wird es schwierig sein, eine "allgemeine" Abgrenzung gegen Parodie, Ironie, Witz, Groteske, Karikatur etc. zu firden. Die divergjerenden Definitionen verschiedener Kritiker zu diesem Problem der "genauer" Abgrenzung gäbe wieder nur eine Aneinanderrejhung verschiedener Ansichten.

\section{b. Theorien}

Bis zum Beginn des 18. Jahrhunderts galt die Satire a]s "unanständige" Art der Poesie. Mit deutlicher Reserve behandelt Opitz die Satire in seiner Buch von der deutschen Poetery (1624). Fr fordext eine Stitenlehre die durch "ergötzliche" Darbietung annehmbar zu machen gei. Die "seele" der Satire sei die "harte verwejsung der laster und anmah-" nung zue der tugend". 
Eine Verbesserung der Sitten wird bei fast alien Theoretikern der Satire des Barock vextreten (D.G. Morhof, Buchner). Die Satiren von Lauremberg, J. Rachel, Grimmelshausen ("Satyrischer Pilgran") und von Chr. Weise werden als Ansätze in dieser Richtung begrüBt. J.B. Mencke macht den Vorschlag, die Satiren "Sitien-Gedichte" zu nennen. Harsdörffer bezeichnet die "Satyra" als "Schimpff--Stachel oder Strafgedicht"

Von "Satiren oder Strafgedichten" handelt auch" Gottsched im zweiten Teil seiner Critischen Djchtkunst. Die Satire, so heibt es, sei "eine Abschilderung lasterhafter Handlungen oder das Gegenteil von Iubgedichten" " Der "Gystematikex" Gottsched teilt die satirische Dichtung in "zwei Hauptgattungen ein, nämlich in die "Iustige oder scherzhafte" und die "ernsthafte oder beiBende" Satire". I Nach" römischen. Muster schränkte er die Satire auf ein längeres Gedicht in Alexandrinern ein. Gottsched begrenzte die Spielwelt des Iustspiels auf die zeitgenössische bürgerliche Wirklichkeit, die pädagogisch in das bürger.jichmoralische Leben zurückwirken sollte. Das freie SpieI wurde durch die Forderung einer "exnsthaften" Satire unter-bunden, dem Witz und der Komik blieben durch die Einengung des "Lächerlichen" auf das "Lasterhafte" wenig Raum. Trotz seiner Barockgegnerschaft steht Gottsched in seiner SatireTheorie noch unter dem EinfluB der Barockpoetiken. 
In 18. Jahrhundert macht sich die deutsche Satire nicht in der von Gottsched geforderten Gedicht-Form der Satire bemerkbar, $\left(z . B\right.$. die Prosasatiren von Rabener ${ }^{I}$ und Jiscow). Die Frage der Gattung wird der Frage nach dem Satirischen untergeordnet. Von den anderen "Formen des Komischen und des Ironischen ist es wie zu dieser zeit allgemein, noch keineswegs unterschieden".? (Etwa bei J.A. Eberhard, 1738-1809).

Nach J.G. Sulzer gehört die Satire unter die "wichtigsten Werke des Geschmacks" und steht untex dem "Gesetz der Nutzbarkeit". Der Endzweck der Satire ist "dem Ubbel, daß sie zum Inhalt gewählt hat, zu steuxen, es zu verbannen, oder wenigstens sich dem weiteren Finreiken desselben zu widersetzen, und die Menschen davon abzuschrecken". 3 In seiner dreibändigen Geschichte der europäischen Satire bringt C.F. Flögel unter anderem auch eine Neugliederung der deutschen Satire Theorien. Seine Feststellungen Iiegen bis auf geringe Erweiterungen im Rahmen der Tradition (besonders Sulzers). Der Satirjker bleibt Moralist und die Satire ein "Werk des Geschmacks".

Aus den Erklärungen der meisten barocken und aufge-

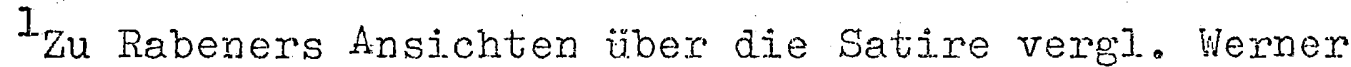
Kohlschmidt, Geschichte der deutschen Iiteratur vom Barock bis zur KIassik (Geschichte der deutschen literatur von den Anfängen bis zur Gegenwart Bd. II) (Stuttgart: Philipp RecIam Jun., 1965) p. 272-275.

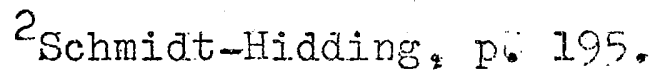

3 Lazarowicz, p. 220. 
klärten Theorien der Satire über Nutzen, Schaden und Zugehörigkeit des Satirisierens, füht erst Schillers Abhandlung. Uber naive und sentimentalische Dichtung (1795) zu einer Neubewertung der Satire. Das der Satire zugewiesene Kapitel setzt sich von dem Moralismus ${ }^{1}$ der früheren Theorien deutich $a b$. In der Unterscheidung zwischen dem "naiven" und dem "sentimentalischen" Dichter, teilt er die Satire dem sentimentalischen Dichter zu. Die drei einzig möglichen Arten sentimentalischer Poesie sind Satire, Flegie und Idylle, wichtig ist in gllen die herrschende "irnpindungsweise". Als satirisch bezeichnet schillex den Dichter, wenn er die Entfernung von der Natur und den Widerspruch der Wirklichkeit mit Ideale (in der Wirkung auf das Gemüt kommt beides auf eins hinaus) zu seinem Gegenstande macht. Dies kann er sowohl ernsthaft und mit Affekt als scherihaft und rit Heiterkeit ausführen, je nachdem ex entweder im Gebiete des viliens oder im Gebiete des Verstandes verweilt. Jenes geschieht durch die strafende oder pathetische, dieses durch die scherzhafte Satjre.?

Uber die Satire heiBt es weiter, "In der Satire wird die Wirklichkeit als Mangel dem Ideal als der höchsten Realität gegenüber gestellt. Es ist ïbrigens gar nicht nötig, daß das letztere ausgesprochen werde, wenn der Dichter es nur im Gemüt zu erwecken weiß." 3

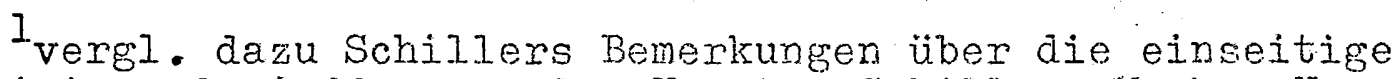
moralisierende Auffassung der Kunst. Schillers Verke, Nationalausgabe $\mathrm{Bd}$. XXI. (Weimar: Herman Böhlau Nachfolger, 1963) Teil 2, p. 310, Anmerkung 486, 12f.

${ }^{2}$ Friedrich Schillen, Uber naive und sentimentalische Dichtung (Stuttgart: Philipp Reclam Jun., 1962) p. 42 .

Ibid., p. 43. 
Der Satiriker hat sich demach nicht vor der Moral, sondern vor dem Ideal zu verantworten. Das wesentliche Element ist aber die Antithese, bei Schiller mit Ideal und Wirklichkeit bezeichnet. Der auf das Ideal verpfichtete Satiriker richtet seine pathetische oder scherzhafte Satire (der Dichter hat die Wahl) gegen eine Welt die vor dem Ideal versagt. Erst durch die ethische Deckung wird somit die Satire zur gerechtfertigten Antithese ihres Gegenstandes.

Die schwierigen Fragen nach dem Verhältnis des Sati* rikers und der Satire zur Komik und zum Hunor bat Schiller * nicht behandelt. Nach B.V. Wiese ist es "erstaunlich" wie sehr in Schillers Theorien die "satirische und gesellschaftskritische Seite der Komödie zurücktritt".I Von den später aufgestellten Theorien der Satire wird die Theorie Hegels bei der Erfassung der satirischen Elemente in den Werken Nestroys zur Anwendung kommen.

IBenno von Wiese, Friedrich Schilier (Stuttgart: J.B. Metzlersche Verlagsbuchhandiurg, I963) p. 54.2. 
c. Anwerdung der Iheorien

Die aramatische Satire der Bithe und die fin Buchform gebotene Satire haben Gerneinsames und sjnd doch wesentlich verschieden. Das Gemeinsame ist die Einkleidung der kritischen Art der Satire. ir eine ansprechende Form. Das geschieht durch Witz und Humor. ${ }^{\perp}$ Der satirische Angrif' darf nicht zu scharf erfolgen, denn ex richtet sich je im Grunde gegen den Zuschauer oder Leser. In der Iiteratur finden sich deshalb die topoj der "verzuckerten Pille", "gesüßten Arznei", "lachenden Sittenkritik" etc.?

Die Person der Buchsatire ist anonym, der Satiriker der Bühne jedoch hat die Unzulänglichkeit, die er bekämpft, an seiner eigenen Person darzustelien. Nestroy wurde deshalb "für aie Utbel verantwortlich gemacht, die er geißelte" (Rommel). Er drückt das in einem Dialog in Mein Freund aus $(G W-V ., 446) .^{3}$ Julius spricht von der Grundung eines "illustrierten Blattes", einer "satirischen "Wochenschrift":

Schlicht: Ein satirisches Unternehmen--? Hast du Freunde?

Julius: Die hoff' ich zu finden.

Schlicht: Mit der Satire? Mit dem ominösen Zauberstab, der die besten Freund' in Feind' verwandelt. Julius: Was fällt dir ein?! Die Menschen lachen gerne.

Schlicht: Das wohl, wenn aber einer nach dem andem merkt, daß er bei den Satiren über sich

Ivergl. p. 39-42 dieser Arbej.t.

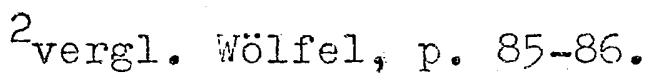

3 Johann Nestroy, Gesamrelte Werke, Bd.V., p.446. Herausgeber otto Rommel (Uien: Anton Schroll Verlas \& Co., 1962). (Abkirzung GW-V. für Gesame]te Werke, Bd.V, witrd hier und im letzten Kapitel benutit.) 
selber gelacht hat, das bildet eine Masse, die einem's bitter nachtragt.

Der Satiriker der Bühne arbejtet in der Regel mit starken Kontrasten, die sich bei Nestroy oft in Form der Karikatur und Groteske bemerkbar machen. In der gleichen Szene setzt der Dialog mit der Ansicht über die Karikatur fort:

Julius: Ich bau' auf mein richt unbedeutendes Talent im Karikaturzeichnen.

Schlicht: Das: ist noch das Allerverfehlteste. In der Karikatur liegt zuvie]. Wirkliches, und die Menschheit will nur recht poetisch aufgefart sein, ein klarer Beweis wie prosám isch sie ist.

Zuerst sei auf ein Charakteristikum der Hauptperson in den Stücken Nestroys hingewiesen. Diese Hauptfigux, von Nestroy fast immer selbst gespielt, bringt in Dialogen, Aufrittsmonologen und Couplets Tejlausschnitte seiner Weltbetrachtung. Hier konzentrieren sich die satirischen Angriffe, und hier wird auch die größte Dichte im sprachlichen Ausdruck erreicht. Wir haben daher in unserer Untersuchung zum überwiegenden Teil mit der NestroyFigur zu tun. M.Mack nenrt diese satirische Hauptperson "satiric speaker" oder "persona".

Die angeführten Dialoge lassen bereits erkennen, daß sich Nestroys Satire gegen alle richtet ("Nenschen", "Menschheit"), die Betroffenen sollen es nur nicht merken. Die Karikatur als Element von Satire und Komik, sieht Nestroy durch die wirklichkeit selbst dargestellt, d.h. die

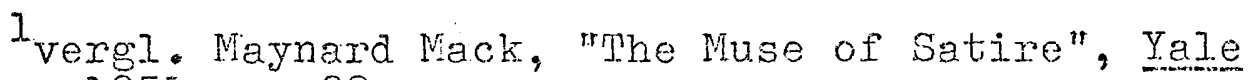
Review, 1951, p.88. 
Wirklichkeit selbst aargestellt, a.h. die Wirklichkeit braucht erst gar nicht verzerrt zu werden, um Kerjkatur zu sein. Es ist aber auch möglich, daß die Uberzeichnung der Wirklichkeit erst das Entscheidende trifft.

Nestroy hat keine Hinweise auf eine Theorie der Satire gegeben. Dafür hat man versucht, die Art seiner Satire mit verschiedenen Methoden und Definitionen zu erfassen. Von der stofflichen Seite, besonders vom Aphorismus her, versuchte dies I. Langer, ${ }^{I}$ vorn philosophisch-theologischen Standpunkt Alph. Hämmerle. ${ }^{2}$ F. Leib 3 will die Art der Satire durch Schillers Theorie erläutern. Nach H. Arntzen ist Schillers "Grunddefinition der Satire die beste-und letztlich einzige, die wir besitzen". 4 Diese Feststellung gilt jedoch nur tejlweise für die dramatische Satire. Vie schon ausgeführt, hat Schiller das Verhältnis von Satire und Komik nicht behandelt. Nach Schiller können sjtiliche Mängel nur Gegenstand der "strafenden" Satire sein, während die "scherzende" Satire die intellektuellen Mängel verlacht. Schiller denkt zu stark in reinen Typen, deshalb läßt sich Nestroys Satire hier nicht einordnen, wenn er etwa sittliche Mängel satirisch-komisch darstellt.

IVergl. Johann Nestroy, Sämt]iche ilerke, Bd. XV., p. 596, Anmerkung 197.

${ }^{2}$ Alphons Hämmerle, Komik, Satire und Fumor bei Nestroy (Freiburg: Dissertation, 1947 ) (vergl. auch p. 56 dieser Arbeit.)

3 Frymet Leib, Die Gesellschaftssatire bei Nestroy (Wien: Dissertation, 1931)

${ }^{4}$ Arntzen, p. 2. 
Wie sich im Iaufe der Untersuchung nooh ergeben wird, fühlt sich Nestroy keineswegs den hohen Idealen der Klassik verpflichtet. Seine Ideale sind deshalb verschieden, damit aber auch die Art seines saticischen Angriffes. Nestroy will gar nicht die "irklichkeit als Mangel" dern "Ideal als der höchsten Realität" gegenüberstellen, dazu hat er gar nicht den festen "idealischen" Standpunkt. Er will die Welt entlarven, und daraus entwickel.t sich sein skeptisches Menschenbild. In den Grenzen seiner VeranIagung, bedingt durch die Forderungen des komischen Theaters, wird der Satiriker von der Zeit "gemacht", der er den Spiegel vorhält. Nestroy war satirisches Denken Zwang; ihm war es auf Grund seiner Veranlagung gar nicht freigestellt, nach Schillers Auffassung zwischen der "strafenden" und der "scherzhaften" Satire zu wählen. Der dramatische stil Nestroys ist an die Eigentimlichkeiten seiner Sprache gebunden. Nestroy ist ein aphoristischer Denker; deshalb fehlen in seinen stücken die großen Zusammenhänge. Jeder Text bedeutet ejnen neven Anfang, in dem gewonnene Einsichten mancinmal revidiert werden.

Es hilft kaum, ein starres Schema und ejne "exakte" Terminologie auf eine lebendige Dichtung anzuwender. Die über die Satire gewonnenen Einsichten sollen vielmehr helfen, den satirjschen Gehalt sichtbar werden zu lassen. Finen besseren Ưberblick erreicht man durch eine mehr flächenhafte Untersuchung; dexen Ergebnisse man 
nachher zu einzelnen Gruppen zusammenfassen kann. Das führt uns zum Inhalt der Satire. 
IV. DER INHALT DER SATIREN NEGTROYS

Am einfachsten ist die Frage nach dem Inhalt (Objekte) der Satire, wenn sich der Satiriker nur mit einem Ubel beschäftigt und seine Angriffe darauf konzentriert. Am häufigsten ist dies bei der Buchsatire der Fall. Der Satiriker der Bühne jedoch steht durch die Forderung des komischen iheaters immer vor der Frage, eine geeignete Basis für seine satirischen Angriffe zu schaffen. Im AlIgemeiren verwenden Satiriker fremae Stoffe als Vorlage. So auch Nestroy. Fr beurteilt die Vorlagen vor ajlem nach den Rollen, die sich daraus gewinnen lassen. (Nian hat oft versucht, den stücken Nestroys den dichterim schen Rang abzusprechen-nur weil er Vorlagen benutzte.)

Mit der Breite der satirischen Skala erreichen

Nestroys satirische objekte barockes Ausmap. Uberblickt man das Gesamtwerk des Dichters, so zeichnen sich einige Objekte ab, zu denen er immer wieder zurückkehrt. Oft ist die Auswahl der Figuren--.etwa bestimnte Berufsgruppen --und deren immer wiederkehrende Verwendung eine Konzession an den Publikumsgeschmack. In anderen Fällen ist der Darstellung aus Zensurgründen kein großer Raum gewidmet, wie etwa bei den Angriffen auf die Politik und den Klerus. ilie bereits ausgefïht, konzentriert sich das satirische Element in den trerken Nestroys zum uberwiegenden Teil auf die Hauptfigur. Diese Gestalt erhält über das jn der Satire übliche Naß von Subjektivität noch den 
besonderen Stempel von Nestroys Fersönlichkeit (nach Rommel: überlegenen, analytischen Verstand und depressiv-pesm simistische Veranlagung). Die Vorwürfe, die Nestroy gegen die Menschen, gegen Geiz, Habgier und Dummeit erhebt; sina alte Modelle der Satire. In den Gestalten des Heuchlers und Schmarotzers, wie sie Nestroy häufig darstej]t, erkennen wir Typen aus der Tradition der Viener Volkskonödie. Die Objekte der Satire werden in der dramatischen Entwicklung Nestroys wenjger oft gewechselt, als durch eine veränderte satirische Sicht verschieden beleuchtet. Drei Schaffensperioden lassen sich feststellen. B. Gutt ein: Frager Theaterkritiker, hat diese Phasen in drei Abschnitte eingeteilt. Den Darstellungsstil der "Früneit" (1832-1838), den Stil der "Reifezeit" (1838-1852) und den "dritten Darstellungsstil" (1852-1862). Diese Einteilung, vornehmich für den schauspielerischen Darstellungssti.l gedacht, stimmt im Wesentlichen auch mit dem literarischen Schaffen des Dichters überejn.

In der ersten Schaffensperjode begann Nestroy in der Art der Zauberspiele seiner Vorgänger. Noch bleibt der Zauberrahmen, in dem die Figuren Verkzeug "höherer Mächte" sind, erhalten. Die allegorischen Vorspiele im Geisterreich werden jedoch bereits parodistischmironisch und in mechanisjerter Form verwanat. Nur in wenigen Stücken versucht Nestroy, wie im alten Schelnenroman, durch abschreckendes Bejspiel erzieherisch zi wirken. Das Spaßhafte, Naiv-Komische seines Vorgänger ersetzt er durch 
Witz und Vergeistigung. Die Stioke befreien sich von dem pompösen Balast des Zauberwesens.

Den bilderreichen Stil, der auf die Barocktradition der Wiener Volkskomödie zurückgeht, behält Nestroy bei. Er durfte bei dem Theaterpublikurn noch ein echtes Gefül für den barocken Sprachstil voraussetzer. In dem Original-Zauberstück Der konfuse Zauberer oder Treue und Flatterhaftigkeit (1832), zeigen sjch zum erstenmal die ungewöhnlichen sprachlichen Fähigkeiten Nestroys. Es ist auch das erste Stück mit satirischem Einschlag und aphoristischen Wortfolgen. Exzentrisch-grotesk wird der Grundton der später geschriebenen Stücke, besonders Inmpazivagabundus (1833). Vorherrschend ist das parodistische Element in Robert der Teuxe] (1833). In dem Stïck Die beiden Nachtwandler oder das Notwendjge und das tuberflüssige (1836) werden die"höheren Mächte" satirisch angegriffen. Der Seiler "Strick" sieht die Welt in ejnem "verkehrten Iicht". Nestroy entlarvt die sich zwischen das Traumreich der Phantasie und die Realität des All.tags geschobene Scheinwelt der IJlusion.

In der "Reîezeit" (1838-1852), die wir besser schon 1835 ansetzen können, (mit der Parodie Weder Iorbeerbaum noch Bettelstab, 1835, und der Posse Zu ebener Erde und erster Stock, 1835) nimmt das Groteske ab, dafïr wird aber Nestroys leltsicht komplexer. Aus dieser Periode wurden die meisten für unsere Untersuchung wichtigen Stïcke ausgewäh]t. Nach 1852 wandeIt sich des Dichters Stil never- 
lich wieder stärker zur Karikatur und Groteske. Der Sarkasmus ist abgeklärter und Humor bildet den Iintergrund mancher Stücke. Dem Satirischen bleibt Jestroy bis zu seinem letzten Stück Hëuptling Abendwird (1862) treu.

Es ist möglich, einen Teil der objekte in die eine oder andere Kategorie zu stellen. Die Satjre befaBt sich mit Typen, sie zeigt das AIIgeweine durch das Einzelne. "Ich hasse nicht das Einzelne, ich hasse alles, wo sich die Erbärmlichkeit auf Kosten des Verdienstes erheben will, es heiBe Geldstolz, Adelsstolz, Gelehrten- oder Küntierstolz." (GV-VI., 572). Dje wesentiche Aussage dieses Aphorismus ist die Betonung auf "alles". Der satirische Angrifi trifft zwar die typische menschliche Schwäche und Torheit, den typischen Schein-mer richtet sich aber auf spezifische Objekte.

Zu dem Problem der Objekte sagt K. Kralis: "Die Satire wählt und kennt keine Objekte. Sie entsteht so, daß sie vor ihnen flieht und sie sich ihr aufdrängen." ${ }^{l}$ Fier ist der Autor Interpret seiner eigenen satirischen Richtung.? Durch die journalistische rätigkeit bedingt, hat seine Satire die Tendenz zur Polemik. Die Satire ist in den Werken Nestroys nur ein Element. Die Wirkung seiner Stücke beruht deshalb nur zu geringem Teil auf polemj.scher Satire, überwiegend aber auf der Mischung von Zeit-

$I_{\text {Karl Kraus, Beim Wort genommen, zitiert nach }}$ Joachim Stephan, Satire und Sprache, $Z u$ dem Werk von Karl Kraus (Minchen: Anton Pustet VerlagsbuchandIung, 1964) p. 35 .

2vergl. Kraus, Nestroy und áie Nachwelt, p. I. 
kritik und Komik. Die Wahl der Objekte ist beeinflußt durch die Forderungen der Bühne.

Mit witzigen Aggressionen unterhöhlt Nestroy die. biedermeierliche Selbstsicherheit, spottet er über Un-.. echtheit und Verlogenheit der Iebensformen. Aber auch soziales Unrecht und vormärzliche Bevormundung verfal len seinen satirischen Angriffen. Immer ist er bemüht, die falschen Hüllen dieser Welt schicht für Schjcht abzulösen, bis schlieblich der schein in sich selbst zusammenfälıt.

Mit dem Barock ist Nestroy durch die Schein - Sein Problematik verbunden. Sein Barockerbe ist, die Wahrheit gegenüber dem Schein durchzusetzen. Ihm geht es aber nicht mehr um den Schejn der Welt, hinter dem Tod und Ieere stehen, sondern allein um den Schein in der Welt, hinter dem die Menschen ihre Unzulänglichkeit zu verdecken suchen. Im Gegensatz zu dem barocken Menschen, dem alles, was er darstellte, zu einer Rolle wurde, erkennt Nestroy die Mechanik hinter dem Pathos. Er deckt den Mechanismus auf, um auf den Schein aufmerksam zu machen oder ihn plötzlich versagen zu lassen. Nestroy tritt der Realität entgegen, um ihr zu sagen, wie sie ist.

Menschenkenntnis befähigt Nestroy, in seelischen Vorgängen, wie sie sich in den Beziehungen der Menschen untereinander äußern, das Wesentliche zu erkennen. Das ermöglicht die realistisch-wirkende charakterzeichnung 
seiner Figuren. Dies bezieht sich vor allem auf die Figuren, welche die unteren Schichten des Volkes darstellen. Die adeligen Gestalten sind fast "reine" Typen. In der Regel nimmt die Typisierung mit höherein sozialen lilieu zu. Die nicht rational erklärbaren Handlungen des Menschen nennt Nestroy die "psychologischen Quadrillierungen, die das Unterfutter unseres Charakters bilden" (Das IwädI aus der Vorstadt, GW-III., 533).

Nestroys Denken j.st bildhaft und phantasievoll, aber auch bohrend. Mit den Dichterr des Barock hat Nestroy das Zusammenwirken von Ratio und Bildhaftigkeit gemeinsam. Nestroy erhitzt sich an einzelnen Objekten, bis er sie von den verschiedensten Gesichtspunkten beleuchtet hat. In seinem Nachlaß fjndet sich das bezeichnende Bekenntnis: "Je tiefer ich in meinen Ideen das Senkblei auswerfe, desto mehr finde ich in mir den Abgrund der Widersprüche." (GW-VI., 574).

Man hat Nestroys Stücke vor allem als reine Theaterstücke betrachtet. Sie könnten aber auch als Ideenstücke gesehen werden, in denen die Ideen in komischer Einkleidung auftreten. Dies hat dazu gerührt, daß sie nicht beachtet wurden. Mit sprachlicher Meisterschaft drückt Nestroy seine bis ins Metaphysische rejchenden Gedanken aus.

a. Mensch

Der Gegenstand der Satire Nestroys ist dex Mensch schlechthin. Der Dichter kornmentiert und attackiert 
aurch seine Figuren die Eigenheiten, Schwächen und Laster des Menschen.

In der Burleske Die schlimmen Buben in der Schule gibt der Schiler Willibald eine Definition des Menschen: "Der Miensch ist das Vesen, welches die oberste Stufe in der sichtbaren Schöpfung einnimmt, welches sich sogar für das Ebenbila Gottes ausgibt, worüber sich jedoch Gott nicht sehr geschmeichelt fühlen dürfte." (GV-V., 32/33). Das Zitat wird eingelejtet mit dem Hinweis auf die Stellung des Menschen in der Schöpfung. Denach wird der Mensch mit Gott auf eine Sture gestellt. Zusätzlich wird in einer weiterer Anspielung auch "Gott" mit einbezogen. Das ganze Zitat endet wicht wie ein Witz in einer plötzlichen Entladung, sondern bleibt in einem geistigen Schwebezustand, dessen Wirkung man mit "dry, inner laughter" (Worcester) bezeichnen kann. Der äberhebliche Mensch fällt von seinen sich selbst angewiesenen Platz wieder auf die Frde zurück. Die Satire bedient sich hier des Stilmittels der Ironie. I In zwei Stufer wird mit ironischer Anspielung die überhebiiche Rolle des Menschen bloßgestellt.

In allen seinen Stücken bedient sich Nestroy mit wechselnder Häufigkeit und Intensität des Stijmittels der Ironie. Außer einigen kurzen Hinweisen (bei Romnej) be-

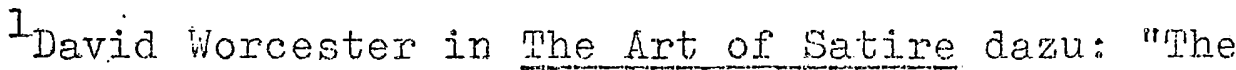
spectrum-analysis of satice runs from.. . invective at one end, to the . - most delicate irony at the other." (New York: Russel \& Russel, 1960), p. 16. 
achtete man die Ironie fast ausschlieBlich unter dem Be-griff "Sarkasmus". I Unter dieser Voraussetzung wurden die subtileren, indirekten Tormen der Nestroyschen satire (Ironie) übersehen. 2

Durch den Zinmermann Peter Span (Der Unbedeutende) deckt Nestroy seine Weltsicht auf.

Peter: Wann $i$ als Zimmermann arbeit' boch ob'n auf'n Da g'schicht's mir oft, daß ich Bemerkungen Dach,; An der Aussicht auf d'Leut' herab tu' ich mich lab'n, Seh' ich, was s'oft alis treib'n, ohne a Aussicht

$$
(G W-I V ., 53 I)
$$

Aus der Vogelschauperspektive übersieht Peter das Treiben der Menschen.

Peter: Der Zollstab gibt uns die wahrste Ansicht von Iränge und Breite, von GröBe überhaupt, und wann man die einmal. hat, da fallen einem dann allerhand Mißverbëltnisse auf--wie so mancher so groß herauskomt, und wenn man ihn genau abmeßt, so kJein ist, daß man ihm gern noch was aufmesset. . . So ist es auch beim WinkelmaB; man denkt dabei unwillkürlich an die vielen menschlichen binkelzüge, die offenbar

$I_{G}$. Highet in The Anatomy of Satire: "The word "sarcasm is often associated with jrony. By derivation it means only cruel and biting speech of any kind."

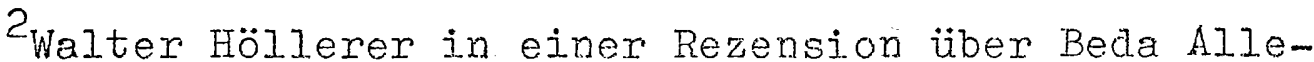
mann, Ironie und Dichtung, Zeitschrift fur deutsches Altertum und deutsche literatur (wiesbaden) Bd. 68 (1957), p.127135. Höllerer weist darauf hin, daß "eine so erregende Kette von Namen.. Wie Iichtenberg, Lenz, Büchner, Heine, Nestroy - . nicht einmal inselhaft erscheinen (bei Allemann) . . vor allem aber, daß bej diesen Autoren die Ironie nicht so leicht auizufinden ist" . . "Denn erst in einem fortgeschrittenen Zustand des Schreibens und Iesens und Rezipierens werden Formen der Ironie überhaupt erkannt . . Formen, die man vorher als rein registrie- "." rende oder sogar pathetische wïgungen angesprochen hätte." 
unter die Gattung der spitzigen Vinkel gehörer, an die Aufenthaltsorte des Unglucks und der Armut, die unter die stumpfen Winkel gehören. Die schwierige Genauigkeit, die der rechte Winkel erfordert, mahnt uns daran, daß das Rechte überhaupt nicht leicht in Winkeln zu finden, eine. Behauptung, die sjch auch bis auf Winkelagenten, Winkelsensalen, Winkelschreiber etc. etc. ausdehnen ließ'..- Fin noch veiteres Gedankenfeld liegt im Zirkel. Zirkel is die vollkommenste Rundung, drum fallt es auch in die Zirkel am meisten auf, wenn sich einer eckig benimnt.-Der gesellschaftiche Zixkel unterscheidet sich vom mathematischen wesentlich dadurch, daß der mathematische einen einzigen Mittelpunkt hat, der akkurat mitten im Zirkel liegt-..der gesellschaftiche Zirkel jedoch hat in der. Mitte nur den scheinbaren Mittelpunkt, den Kaffeetisch, währenddem der eigentliche Nittelpunkt, um den sich die Peripherie der Unterhaltung dreht, meistens außerhalb des Zirkels liegt, weil gewöhnlich nux die Abwesenden ausgericht't werden. (GW-IV. 533/34).

Mit den Werkzeugen des Zimmermanns, "die man nicht leicht, ohne zu denken in die Hand nehmen kann", macht sich Nestroy an seine "satirische Arbeit". Er stellt Abweichungen vom "rechten" Winkel fest und deckt Mißverhältnisse auf. Peter wäre keine Hauptfigur Nestroys, wenn ex trotz der Gradlinigkeit nicht anfangen würde zu spekulieren. In einem Monolog drückt das Peter so aus: "Hm--welcher Entdecker hat das schon bemessen, wie weit sich die äußeren Vorgebjrge der Möglichkeit ins Meer der Unmöglichkeit hinein erstrecken?" Mit dieser Metapher stellt Nestroy die Grenzen des Möglichen in Frage. Zwischen Gegenstand und Abstraktion werden die "menschlichen Winkelzüge" satirisch ausgemessen, um mit dem Zirkel, der"vollendetsten Rundung", in der nicht so vollendeten Sphäre des Kaffeeklatsches zu enden. 
Die problematische Wirkifchket, in der die Wensch-

heit lebt, zeigt der Commis Weiaberl in Einen Jux will er sich machen. Auf der "Grenze zwischen. Knechtschaft und Herrschaft", zieht der gerade vorn Comnis zum Associé be-. förderte Weinberl resignierte, aber auch ironische Vergleiche zwischen Handelsstand und Menschheit.

Vor dem Handelsstand kriegt man erst den wahren Respekt, wenn man zwj.schen Handelsstand und Menschheit überhaupt eine Bi.Janz zieht. Schaun wir auf'n Handelsstand, wieviel gibt's da Großhandlungen, und schaun wir auf die Menschheit, wie wenig große Handlungen kommen da vor:--Schaun wir auf'n Handelsstand, vorzüglich in der Stadt, diese Menge wunderschöne Handlungen, und schaun wir auf dMenschhejt wie schütter sind da die wahrhaft schönen Handlungen ang'sät:---Schaun wir. auf 'n Handelsstand, diese vielen Galanteriehandlungen, und schaun wir auf d' Menschheit, wie handeln $s^{\prime}$ da oft ohne alle Galsnterie, wie wird namentlich der zarte, gefuhlvolie, auf alle Galanterie Anspruch machende Teil von dem gebildetseinsollenden, spornbegabten, zigarrozuzelnden, roßstreichelnden, jagdhundkaschulierenden Teil so ganz ohne Galanterie behandelt:- Jetzt, wenn man erst die Handlungen der Menschheit mit Gas beleuchten wollt'--ich frag', wieviel menschliche Handlungen halten denn eine Beleuchtung als wie eine Iandlung auf'n Stock-im-Eisen-Platz aus?--Kurzum, man mas Verm gleiche anstellen, wie man will, der liandelsstand is was Erhabenes, wir haben einen hohen Standpunkt, wir: von der Handlung, und ich glaub?, blok wegen dieser schwindelnden tiohe fallen so viel' von der Handlung: (GW-III., 615i.)

Es ist ein Monolog mit doppeltem Boden, denn er beruht auf einem Selbstbetrug. In einer Zwischenbilanz weist Weinberl den Handlungen der Menschen Iichtempfindlichkejt nach (bei Gasbeleuchtung!). Hoch am Ende geht auch dje Summe für den Handelsstand nicht auf. Aus dem "Frhabenen" und "hohen Standpunkt" des Handelsstandes wird eine "schwin.. delnde Höhe", daß heiBt, etwas Trügerisches. Dem "wahren 
Respekt" vor dem Handelsstand ist damit der Boden entzogen, der Vergleich mit der Menschheit fälit in sich zusammen. An Ende steht Weinberi (Nestroy) hinter sich selbst und spottet über Handelsstand und Menschheit. Mit Geschick verwendet Nestroy hier das Stilmittel der Ironie. Eine philosophische Vorstellung der Welt hat Iniereim in Der böse Geist Lumpazivagabundus. Nach dem Genuß von einigen G'mischten ergibt er sich astronomisehen Betrachtungen.

Ich hab" die Sach" schon lan" heraus. Das Astralfeuer des Sonnenzirkels ist in der goldenen Zahl des Urions von dem Sternbild des Planetersystems in das Universum der Parallaxe mittelst des Tixstern. Qusdranten in die Ellipse der Fikliptik geraten; folgitich muß durch die Diagonale der Approximation der perpendikulären zirkeln der nächste Komet die Welt zusammenstoßen. Diese Berechnung ist so klar. wie Schuhwix. Freilich hat nicht jeder die Wis-. senschaft so im klein' Finger als wie ich; aber auch der minder Gebildete kann alle Tag" Sachen genug bemerken, welche deutlich beweisen, daß dje Welt nicht lang mehr steht. Kurzum, oben und unten sieht man, es geht rein auf'n Untergang los. (GW-I, III 63i/32)

Mit burlesker Übermutskomik gibt Kniereim eine Entschuldigung für seine Abneigung gegen die Arbeit. Es ist das in der Wiener Volkskomödie oft abgewandelte Motiv des carpe diem. Glejchzeitig parodjert der philosophie... rende Schuster, an der Grenze von Unsinn und Tjefsinn, die Fachsprache der Wissenschaftler. Nach der Auslegung Kniereims soll der Komet den Untergang der Welt herbeiführen. Mit satirischer Absicht wird der himmlische auf 
den irdischen Ruin bezogen," . . kurzum, oben und unten sieht man, es geht rejn auf "n Untergarg Ios." Das vielseitige Denken Nestroys läßt hier einen satirischen Seitenhieb auf' die Geschäftswelt vermuten. Als Vorlage nimmt Nestroy wahrscheinlich die zahlreichen Konkurse der Zeit (um 1830). Empfiehlt doch auch Weinberl (Einen Jux will er sich machen), "Abfahren?--. Sie haben recht, Krida ist da, also verschwinden--das komnt im Merkantilischen häufig vor!" (GW-III., 657). In Kniereims Zwischenwelt zwischen Schein und Sein entdeckt Nestroy die Wirklichkeit der Illusionen, indem er sie analysiert und mit satirischem Iachen bloklegt.

In der Parodie Robert der Teuxel auf die romantische Oper Robert der Ieufel von Meyerbeer und Scribe reduzjert Nestroy den "romantischen Teufel" (Robert) auf das Banale. Die Figur des Reimboderl erhält in der Nachbildung eine Doppelfunktion. Äußerlich gutmitig, offerbart er im Rausch die Wahrheit über seine innere Veranlagung. Als Mittel dient ein Rock (Caputus Infernalis), den. er auf der Straße findet. Er zieht ihn an, verzerrt das Gesicht und schreit: "Ha! Nur Böses: Jie Welt möcht" ich mit Arsenium anstreichen, daß die ganze Menschheit vergift't war in drei Viertelstund. Wenn ich nur wenjgsters wen ausrauben körnt' zum Pläsien. (Sich umsehen) Ist denn kein Mensch zum Ausrauben da?" (Gi-II, 46). Er sjent 
einen alten Bettler, wirft ihn zu Boden und will ihn ausrauben. Das Possenhafte wird zum Grotesken, die Nachbildung der literarischen Vorlage wird zur grotesken Pam rodie. Nachdem Reimboderl den Rock ausgezogen hat, bemerkt er, "jch war doch mein Lebtag ein seelenguter Kerl. Die Bosheit muß alle in dem Rock drin stecken." Die satirische Tendenz ergibt sich in dieser grotesken Parodie durch das gezielte Entlarven des "gutmütigen" Menschen, in dessen Innerem das Unheimljohe und auch die brutale Art, zu Geld zu kommen, verborgen ist. Reimboderl ist so wenig wie Kniereim eine Glorisizierung des Betrunkenen, 1 der nur sinnlos daher redet, wie die Kritik oft angenommen hat. Beide Figuren sind persona, Gestalten, durch die der Dichter seine Angriffe führt.

"Was ist der Mensch?" fragt der Lehrer Wampl in der Posse Die bösen Buben in der Schule. I) Schüler Vilizbald antwortet: "Der Mensch ist das Wesen, welches die oberste Stufe in der sichtbaren Schöpfung einnimmt . . ." (GW-V., 32-33). Darauf Wampl: "GrundfaIsch! Der Mensch ist ein Säugetier!" Willibald assozilert daraufhin den Menschen mit der Mjerwelt. "Der Mensch ist auch ein Wirm, denn er krümmt sich häufig im Staube und kommt auf aiese Art vorwärts." Diese satirische Bemerkung zielt in ojie.

$I_{\text {T. }}$. Rose dehnt diese Ansicht auf ein ganzes Stück von Nestroy aus. "His "Iumpazivagabundus" (1833) was hardly more than a glorification of vagabonage." Ernst Rose, A History of German Literature (New York: K. Praeger, 1960) p. 24I. 
sem Beispiel auf den "kriechenden Lehrer Wampl, der sich durch "Krïmmen" vor dem Wirtschaftsintendanten eine bessere Stellung sichern will.

Die Darstellung menschlicher Dumrneit gehört zur Tradition der Komödie. Die große Häufigkejt dummer Menschen und der durch sie verursachten Handlungen in den Stücken Nestroys, entspringt neben der Absicht, komische Situationen zu schaffen, auch der Freude, durch den satirischen Angriff das "psychologische Unterfutter" blaßzustelien. Nestroy spottet deshalb selten in airekter fiorm, er brejtet zuerst die psychologischen Voraussetzungen aus.

Der intelligente, aber undurchsichtige Räsoneur Nebel (Iiebesgeschichten und Fieiratssachen) verspottet den Parvenu Fett (ehemals Fleischselcher, jetzt Fartikulier) wegen seiner "verdeckten" Dumbeit. Fett lobt seinen eigenen "Scharfblick", findet die liebe nicht "nobel", redet im "Vokativus"--und verlangt schließlich von Nebel die Zerstörung einer "Leidenschaft" durch eine "noble Intrige". Daraufhin erwidert Nebel: "Nix leichter als das!" Fett: "Es wird nicht so leicht gehn!" Nebel: "Kinderei! Ich werd' schon das rechte Mittel finden. 'Homo 'sum', dagt der Lateiner, das heißt auf deutsch: 'Ich bin ein Viechkerl.""(GN-IV., 131). Die Verdrehung des Zitats erfolgt hier nicht aus Nebels Unkenntnis. Durch die falsche Ubersetzung entsteht eine satirische Spitze auf den Parvenu Fett, dem die Bezeichnung "Viechkerl" ja auch zusteht, hier sogar in doppelter Wejse. 
In einem Couplet der gleichen Posse, beginnt Vebel mit der Menscheit, und endet in Tierreich.

Es verdammt der Mensch manches und nennt manches gut, Der Mensch tut oft was una weik nit, was er tut.

$\dot{E} \dot{s}$ is übrigens bei keinem Hund noch entdeckt, Was er denkt, wann er d Hand seines Schläggebers leckt. Doch i tu' mi hirüber ins Tierreich verirs'n, Und hab' über d'Menschheit woll'n philosophier'n!

(GIIII, II-9, p.I52 u.I53)

Nebel stellt sich naiv, indem er vorgibt, daß man sich unabsichtlich ins Tierreich verirrt. Die Aussage Nebels hat hier zweifachen Sinn. Womentan ist Nebel Bedienter bei. dem "unscheinbaren" Herrn Buchner der "scheinbar" sein Herr ist, und dessen "Bedienter er zu sejn scheint" (GijIV., 131). Nebel ist im Augenblick mit der Relativität der Standpunkte--mit Verspottung---einverstanden, En spielt den "Hund" und "denkt". Das Allgemeingültige ist durch Nebels räsonierende Kritik in parabolischer Tom dargestellt.

b. Gesellschaft

Nestroy hat nicht die Absicht, die Wirklichkeit realistisch darzustellen. Der äußere Anschein weist allerainga auf Realismus hin, wenn Nestroy soziale Verhältrisse darstellt. Als rationeller Denker nimmt er an den protzenden Wohlstand genalu so Anstoß wie am Elend dex unteren Klassen. An der zerfallenden Ordnung findet er ebensowenig Gefallen wie an der extremistischen der Revolution $\operatorname{von} 1848$.

Das Milieu der Geselischaft ist nach der Tradition 
der Wiener Volkskomödie die "Wienerische Theaterwirklichkeit" (Rommel). Nestroy stellt die Welt des biedermeierlichen Wien auf die Bühne---in Kulissen, Kostünen, Dialekt, Musik und äuBerlich schwereloser Heiterkeit. Die Auswahl der Gestalten der bürgerlichen Welt und des Handwerkerstandes aber geschient nicht nach soziologischen Gesichtspunkten. Wie bereits erwähnt, sind die Figuren Modelle des komischen Theaters und gehen in ihrer Wienerischen Ausformung auf Prehauser, als schärfer gozejchnete Typen auf Hafner zurück. Auch die Narnen wählt Nestroy vom Standpunkt der komischen ifirkung, sie haben meistens spottenden Charakter ("Massengold", "Nebel", "Herr von Platt", "Fett", "Schafeeist" U.sw.).

Die scheinbar veristische Abbildung ist demnach ein "Nebenprodukt", der mit"ilener Wirklichkeit" angereicherten Typen der Wiener Volkskomödje. AuPerdem hat Nestroy stofflich viel aus den literarischen Vorlagen seiner stücke entnommen. Die Frage, ob es sich um realistische Kritik oder um Komik handelt ist ein wesentliches Nestroy-Froblem.

Immer wieder versuchte die zeitgenössische Kritik (besonders Jeitteles und Saphir) Nestroy zu einem "modernen Volksdramatiker" zu "erheben", das Wiener Volkstheater zu einer "moralischen Anstalt". In dex Lokalposse Zu ebe-ner Erde und erster Stock (1835) sah die Kritik eine aus dem Leben gegriffene Handlung, Eersonen aus dem Volksle.ben, gesunde Komjk und exzieherische Tendenz. Aber ge-. rade das stïck Zu ebener Frde... beweiBt, daß es Nestroy 
nicht um Realismus geht. Nestroy verwendet in diesem Stück eine horizontal geteilte Bühne, auf der sich das Spiel der Armen, die zu ebener Erde wohnen, und der Reichen im ersten Stock gleichzeitig vorfühen läßt. Er tut das jedoch nicht nur, um der Kontrast von arm und reich szenisch zu unterbauen, vielmehr unterbaut der Kontrast die Szenen. Mit barocker Freude an der Antithese entwickelt Nestroy durch Herausarbeitung der Gegensätze komische Spannung; durch den satirischen Anogriff trifft er arm und reich.

Zu dem Thema "Reaiismus" äußert sich Nestroy durch - Titus aus der Posse Der Talisman. Aut ejrer schöngeistigen Soirée bei Frau von Cypressenburg wird Titus ais neuer Sekretär vorgestellt.

Frau von Cypressenburg: Dieser Herr wird Ihnen in der nächsten Soirée meine nevesten remoiren vorlesen.

Alle: Scharmant:

Herr von Platt: Schade, daB die gnädige Frau nichts fürs Theater schreiben.

Frau von C.: Wer weiB, was geschieht; es kann sein, das ich mich nächstens versuche.

Titus: Ich hör", es soll unendlich leicht sein, es geht als wie g'schmiert.

Herr von F.: Ich für mein Teil hätte eine teiden-schaft, eine Posse zu schreiben.

Titus (zu Herrn von $P_{0}$ ): Warum tun Sie's dern nicht?

Herr von P.: Mein Witz ist nicht in der Verfassung, um etwas Lustiges damit zu verfassen.

Titus: So schreiben Sie eine traurige Posse. Auf einem düsteren Stoff nimmt sich der matteste Witz noch recht gut aus, so wje auf einem schwarzen Samt die matteste Stickerei noch effektuiert.

Herr von P.: Aber was Trauriges kann man doch keine Posse heiBen?

Titus: Nein! Wenn in einem Stück drei G'spaß und sonst nichts als Tote, Sterbende, Verstorbene, Gräber und motengräber vorkommen, das heiBt 
man jetzt ein Lebersbila. ${ }^{1}$

Herr von P.: Das hab' i.ch noch nicht gewußt.

Titus:. Is auch eine ganz neue Frfindung, gehört in das Fach der Haus- und Hirtschaftispoesie.

(GW-III., 475/76)

In diesem straffen DiaIog mit aggressiver Tendenz stellt sich Nestroy gegen den "Geschmack" der Gesellschaft. Die tendenziös-zweideutige Bemerkung "es geht wie g'schmiert" richtet sich gegen das massenweise Vierfassen von pseudorealistischen Theaterstücken mit "einigen G'spaß". Nestroy will das "Interregnum der Langweile aufheben und den Geist wieder auf den Thron setzen!" (GW-VI., 572). Hinter der heiteren Fassade seiner Stücke füht er seine satirischen Angriffe gegen die Gesellschaft, ohne moralische Besserungsabsichten, ohne "verklärte Sittenschilderung".

Dem Menschen steht zwar "die Stütze der Vernunft zu Gebote aber leider gebraucht er sie fast nie", heißt es im Talisman. In der Fosse Haus der Temperamente verspottet der Eriseur Schlankel dje fragwürdige Einrichtung des Duells.

Braus: Was ich Ihnen getan, ist so viel als nichts: Schlankel: Sie haben mich in dex Weinstube auf den Stiefel getreten, das hat mich an meiner Ehre gekränkt.

Braus: Steckt denn Ihre Fihre in dem Stiefel?

Schlankel: Ja, denn ich stecke im stiefel, und die Ehre steckt in mir, folglich steckt sie auch im stiefel so gut als jch.

${ }^{I}$ Das "I ebens- und Charakterbila" war nach den Zauberstücken Raimunds eine erfolgreiche Gattung auf den Vorstadtbühen. Der Inhalt dieser pseudo-realistischen Stücke war eine in "ernst-heiterem Ton vesklärte Sitten schilderung" (Rommel). 
Braus: Ich habe Thren Fuß unter dem Tisch gar nicht bemerkt.

Schlankel: Diese Achtlosigkeit gegen meine Person war schon Beleidigung, Sie mijssen sich schlam gen!

Braus: Was wollen Sie denn aber ins Teufelsnamen? Schlankel: Nichts als Ihr BIut!

Schlankel: Die Ehre ist die feine Wësche, in welche sich die seele des Gebildeten kleidet, drum muß so eine Ehre auch fleißig gewaschen werden, das geht aber nicht mit wasser und Seife, nur mit dem BIut des Beleidigers wäscht man die Elure rein.

Ėdmúa (nachdem er mit Schlankel ein Zeichen des Einverstänanisses gewechselt hat): . . Innen ist's doch gleich, ob Sie sich mit mir oder mit dem Herrm schlagen?

Schlankel: Ganz ergl, đje Beleidigung fordert B].ut, das des Beleidigers oder dessen Stellvertreters, alles eins:

Schlankel und Braus (beide sind bezeichnenderweise Choleriker) werden durch eine Nichtigkeit in eine "shrenbeleidigung" verwickelt. Durch die Verwendung satirischer Ironie wird das von den "Gebildeten" geforderte Duell verspottet.

Über kein Thema hat Nestroy soviel Spott, soviel Pessimistisches geäuBert wie über Liebe und Ehe. Über die Liebe stellt der Winkelagent Schnoferl (Ein Mäd] aus der Vorstadt) mit pessimistischem Spott über sejne Frfolge in der Iiebe fest: "Für mich war die Ijebe kein buntes Gemälde in heitrer Farbenpracht, sondern eine in der Drukkerei des Schicksals verpatzte lithographie, grau in grau, schwarz in schwarz, dunkel in schmutzigr verwischt. Die pragmatische Geschichte meines Herzens zerfallt in arei miserable Kapitel: zwecklose mräumerejen, ab"brente Versuche und wertlose Triumphe." (GW-III., 517). Am Schlus 
des gleichen Stückes als Schnoferi von Frau vor Exbsenstein als "Lohn" die Zusage zur Heirat bekommt, ist er aufs höchste überrascht.

Schnoferi (in Ekstase): Ha, so zerschmettert, ihr Kniescheiben! Stiurz nieder, Winkelagent! so eine Seligkeit kann der Mensch nicht als so stehender: ertragen!

- (aufstehend): Also hier (auf Thekla und Gigl zeigend) steht ein giluckliches Paar; hier (auf sich und Frau von Erbsenstein zeigend) ein enorm glückliches; und Sie, Ferr von Kauz, klauben sich unter die sprichwörter: "Der Krug geht so lang zum Brunnen, bis er bricht", oder "Tue recht und scheue niemand!" oder "Nichts ist so fein gesponnen, es kommt dennoch an die Sonnen", oder "Ehrlich währt an längsten"--unter diesen Sprichwörtern sucher sje sich das passendste als Moral heraus!

(GW-III., 599-600).

Die burleske Komik enthält durch die Ubersteigerung einen Zug ins Ironische. Durch die Häufung von Sprichwörtern wird die Überzeugungsknaft der Noral ausgespielt. Man ist nicht sicher, ob alle Sprichwörter auf Herrn von Kauz bezogen sind, oder als Moral" für die the gedacht. Die obligatorisch gut ausgehenden Schlüsse seiner stücke, die in der Mehrheit ir einer Verlobung oder Heirat enden, sind eine Konzession an das Publikum. Nach den ständig wiederholten Ausfällen und Einwänden ïber das "Trauerspiel" der liebe im Stück selbst, ist der gute Ausgang als Ironie zu werten.

Nestroys satirisches Hauptmittel ist der Spott, je- 
doch nicht mit dem $Z_{j}$ el zu bessern, sondern mit der Absicht, Ubertreibungen jeder Art auf ein mittleres Maß zu reduzieren. Die negativen Erscheinungen des Lebens werden konzentriert dargestelit. wobei durch diese Zuspitzung deren Widensprüche hervortreten. Nestroys Satire ist aber kein frontaler Angriff und keine scharfe Verurteilung all dessen, was hohen Idealen nicht entspricht. Seine Waffe ist in vielen Tällen die satirische Ironie (als Stilmittel der Satire), die sich als Unterströmung in der Komik bemerkbar macht.

In der Fosse Mejn Freund philosophiert der Buchdruckergehilfe Schlicht zuerst über die Relativitat der Gerechtigkeit, schlieBlich kommt er zur Moral.

Ich weiß es, es gibt dutzend weis" Weltweise, die auf alle Neis' beweisen, đaß die Schlechtigkeit ein moralisches Zentralfeuer is, welches ausströmt in den ganzen Tatenkreis der Schlechten.--Diesen Lehrsatz brack' ich mit einer Analogie vom Physischen auf's Geistige zusamm'. Es gibt keinen mit einem zu kurzen FuB, der nicht auch ejnen längeren $F u B$ darneben hat--'s gibt keinen Einseitigen, der bicht auch eine andere seiten hat, die den Gegensatz zur. ersten Seite bildet, so dab grad der Finseitige der Vielseitige oder wenigstens der Zweiseitige is. Das is echt philosophisch-und so behaupti ich, mup oder kann, wenigstens dex auf einer seite moralisch Gesunkene auf der andern Seiten seine moralischen Erhabenheiten hab $\mathrm{F}$.

Der Spott in seinem Verhältnis zur Ironie hat hier die Qualität nach außen als Finverständnis zu erscheinen, in einem Unterton, trotz der Bejahung, den Gegenstand zu verspotten. Die ironische Unterströmung über die Relativität

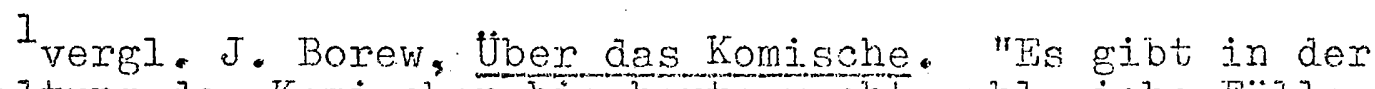
Gestaltung des Komischen bis heute recht zahlreiche Fälle, in denen die moralische Verurteilung nicht in Einheit mit der Verspottung auftritt. . . " p. 283. 
der Vergleiche ruft dry inner laughter hervor.

In der Posse Zu ebener Frde und erster Stock vertraut sich Emilie, eine Tochter des Millionärs Goldfuchs, in einer Liebesangelegenheit dem höhischen Diener Johann an.

Emilie: Ich hoffe nicht, daß Ir mix Ursache geben wird, mein voreiliges cutrauen zu Ihm zu bereuen.

Johann: Sie haben Gold gesäet, Sie werden goldne Früchte ernten.

Enilie: Ich liebe--

Johann: Haben vollkommen recht; Liebe ist die schönste Blüte des Lebens.

Emilie: Ich weiß keine Rettung, als wenn Adolf mich entführt.

Johann: Haben vollkommen recht; Entruhrung ist die Poesie des Durchgehens.

Emilie: Ich will lieber als Adolfs Gattin im Flend. sein als an der Seite eines anderen im Uberfluß leben.

Johann: Das hat zwar noch keine g"sagt, die schon im Flend war, aber Sie haben dennoch vollkommen recht, weil das romantische Elend, von dem zur Gewohnheit gewordenen fJberflus aus betrachtet, sehr eine reizende Ansicht gewährt.

(GII-II., 489/490).

Der Diener Johann verwendet für seine Bemerkungen oft gehörte Phrasen der feinen Gesellschaft. Die zignische Art und Verwenaung der schablonenharten Antworten exhöht noch den satirischen Effekt. Gewisserrapen mit einer Unterströnung verspottet der Untergebene aurch seine Intelligenz den Dürkel der Reichen.

Nestroys Herr von Ijips (Dex Zerrissene) erscheint als ein Gegenstück zu Raimunds Rappelkopf (Der Alpenkönig und der Menschenfeind). Beide Hauptefiguren sind mit sich, und der velt nicht einig. Raimund legt mehr Wert auf die Gestaltung der persönlichen Schwierigkejten, während. 
Nestroy durch die Figur Iips das AlIgemeingültige darstellt und die Zerrissenbeit im Algemejnen unterstreicht. Iips ist ein Zerrissener, er betrachtet sich in seiner Rolle, und gibt Kommentare dazu.

Iips: Sie müssen wissen, mein Inneres is zerrissen wie đie Nachtwäsch" von einem Bettelnamn-a da hab" ich mich also unlängst erschiepen wollen, und derweil ich so im Schuß ein Testament aufsetz' zugunsten meiner Freunde, is mir der. Schuß zum erschießen vergangen.

Madame Schleyer: So einen veränderlichen Herrn tät * auch 's Heiraten bald reuen.

Lips: Dafür is ja eben 's Heirat's erfunden, daß's nix mehr nutzt, wenn's einem reut; wenn die Reue nicht wär!, wär ja die Liebe genug. A:Iso jetzt in vollem Ernst: Ihre Antwort!

Madame Schleyer (für sich, in Freude und UngewiBheit schwankend): Ich wei.B nicht, trëunt mir..... oder--

Lips: Spielen Sie mir jetzt die Komödie vor, als ob nicht mein Reichtum, sondern meine liebenswürdige Persönlichkeit Ihren Fntschlus bestimmet:

In einer früheren Fassung der Yosse, ${ }^{1}$ spricht Iips von "Formely", wenn er Frau von Schleyer alles vorspricht, ihr die Antwort "soufliert". Erst ein "gewisses Stocken, vermischt mit der beliebten Schnupftüchelspielerei, dann Utberraschung, Erröten, eine Uneigennittzlichkeitstirade . ." endlich "Augenniederschlagen und eine gefühlvolle Einschnei-chelungsformel . .-.-so lautet ungeföhr die Komödie, die . Sie mir jetzt vorzuspielen hab"n". In dieser Fassung werden die Gefuhle, die etwas Spontanes sein sollen, verdäch-

$$
{ }^{1} \text { J.N. Sämtliche Verke, Bd. XII, Anhang, p. } 611 \text {. }
$$


tigt, mechanisch ${ }^{I}$ und berechenbar zu sein. Es ist ejn Spott über das Draußen und Drimen zuglej.ch. Der Zuhörer wird hier parodiert, indem Nestroy das Marionettenhafte auf ironischem Hintergrund vorführt.

Nestroy steht mit der Darstellung und Verspottung der Zerrissenheit in der glejchen Tradition wie Büchner, Grabbe und Heine. 2 Das klassisch-romantische Weltbila mit seinem Idealismus wird um 1830 als nicht mehr der Wirklichkeit gerecht angesehen. Im Bereich der Wiener Volkskomödie hatte Raimund noch den Standpunkt im christilichbürger]ich-idealistischen Sinn. Bei. Nestroy hat schon die Desillusion den Vorrang, in seinen Stücken (ab 1832) macht sich aus diesem Grund. als geistige strömung ein "schwebendes Gleichgewicht" bemerkbar. Nestroy läBt den Winkelagenten Schnoferl (Ein"MädI aus dex Vorstadt) sagen, er befinde sich in einem "Zustand wo man über alles räsom niert, aber auch alles akzeptabel findet".

Das Pathos der idealistischen Dichtung reizte Nestroy, deshalb will er nicht, wie Raimund, dieses Fathos

${ }^{1}$ Nach Rommel ist die "Mechanisierung im Denken und Empfinden und in dex Struktur des Iebens uberhaupt" Gegenstand von Nestroys Satire (NSi - XV., $295 \mathrm{ff}$. ). Die Mechanisierung des Lebens ist nach der Komik Theorie Bergsons das Urphänomen der Komik (GW-I., 1.55).

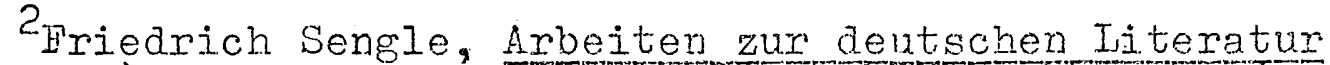
1750-1850). "Der Fatalismus, der Tebensnihilismus (Taul Hankamer) der Barockkultur taucht wieder empor, aber der überweltiche Trost, an dem sie sich noch bielt, gevinnt seine kulturprägende Kraft nicht zurück. Um 1800 erschienen bereits radikale Manifestationen des weltschmerzes, und in der theit Heines, Lenaus, Grabbes, Platens, Bich.ners, Nestroys beherrschen sie schljeplich eirlen gewalti. gen Sektor der geistigen Welt." p. 115. 
ernsthaft nachahmen, sondern er parodiert aiese Formen. Bereits in den Zauberpossen parodiert Nestroy vereinzelt den Stil und das "Zauberische" der Geister- und Zaubermärchen. Eine frühe Parodie Nestroys Der einsilbige oder ein dummer Diener seines Fierrn (1829), auf Grillparzers Ein treuer Diener sejnes Herm, ging verloren. Die parodierenden Possen Der gefühlvolle Kerkermejster (1833), Zampa der Tagedieb (I832), Robert der TeuxeI (I833) und Weder Iorbeerbaum noch Bettelstab (1835) wurden Bihnenerfolge. Die Parodien Maxtha (auf und Iohengrin und Tannhäuser (auf $R$, Wagners Opern) dagegen waren weniger erfolgreich. Alle Parodien auBer Robert der Teuxel und Weder Lorbeerbaum noch Bettelstab stehen in der Tradition der Hiener Volkskomödie. Als Gegen- oder Seitenstïcke richten sie sich nicht direkt gegen die parodierte Vorlage, sondern sind nur der äußere Rahmen eines burlesken und teilweise kritischen Kulturspiege].s.

In den parodierenden Possen Robert der Teuxel und Weder Lorbeerbaum noch Bettelstab enthült Nestroy die Schwächen der nur auf äuBeren Effekt gerichteten Vorlagen... Mit dem sarkastischen Ton der satirischen Angriffe in den erwähnten Parodien, machte sich Nestroy bei dem Publikum nicht beliebt. Dafür wurde seine "Meister-Parodie", Judith und Holofernes (1849) (dem Theaterzettel nach eine "Travestie mit Gesang"), ein auBerordenticher Erfol.g. In dieser Parodie greift Nestroy vor allem die "unechten" 
Szenen an. Hebbels Tragödie stellt Holofernes als einen Mann von ungewöhnlichen Sigenschaften dar. Die Begegnung des Holofernes mit Judith gestaltet Hebbel als erotischen Konflikt. Aus Zensurgründen verwienerte Nestroy die Erotik ins Harmlos Burleske. Nestroy reizte vor. allem das Pathos des zum Halbgott aufgeblähten Holofernes. "Hätt i.ch doch nur einen Fejnd", deklamiert in Hebbels Drama der Holofernes, "nụ Einen, der mir gegenüberzutreten wagte! Ich wollt ihn küssen, ich wollte, wenn ich ihn nach heißem Kampf in den Staub geworfen hätte, mich aufihn stürzen und mit ihm sterben:" Nestroys Parodie übertrumpft das falsche Pathos Holofernes:

Ich bin der Glanzpunkt der Natur, noch hab' ich keine Schlacht verloren, ich bin die Jungfrau unter den Feldherrn. Ich möcht" mich einmal mit mir selbst zusammenhetzen, nur um zu sehen, wer der Stärkere is, ich oder ich. $(G-W . ; 22.2)$

Durch kleine Verschiebungen des lextes gelingt Nestroy im folgenden Beispiel eine Auflösung der phantastischen Rederei des Holofernes--in eine gelassene Ironie.

Judith: Nur einer kann so aussehen: Holofernes: Fänd" ich den zweiten, so würde ich ihm den Kopf vor die Füße legen, denn auf mein Gesicht glaub" j.ch allein ein Recht zu haben.

(Hebbel)

Holofernes: Wär' mir nicht lieb, wenn's außer mir noch einen gäbet. Ich hab' die Spjegeln abg'schafft, wei] sie die Frechheit haben, mein Gesicht, was einzig in seiner Art is, zu verdoppeln. (ivestroy)

Holofernes' Maßlosigkeit ređuziert Nestroy auf eine Capitano-Figur der Commedia deIl'arte. Urebbel selbst hat später die Nängel seines Jugenawerkes angedeutet. Mit 
der Parodie Judith und Holofernes ${ }^{1}$ erreicht die Parodientradition der Wiener Volkskomödie ihren Höhepunkt.

Als Element ist die Parodie auch in den übrigen Stücken vorhanden. In der Posse Der Zerrissene wird das klassische Pathos zur Parodie. "Diesen Undank mu? die Nemesis rächen!" deklamiert Lips, und fährt fort (mit Bezug auf Madame Schleyer): "Also heraus jetzt mit dem Entschluß, meine Fiolde!" (GH-IV., 383). In der Erwartung von einer Viertelstunde Bedenkzeit, nach der inm Madame Schleyer ihren Fntschluß zur Heirat bekannt geben wird, druickt sich Lips in der Farodie des hohen Tragödienstils aus: "Also in einer Viertelstund', Angebetete --ich werde die Sekunden zählen--das Blut drängt sich zum Herzen, das Hirn pulsiert--der Atem stockt!--In einer Viertelstunde--Leben oder Mod." "Daraufhin geht Lips in den Speisesalon: Eine parodistische Kritik auf die dramatischen Umstände, wie Luise, in Schillers Kabale und Iiebe, inr Ieben beendet, ist Nestroys lakonische Feststellung: "D.IJemonadi macht alles so schaurig." (Der rod am Hochzeitstage, SW-I., 129). Die literarische Parodie ist durch die Kritik des Inhalts immer eine bis zu verschiedenen Graden verzerrte Hiedergabe der Vorlage. Eingestreut in seine Possen findet man Nestroys parodistische Kritik auf die Ubertreibungen der zeitgenössischen Iiteratur.

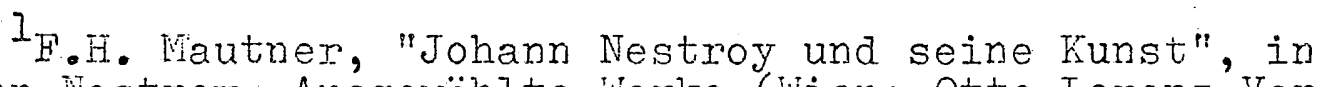
Johann Westroy, Ausgewählte Werke (Wien: Otto Lorenz VerIag, 0.J.). Nach Nautner ist diese Parodie das "klassische Beispiel des kritischen Parodie in der deutschen Iiteratur. überhaupt." p. 59. 
Nestroy war ein Feind von Täuschungen und Selbsttäuschungen, doch die bewukte Selbsttäuschung, die er Chimäre nennt, hat er nicht abgeleknt. Die Chimäre ist ihm sogar ein Weg zum Glück, ". . sich so hoch erheben" --in der Phantasie--daß einem die Velt winzig klein erscheint. . "I Den Mangel an geistiger Fntwicklung verspottet Nestroy bei den "guten Geschöpfen", den stumpfen Kleinbürgern, deren Träume beim Reichtum enđen. "Es gibt gute Geschöpfe, bei denen selbst die wïnsche den Stempel ärmlicher Einbilaungskraft tragen. Finen Frinzen können sie sich träumen, der sie mit Gold, Equipage und Dienerschaft überschüttet, aber nie einen Engel, der ihnen die Hälfte seines sternes anbietet; ihre Träume können sich bis zum Feenmärchen, doch nie bis zum Gedicht erheben." (GW-VI., 56I/62). In einem Couplet "berejchert" der arme Schrèiber Federl (er selbst nennt sich "kalligraphische Mähre":) seine Lage durch die Phantasie.

Wem a trarige Wirkljchkeit nur is beschert,

Der mul als Ressource sich al.ls denken verkehrt;

Ich schau' oft mein' Sack an (wendet dje leere Tasche um) und denk! mir dann: Ah!

$\mathrm{Da}$ is a Million drin, (wendet die andere ebenfalls leere Tasche um) in dem sein gar zwa: Wann jetzt die, die in d'r Equipagi umfahr'n, Sich plötzlich verwandelten in arme Narr'n, Müßten betteln bei mir um a G'wand, um a alts-Das is wohl nur Chimäre, aber mich unterhalt't's. (GW-IV., VorspieI, p.25)

In Nestroys tabellarischer "Jbersicht ubber "Ideen", Gil-VI., p. 558 . 
Hier stellt Nestroy die Verkehrung in den "Dienst seiner satirischen Negation" (Lazarowicz). Als Satiriker ist Nestroy nicht bereit, die Welt hinzunehmen wie sie ist, die Verkehrung sieht er aber nur für den Armen; für den Reichen ist die velt "geordnet", weil ihm alles zur Verfügung steht. Durch die Welt der "Chimäre" wird der Reiche zum "armen Narren".

Ein Thema der Biedermeierzeit war der Parvenu, der Unordnung in das ständische System bringt. Dramatisch interessant wird für Nestroy das Zusarmentreffen des Parvenus mit dem Adeligen. In Iiebesgeschichten und Feiratssachen gibt es eine Szene zwischen dem ehemaligen Fleichselcher Fett, der sich jetzt Partikulier nennt und "Herr von Fett" titulieren läßt, und dem Marchese Vincelli. Der Marchese wird angemelỏet:

Fett: Sakerlott, jetzt muB ich mich in Positur setzen! Er soll mich in Lektüre überraschen! Georg!

Georg: Euer Gnaden:

Fett: Gib mir den "Hans Jörge "I herüber! (Georg tut es eilig) Und jetzt stell' dich zu der Tür und meld" ihn an, aber laut, nicht wispeln, als ob du einen Schneider anmeldest!

Georg: Weiß schon: (Öffnet die Mitteltüre und stellt sich unter dieselbe.)

Fett: Wenn ich nur glejch recht einen vornehmen Eindruck auf ihn--ich mach' halt alles, was er macht, nachher is's g'wiß nit g'fehit!

Georg (unter der Türe meldend): Der Herr Marquis von Vincelli:

Fett: Iauter, du Esel:

Georg (schreit aus voliem Halse, daß der eben eintretende Marchese beinahe erschrocken zurück-

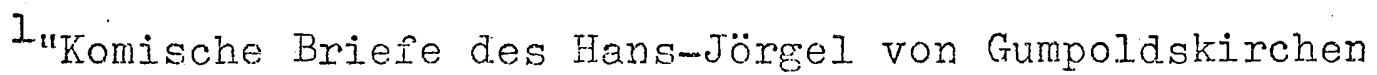
an seinen Schwager Maxel in Feselau und dessen Gespräche iber dje Tagesereignisse in Wien", Nachbildung der berihmten Eipeldauer Briefe (1785-1821). (Rornmel), GW-IV, An-. hang, $p .731$. 
prallt): DeI Herr Marquis von Vinceliz:

Fett: Habe die Ehre: (Vincellis Grus und Kopfnicken imitierend.) Herr Vincelli vermut. lich!?

Vincelli: Marchese Vincelli, so ist es!

Fett: Herr von iett, so ist es! (Fin sich) Auf die Art kann's nicht g'fehlt sein-mud jetzt will ich zeigen, daB ich ein gebietender Herr bin. ( $\mathrm{Zu}$ Georg) $\mathrm{Na}$, du Dalk, siehst nicht, daß wir Sesseln brauchen, laBt uns dastehn als wie ein paar. Maulafien und--ah, es is schrecklich-m

Vincelli (für sich): Welche Pöbelhaftigkeit-m: Viir vergehen fast die Sinne: (Beide setzen sich)

Fett: Aha, wegen der Heirat von Ihrem Sohn mit meiner-

Vincelli (für sich): Mit aiesem Menschen wollte mein Sohn mich in Verbinaung -.. (zu Fett) mein Herr, vergessen sie nicht, wie gros der Unterschied unseres Ranges, unserer--

Fett: Larifari, tschiritschari--Sie hab'n a no weit hin, bis S. Kaiser von Marokko sein. Und sie is eine, die Maxen2 hat.

Vincelli (für sich): Schatten meiner Ahnen-Maxen -n's ist abominable!

Fett: Übrigens muR ich Ihnen sagen, jich kimmer. mich um den ganzen Balawatsch nicht so viel.?

Vincelli (fur sich): Balawatsch-..ich komme von Sirinen!

Fett: Das is der Iucia Distel ihre Sach', da soll sie-..

Vincelli: Lucia Distel-welch ein Name!

Fett: Na, weg'n Namer, das wär's geringste, wenn $s^{\prime}$ Ihren Sohn heirat't, nacher is sie eine Bintschelli:

Vincelli (heftig): Daraus wird nichts! (fiur sich) Um jeden Preis muß da vorgebeugt werden! (zu Fett, in freundicheren Tone) Hören Sie, mein lieber-...

Iahnlich "Jarifari", ein Ausdruck der eine Vorhaltung als verächt]ich und unsinnig entwerten will.

${ }^{2}$ Geld. (nach Rommel, vielleicht ein Goldstick, Max d'or', nach dem bayrischen Kurfirsten Max Emanuel benannt).

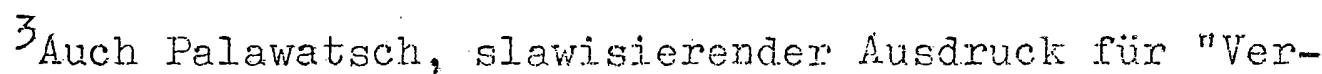
wirrung, Unordnung". 
Fett (für sich): Aha, jetzt zieht er schon andere Saiten auf: (zu Vincelil, indem er ihn derbvertraulich aufs Knie schlägt) So is recht, nur $z u$ in der Dj.cken, den I'on la ' ich mir g'faII'n.

Vincellí ( für sich): Geister meiner Vorfahren--: (Sich wieder fassend, zu Fett) Sagen Sie mir aufrichtig, suchen Sie vielleicht pekuniären Gewinn bei der Sache?

Fett: Sie--jetzt hätt' ich bald g'sagt, Sie Dappschädj, Sie-ich bir eh ein reicher Kampl. Wissen $S^{\text {'i }}$ was, ich will Ihnen ein' Rat geben: wann Sie durchaus nicht anbeißen wollen, so waschen $S^{\prime}$ Ihrem Buben tüchtig den Kopf--oder noch besser-meden $S^{\prime} z^{\prime}$ erst mit ihr, ich schick' Ihnen $s^{\text {"her. }}$

Vincelli: Ja, ganz recht, tun Sie das, mein Bester! (Steht auf)

Fett (ebenfalls aufstehen): Na, bin ich a Kerl, der in d'Welt taugt, oder nicht? Sixt, Alter, nur reden muß m'I! Jetzt laß air derweil die Zeit nicht lang wer'n, Bruder Tschinelli, ich schick' dir s' her, wart' nur ein' Augenblick du Teuxels-Tscininelii, du: (Geht durch die Seitentür links ab)

Vincelli: Das kostet mich zehn Jahre von meinem Leben. Die Gemeinheit dieses Menschen hat mit völiig die Glieder verrenkt--ich bin dem irsticken nahe, ich muß Blut lassen, in Dampfbädern schwitzen, Brunnen trinken und mich durch langanhaltende Etikette wieder purifizieren.

(GW-IV., 154-1.57)

Iucia Distel, Iedige Schwägerin von Fett und sein weibliches Gegenstück, beschließt die Unterredung mit dem Marchese: "Ich sag Ihnen's in guten, mein bester Ilerr von Violoncelli, so kommen Sie mir nicht mehr!" (GW-IV., 160). In einem abschließenden Monolog sagt der Marchese Vincelli unter anderem: "Ich möchte mich lieber ein Stündchen in die Gruft meiner Ahnen setzeì, um von edlem Moder umgeben, die pöbelhafte Iuft zu verschmerzen, die ich hier gea.tmet." (GW-IV., 160).

Bei Nestroy erscheinen Adeljger und Farvenu komisch, Vincelli weil er überspant ist, Fett und Iucia weil sie 
unzulänglich sind. Fett möchte als Vornehmer auftreten, aber seine Primitivität schlägt immer wieder durch. Der Marchese will unnahbar bleiben, aber Fett durchbricht alle Schranken. Nestroy greift hier auf die HanswurstTradition der ilener Volkskomödie zurück. Das Verhältnis Fett-Vincelli ist vergleichbar mit dem zwischen Hanswurst und der höfischen Velt. Ein wesentlicher Unterschied besteht jedoch in der störung der Einheit beider Welten. Die Selbstgewi Bheit des Adels wurde durch Hanswurst nicht innerlich betroffen, auch wenn er in naiver Unverschümtheit derb-vertraulich wurde. Nestroy zeigt, wi.e durch den reichgewordenen Fett der Adel in seiner in.neren Substanz getroffen wird. Dem Unterschied des Ranges setzt Fett seine "Maxen" entgegen. Mit spottenden Namenverderhungen ${ }^{I}$ glaubt Fett den Narchese auf sein Niveau herunterzuehen zu können. Durch die Figur von Lucia Distel unterstreicht Nestroy nur noch die Primitjvität von Fett. Eigentlich verachtete Nestroy als Intellektueller den beschränkten Kleinbürger genauso wie den protzer den Parvenu. Der Zusammenbruch der Standesgrenzen war für Nestroy demnach nicht nur AnlaB zur Komik. Als Satiriker glaubt er an die Unzulänglichkeit des Menschen, gleichzejtig aber verwirft er auch die Möglichkeit einer Gleichstellung aller Menschen-nur die Ujbertreibungen verfallen seiner Satire.

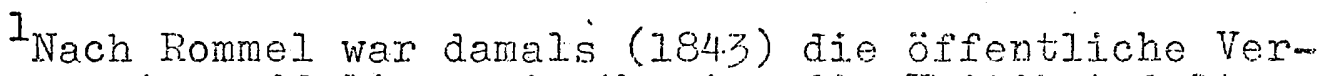
spottung eines Adeligen ejn Wegnis; die Fritik tadejte Nestroy deswegen. (SW-XI, p. 622). 
Nach der Revolution von 1848 übt der "politische" Schneider Heugeigen in einem Couplet (Iady und Schneider) Kritik an der "Gleichmacherei".

Doch die Gleichheitsversek'nen sag'n gar, es soll rein Zwisch'n ein' Schust'r und ein' Herrog rein Unterschied sein:

Und grad, wenn wir in Rang und stand elle sind gleich, Wird noch bitt'rer der Abstand werd.' zwisch'n arm urd reich;

Mit zehn Fürsten und Grafen red't man Ieichter ganz g'wiß

Als mit ein" Flecksieder, der Millionär worden is. Auch Aufwand, Juxus, Verkehr, fallt alls mit d'grosSo daB d' G'werbsleut. vor Gleicheit noch betteln gehn wer'n..... Schaut man $a^{i} G$ leichheit so an, sagt msin: "Nein, Da hört es auf, ein Vergnïgen zu sein."

Daß alle Menschen gleich werden können ist eine Urmöglichkeit; die wirtschaftiche Chance eines rlecksieders Millionär an werden ist hier ironisch behandelt. Würe der Flecksieder aber Millionär--wäre er trotzdem weder "Herr" noch "gleich" mit den Adeligen. Mit Hilfe von Ironie weist Heugeig'n den schönen Ideen ihren eigenen Vider.. spruch nach.

Fin Freund des Adels war Nestroy nicht; sein satirischer Angriff traf ihren Adelsstolz genau so wie ihre unbegründete Utberheblichkeit. In adeliger Geseilschart wird die Frau des reichen, aber nicht adeligen Grundbesitzers Kern (Der alte Mann mit der jungen Frau) ohnmächtig. Die Gräfin Steinheim bemerkt daraufhin zu Baron Wet-terhahn mit Bezug auf ein "adeliges Privileg": "Es ist empörend, solche teute wollen auch schon ohnmächtig werden." (GW-V., 4OI). Diese FeststelJung der Gräfin wirkt 
im Zusammenhang der Szene als Spott auf die Utberheblichkeit und Gefühlskälte der Gräfin. Die Verwendung eines falschen Adelstitels greift Schlicht in der Posse Mein Freund an. Ein ehemaliger Bekannter Schlichts; Julius Fint, gibt sich jetzt als Baron von Hohenfint aus--Fint will in einer Heiratsangelegenheit die Unterstützung Schlichts gewinnen.

Julius: Die Auseinandersetzung, wie ich zur Kenntnis und zu den Rechten meiner Geburt gelangte, bedarf längere Zeit...

Schlicht: - . und ich sag' Ihnen, das das wirklich ein spariges Zusammentreffen 's. Sie reden von Inren Rechten der Geburt, und ich studier grad, ob es recht is, dal Sie geboren sinda.

Hier wird die Person für inr Verhalten verantwortich gemacht, eine sachliche Voraussetzung löst den Angriff aus. Weil es in diesem Fall nicht zuerst um den Typus, sondern den Einzelfall geht, hat die Satire polemischen Charakter.

Die Mode als zeitgebundenen Ausdruck, als "Garderobe", hat Nestroy begrüß; satirisch beleuchtet hat er die Unstimmigkejten, das "aufputzte Nesen". In Iiebesgeschichten und Heiratssachen heißt es:

Ja, es glaubt's kein Mensch, was der Mensch alles braucht, bis er halbwegs ein' Menschen gleichsieht. Kurios, der Mensch, heist's, is das Meisterstück der Schöpfung, und man muß sich völlig arm zahI'n an Schneidern, daß man das Meisterstuck nur gehörig verstecken kann. (GW-IV., 126)

In dieșem Wortspiel weist Nebel (Nestroy) dem Menschen seine Unzulänglichkejt gleich zweimal nach. Er ist gar nichts so Besonderes, der Mensch, denn er versteckt sich hinter der äußeren Aufmachung. Der innere Wert eines 
Menschen wird ohne teuere Kleider gar nicht beachtet. Um das satirische Enthüllen war es Mestroy ernst. Die Verpflichtungen für den äußeren Schein werden umso größer, je mehr das innere sein an hert verliert.

Mit der DarstelIung ajes intelligenten Arbeiters Gottlieb Herb (Der SchüzIing) geht Nestroy uber die TypenTradition der Wiener Volkskomödie hinaus. Aber wie alle Komödiendichter, reagiert auch Nestroy auf die Veränderungen der Geselischaftsordnung und die Strömungen der Zeit. Durch die Gestalt des Gottlieb stellt Nestroy den gerade "modernen" Selbstmord-.das "Verther-bieber"-wals Pose dar. Als Vorwand zu Gottliebs Selbstmord dient der ablehnende Bescheid eines Stellungsgesuches. In einem Monolog legt er daraufhin seine Gründe auseinander. .

Es gibt wohl viele, die ganz stolz den selbstmorä eine Feigheit nennen .. "s Moralisieren is leicht, wenn man die lelt vom grünen palgrund aus betrachtet, ich aber schau' sie vom Giphel des kahlsten aller Felsen, vom Kulminationspunkt alles Elends an, und in dieser Vogelperspektiv" haben die bausbackigsten Sentenzen eine hohle, nichtige Gestalt: $(G W-I V, 622 / 23)$

Mit übersteigerten Ausdrüken parodiert er das Fathos. Immer wieder setzt er die Pistole an, doch ebenso oft wird er gestört. Eine Drehorgel spielt im Hof, eine Feier in der benachbarten Wohnung und der kurze Besuch eines Freundes-alles hëlt ihn zurück. Er redet sich ein, Rücksicht nehmen zu müssen auf seine Umgebung.

Nein-das seh" ich schon, hier kommt kein ordentli- " cher. Selbstmord zustand' Alles braucht einen zweckmäßigen Ort--die Liebe den Blunenhajn, die Freude den erleuchteten Bankettsaal, die Trauer den schwarzbehangenen Katafalk-mauch der SeIbstmord will sein 
IokaI, will seine Deforierung haben: abgelegene Gegend, feuchte Nacht, Sturmgewölk" das in seiner. Zerrissenheit über den ruhigen, klaren Mond herfahrt, wie ein zerrissenes Gemit, das mit der Vorsehung hadert, Vindessausen im Baumlaub, die Äste knarren, der Uhu krächzt, die Turmuhr dröhnt--angesetzt-mein Knall-und 's is vorbei: So soll's sein! $(G,-I V, 625)$

Nit scharfer Ironie wird die Romantik mit ihrer überdennten Darstellung der Natur, bei der die Natur zur Kulisse wird, angegriffen. Antithetisch wird dem "ruhigen, kiaren Mond" das "zerrissene Gemüt" gegenübergestellt. Später als Gottileb in einer abgelegenen Gegend nochmals versucht sich zu erschieBen, jst ihm die "Nacht bei. weitem nicht schaurig genug". "Geduld--vielleicht macht sie sich

" noch bis Vitternacht:" Der ironische Spott gilt der Idee des "romantischen" Selbstmordes. Am Finde seines "Ent schlusses" stellt Gottlieb fest: "Es j.st beinah, als ob uns die Natur zeigen wollt", daß aas miserabelste Leben mehr Wert is als der brillanteste Tod." (GH-IV., 632). Berufe und Institutionen verfallen bei Nestroy oft der Typisierung ohne dem Besonderen Rechrung zu tragen. Durch Verwendung der juristischen Fachsprache, die sjoh in ihrer rein funktionelien Art von dem mundartichen ivienerisch unterscheidet, ergeben sich deshalb starke Kontraste. (Die Sphäre des Rechts war Nestroy durch sein früheres Jusstudium vertraut.) In dem Amtsschreiber Klecks (Nur Ruhe) zeichret Nestroy einen ausgeprägten juristischen Charakter.

Klecks (zu Herrn von Horniss].): Bjtte um nockmalige Namhaftmachung sämticher Verbrechen.

Herr von Hornissl: Er ist mit meiner Frau auf und davongegangen. 
Klecks: Widerrechtljche Fhestörung, erschwerende Umstände: auffallende Stellung bei geschehener Attrappierung.

H. von Hornissl: Mejne Ehre als Gatte is kompromitti.ert.

Klecks: Das auch; verheiratete Enrenbeleiäigung, erschwerende Umstände: Alter der Verlockten.

H. von Hornissl: lieine Tochter hat er aus den väterlichen Armen gerissen.

Klecks: Das hat er auch getan? Ungesetzlicher Kinderraub, erschwerende Umstönde: Einfihrung der Schuldlosen in den gleichzeitigen Wohnort eines verithrischen Nerkfuhrers.

Schafgeist: Hör'n $S^{\prime}$, jetzt hab'ich's bala genug! Klecks: Still! Das Gericht hat nie genug:

H. von Hornissl: Seinem Neffen, der den meinigen ins Wasser gesturzt hat, hat er zur ir]ucht verholfen.

Klecks: Das hat er auch getan? Unterschleif und Teilnahme an Mordversuchsattentatveracht, erschwerende Umstande-...

Schafgeist (höchst ärgerlich): Das Sie ein boshaftiger dummer Kerl sind.

Klecks: Also auch Ansehnsverletzung des Reprësentanten des Krimjnaltribunals? Erschwerender Umstand: ein öffentlicher dummer Kerl. Da häufen sich zu viele Verbrechen! Fort mit ihm! (Winkt den Wächtern) (GW-IV., 267)

Für Klecks existieren Menschen nur in der Form ron Gesetzesbrechern. Er wendet daher aus seiner Sicht den vienschen auf das Gesetz an-wund nicht das Gesetz auf den Menschen. Finfache Tatbestände werden von KJecks in eine komplizierte, unsinnige Sprache übertiragen und dadurch verdreht. So wird aus der Threnbeleidigung, die Herr von Hornissl angibt, eine "verheiratete Ehrenbeleidigung". Die schablonenhaften Wiederholungen und Verallgemejnerungen des Amtsschreibers zejgen sein starres Denken. Durch das "juristische Schema" wird aus der ganzen Handlung ein satirisches Zerrbild. Klecks kennt sich nur als Repräsentanten des Gerichts, nicht als ejgenes Ich. Nur mit dem tendenziösen "Sti.1I:" beleuchtet er seine zynische 
Gemütsanlage. Diurch die satirische Darstellung des Amtsdieners greift Nestroy auch indirekt die unpersönliche Institution des Gerichtes an.

Mit seiner antiklerikalen Geisteshaltung stand Ne- • stroy den Josephinern und Liberalen nahe. In der Literatur der Zeit fand diese Stimmung durch Grillparzer, Lenau, A. Grün u.a. ihren Ausdruck. Aus Zensurgründen konnte Nestroy seine Angriffe gegen die Machtistellung der Kirche vor der Revolution (1848) nicht auf die Bühne bringen. In der Posse Höllenangst (1849) glauben der Schuster Pfrim und sein Sohn Wendelin, der Teufel habe mit ihnen einen Vertrag gemacht; sie beschliepen, den Böm sen zu prelien.

Pfrim: Nix leichter als das. Auf zehn Jahr' schliebt er mejstens seine Kontrakt', da machen wir das Ding so: Neun Jahr! Ieben wir recht flott und fidel, und im zehnten Jahr gehen wir auf Rom, nacher is der Teufel erst noch der $G$ 'foppte.

Wendelin: $\mathrm{Ja}$, geht denn das?.--

Ffrim: In Rom geht alles. Also g'scheit sein: Wendelin: Mir fallt eir halbeter Stein vom Herzen. Pfrim: Wie g'sagt: Neun Jahr' fidel leben und im zehnten Jahr Buße, das is das Wahre; $(\mathrm{GT}-\mathrm{V} \cdot, 283)$

Nestroy macht die falsche Ansicht von christlichen Leben und christlicher Buße sichtbar. Man darf seelenruhig ein ausschweifendes Leben führen, eine Bußfahrt nach Rom sichert die Absolution. Die scheinbar moralische Idee der späteren Besserung wird verspottet. Die Zusammenarbeit von Kirche und absolutistischem staat miBfiel Nestroy ebenso wie die politische Betätigung des Klerus. In dem Revolutionsstück Freiheit im KrähwinkeI begrijßt 
er die Vertreibung der Iigoxianer ${ }^{1}$ mit einem Chor.

Wir sehen mit Freuden

Die schwarzen Herren scheiden,

O herrliche Zeiten:

Vorbei jst der Druck:

's is memento mori.

Für d.' Brüder Ligori

O bittrer Zichori,

Kommts nimmermehr z'ruck: (GW-T,, 121)

Das Ade für die "schwarzen Herren" ist hier aktuelle satirische Zeitkritik.

c. Geld

Die Macht und Bedeutung des Geldes war schon immer Angriffsziel der satirischen Kritik. Das Geldmotiv hat in der Tradition der Wiener Volkskomödie große Bedeutung. Hensler sagt in der Teufelsmühle am Wienerberg: "Geld ist Meistex in der Welt, Geld macht zum Mann, Geld macht klug den faden Wicht." 2 . In Neisls Besserungsstück Der lustige Fritz heißt es: "Seit die zauberischen Talismane aus der Welt verschwunden sind, ist das Geld an die stelle getreten--das zaubert alle Augenblicke, als wenn wir in einem Feenreich lebten."3 Quecksilber, der Held in Raimunds Barometermacher guf der Zauberinsel, bekommt von der Fee einen Stab, der alles in Gold verwandelt. Die Macht des Goldes zeigt sjch: als die Matrosen davon erfahren, fallen

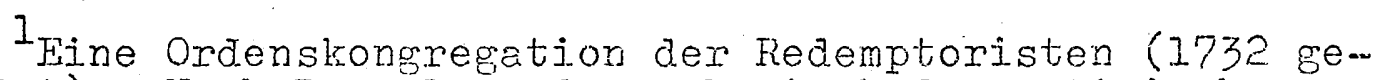
gründet). Nach Rommel wurde mechanisch das satirische Klischee, welches Aufklärung und Liberalismus gegen die Jesuiten ausgebildet hatten, auf die Iigorianer übertragen. (GW-V., 721 Anhang).

${ }^{2}$ Otto Rommel, Barocktradition im österrejchisch. bayrischer Volkstheater (Leipzig: Reclam Verlag, 1935-38) $\bar{B} \bar{d}$. II, $178 \mathrm{ff}$.

İbid., Bd. IV, p. 48. 
vor Quecksilber auf die Knie.

Nestroy betonte die Bedeutung. des Geldes noch stärker als seine Vorgänger. Die Behandlung des Geldmotivs in der Wiener Volkskomödie vor Nestroy war naiv. Auf die verderbliche Virkung des Geldes wurde zwar hingewiesen, am Fnde abex gezeigt, daß man "gesund und fröhlich" auch ohne Geld leben kann. Nestroys Skeptiker wi.ssen, daß man Geld haben muß, auch wenn einem aje Rolle, die es in der Gesellschaft spielt, nicht gefällt. Der Diener Nebel (Liebesgeschichten und Feiratssachen) vexspottet den Philosophen, der sagt: "rreilich, Geld macht nicht glücklich-aber der Gott dankt hatt', wenn ihm wer eins g'liehen hätt" (GW-IV. 113). Schon in dem Zauberm spiel Der konfuse Zauberer oder Treue und Flatterhaftigkeit wird die Zufriedenheit ironisch belächelt. Der Magier Schmafu "besticht" in einer wichtigen Sache einen Geist mit einem Kreuzer und empfiehlt ihm: "zufriedenheit ist der größte Reichtum. Bewahre djese Grundsätze!" (Gi-I. , 442).

Bezeichnend ist, woran Nestroy den Hausknecht Melchior (Einen Jux will er sich machen) zwei Einbrecher, die dieser zunächst für Gespenster hält, als Menschen erkennen läßt。

Melchior (hinter den Fenstergardinen hervorguckend, schaudernd für sich): Den leichten Tritt, man hört's gar nicht: es sind Geister!

Rab: Ich meinesteils mache mich immer gleich aus dem staub, wenn ich das Geld habe, denn nur Geld, Geld....

Melchior (für sich): Sie gehn aufs Geld, es sind Menschen. 
Rab: Nitt Pretiosen befaß' ich mich nicht so gern. (Nimmt von Weinberl die Laterne und nähert sich dem Silberkasten.)

Weinberl: Ah was, Silber is auch nicht zu verachten, je mehr, desto besser, man hat nie genug.

Melchior (für sich): Sie haben nie genug-es sind Menschen!

(GW-III., 696)

Die Bedeutung des Geldes für den Menschen ist so groß,

daß selbst der dumme Hausknecht Melchior, Mersch und

Geld sofort in Zusammenhang bringt. Das Unersättliche

in Geldsachen wird durch das stehlen von allem, was zu

Geld zu machen ist, noch unterstricher. Durch die komi-

sche Situation wird der spott hier gemildert.

In einem Couplet der Fosse Eisenbahnheiraten weist

der Portrait- und Zimmerlmaler Patzmann dem Zufrieden-

heitsideal mit einer einfachen Uberlegung seine Unmöglich-

keit nach.

Zufriedenheit wird als Surrogat angerüht

Einem jeden, dem's Schicksal kein' Reichtum bestimmt,

Darüber kommen fast alle Gelehrten überein:

Der Mensch kann mit wenigem glücklich auch sein!

Schad' nur, daß die Gelehrten nj.cht erfinden die Kunst,

Wie man dies wenige haben könnt' umsunst.

Der Mensch braucht nicht z'wohnen am schönsten Flatz Wiens,

Aber a Hïtten beim Lini-Graben kost't auch an zins,

Z'Mittag a Pfund Fleisch, auf d'Nacht Augsburger Würst',

Damit lebt der Zufried'ne so gut als ein Tirst;

Doch selbst dazu hat man d'nötigen Maxen oft nicht;

Der G'nügsamste macht dann a so a langs Gesicht?

Laßts mich aus mit der Welt,

Es is nix ohne Geld! (GW-IV., 331.)

Patzmann spottet hier über den "Ersatz" für das Geld, aenn

er glaubt einfach nicht daran. Nur die Reichen können

sich den Luxus der Zufriedenheit leisten.

Es ist nicht das Gelt selbst, gegen das sich Nestroy wendet, sondern dagegen, daß es dem Menschen zum Ideal 
wird und zum $Z_{i e l}$ seines strebens. Darüber äußert sich Wendelin in der Fosse Föllenangst: "Und dem Gold erzeigt d'Nenschheit fast göttliche Ehr', d'meister Leut' geb'n ihr Seel" drum als Agio her." (GW-V., 264). In seiner Art erinnert der spott auf das Gold an die satirischen Predigten Abraham a Santa Claras gegen das Geld. In seinen Ekklesiastes X heißt es: "O allmächtiges Geld, dir geschieht die größte Ehr'--Pecuniae oboedinunt omnia, Geld kann alles!"

In Nestroys Aphorismen-Sammung finden sich die geistreichen Wort: ". . heiBt Geschmeide-weil es Weiberherzen geschmeidig macht." (GW-IV., 565).

Die Devotion vor dem Geld ist in den meisten stïcken Nestroys ein vielfach abgewandeltes Thema mit satirischer Tendenz.

\section{d. Politik}

Die politischen Possen Nestroys wurden in verschiedenem Iicht gesehen. Während man die Posse Freineit in Krähwinkel als Verherrlichung der Revolution begruilete, beurteilte man seine anderen politischen Stücke (Iady und der Schneider, Höllenangst, Der alte Mann mit der jungen Frau und Verwickelte Geschichten) als Verrat. ${ }^{I}$ Mit Bezug auf die Revolution von 1848 schreibt Rommel, Nestroy "sei rein bürgerlich orientiert gewesen" (SW-V., 394). Die

I Nian hat Nestroy in pathetischer Anklage vorgeworfen, er habe die "edle Sache der Freiheit in den Kot getreten". SW-V., 628. 
Zugehörigkeit Nestroys zom bürerlichen Vittelstand hat sich literarisch richt ausgewirkt, weil es Nestroy in erster Iinie darum ging, die Unzulänglichkeiten der Revolution zu kritisjeren. Nestroy sah sich keiner partei verpflichtet und seine satirischen Angriffe trafen alie Schichten. ${ }^{1}$ Die politischen Possen sind die dichterische Reaktion auf die Revolution, Nestroy ist weder ein systematischer noch ein historischer Denker.

Durch die Typen aus der Iradition der Wiener Volkskomödie und dem Stoff der Vorlagen (bei rreiheit im Xrähwirkel, zoB. die Krähwinkeliaden als karikierende Darstellung der kleinstädtischen Borniertheit) hatte Nestroy bereits den Rahmen der theatralischen Illusion. Nestroy verstand es meisterhaft, aiese"Theater-Wirklichkeit" mi.t Material, das inm die Wiener Gegenwart bot, zu verbinden; eine "Verherrlichung der einzieen Kaiserstadt Wien und der Wiener Art" (nach der Tradition der Wiener Volkskomödie) lag ihm nicht (Rommel). Wie dje gesellschaftlichen Zustände, erfuhren jetzt auch die politischen Ereignisse eine komisch-gebrochene Darstejlung. Ws ist ein Kriterium der Satire, daß sie umso mehr hervortritt, je problematischer die gesellschaftich-politische Situation ist. Zum Unterschjed von E. Alker, E. Leib, und den ost-

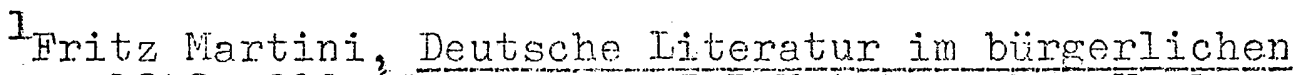
Realismus 1848-1898 (stuttgart: J.B.Metzlerscher Verlag, 1962). "icht nur die reaktionäre obrigkeit, auch die spießbürgerlichen oder leichtherziq-übermütigen Revolntionäre lösen sich in die Karikatur auf. . . .", p. 217. 
deutschen Kritikern, betont Martini, daß Nestroys schwankhaftes Volksapiel" (hier Treiheit in Krähwinkel)

"der Ansatz zu unfassender geselischaftlicher Satire war". I Zu dieser "umfassenden" Gesel]schaftssatire ist es bei Nestroy deshalb nicht gekommen, weil seine Darstellung zwischen Zeitkritik und Komik liegt. Die Figuren als Typen der Satire sind ins Allgemeingütigé abgewandelt, eine Anspielung auf einzelne Personen ist äußerst selten.

Die komisch-gebrochenen Aussagen von Nestroys Hauptfiguren (besonders die seiner Räsoneure) drücken des Dichters skeptische Ansichten aus und sind vielschichtiger. Sie vereinigen in ihrer Person MiBtrauen, Zweifel und Pessimismus, sie sind zu ironisch und witzig um komisch zu seìn. Nestroys Satire erscheint deshalb als "Mißklang seiner eigenen Subjektivität". In einem Aphorjsmus bekennt er: "Das Utbelste is, daß ich da denke, wo man fühlen soll." (Gd-IV., 581). Durch die innere Widersprüchlichkeit erhalten Nestroys satirische Angriffe jene skeptisch-pessimistische Richtung. Durch das Gegenüberstelien der Scheinwerte des AlItäglichen, mit seinen eigenen "nüchternen" Urtejlen iber diese Illusionen er-

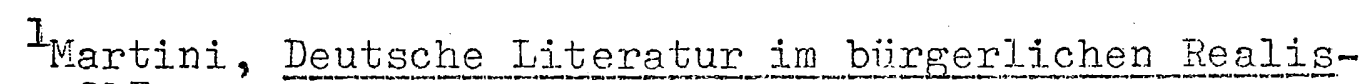
mus, p. 217 .

2Nur einmal brachte Nestroy "Wien ausarucklich" auf die Bïhne. "Eine Wohnung ist zu vermieten in der stadt, eine Wohnung ist zu ver]assen in der Vorstadt, eine Woh-.. nung mit Garten ist zu haben in Hietzing", 1837), das Stück erlebte einen Durchfall, wurde ausgepriffen und von der Kritik verurteilt. 
reicht Nestroy Komik und Satire. Nach der Art des satirischen Maßstabes läßt sich Nestroys Satire am besten in die Satire-Definition Hegels einordnen. Der"Mißklang der eigenen Subjektivität"I bei Nestroy steht im Gegensatz zu der "entarteten Äußerlichkeit"?

Mit seiner Fosse Freiheit in Krähwinkel kam Nestroy den Tendenzen seiner Zeit entgegen. In einem "Hohlspiegel fängt er die Freiheitsbegeisterung" der Revolution ein (Rommel). Von keiner Zensur bedrängt, gibt Nestroy durch Ultra, den Revolutionär und Mitarbeiter der KrähwinklerZeitung, sejne satirischen Kommentare.

Die Zensur is die jüngere von zwei schändlichen Schwestern, die ältere heiRt Inquisition. Die $Z \in n-$ sur is das Jebendige Geständnis der Großen, daß sie nur verdummte Sklaven treten, aber keine freien Völker regieren können. $\left(G N-V_{0}, 82\right)$

Durch das rhetorische Mittel eines Glejchnisses stellt Nestroy die Zensur auf die gleiche Stufe mit der verhakten Inquisition. Die Zensur als Mittel der Großen wird als menschenunwïrig dargestellt. Nestroy hat aus oftmaligen Gelegenheiten die Art der Zensoren beim Zusammentreichen

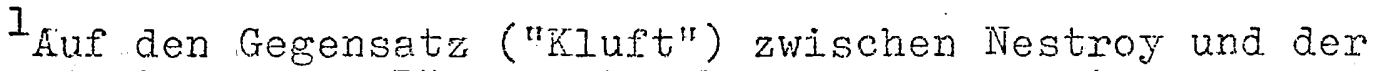
Welt, auf die er als Bühnenautor besonders angewiesen war, macht $F$. I. Mautner aufmerksam: ". . heute wissen wir daß diese Kluft Iruchtbar war, daß wix ihr es zu danken haben, daß seine Komik sich vergeistigte und aktivierte zur Satire." Johann Nestroy, Ausgewählte Werke (Wien: Otto Lorenz Verlag, 0.J.) p. I5.

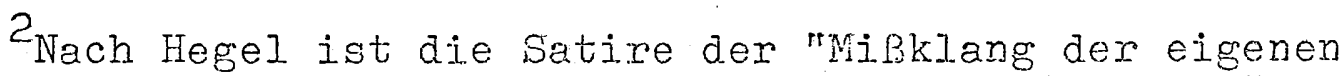
Subjektivität . . der empjuischen Wirklichkeit gegenüber," den "Gegensatz der endilichen Subjektivität und der entarteten AuBerlichkeit". Erwin Rotermund, Die Parodie in der modermen deutschen Iyrick (München: Rides Verlag, 1963) p. 26. 
seiner Stücke kennengelernt.

Ultra: Das weiß ich nur zu gut! Ein Zensor is ein menschgewordener Bleistift oder ein bleistiftgewordener Mensch, ein fleischgewordener Strich über die Ereignisse des Geistes, ein Krokodil, das an den Ufern des Ideenstromes. lagert und den darin schwimmenden Iiteraten die 'KöpI' abbeißt. $\left(G V-V_{0}, 81\right)$

Durch Metaphern steigert Mestroy hier das Wortspièl bis zur satirischen Invektive, ${ }^{I}$ wobei der Zensor an Ende mit einem Krokodil gleichgesetzt wird.

Den Optimismus der Revolution drückt Ultra in einem Couplet aus.

Da fing z'denker an

Der gedrückte Untertan;

'Zum Teuxel hinein,

Milß i denn a SkIav' sein?

Der Herrsch'r is zwar Herr,

$A b ' r$ i bin Mensch wie er;

Und kostet's den Hals.-

Rechenschaft soll. fur alls

Gefordert jetzt wer'n.

Von die großmächtigen Herm.'

Da war' $n$ ' sehr in der Klemm'

Mit 'n Zopfensystem.

(GW-V., 7I)

Weil auch der Untertane ein Mensch ist, fordert Ultra seine Gleichstellung selbst mit dem "Herrn" (Kaiser). Die satirische Kritik gilt dem "Zopfensystem", welches bisher diese Gleichstellung unmöglich gemacht hat. Die Zustände vor der Revolution kritisiert Ultra in einem Nionolog.

Was für eine Menge Rechte haben wir g'habt, diese Rechte der Geburt, die Rechte und Vorrechte des Standes, dann das höchste unter allen Rechten, das Bergrecht, dann das niedrigste unter allen Rechten,

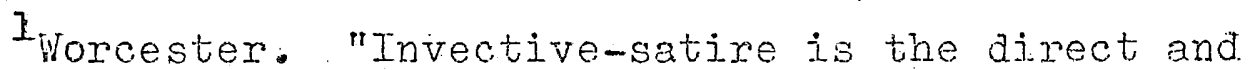
didactic expression of Opinion, relieved from tedium and bad taste by comic mechanisms." $p .44$. 
das Recht, daß man selbst bei erwiesener Zahlungsm unfähigkeit und Armut einen einsperren lassen kann.

Nach den Rechten der Untertanen bis hinauf zum Bergrecht zählt UItra die verschiedenen Freiheiten auf.

Was haben wir ferner alles für F'reineiten g'habt: Utberall auf "n Land und in den Städten zu gewissen Zeiten Marktfreiheit. Auch in der Residenz war Freiheit, in die Redoutensäle nämlich die Maskenfreiheit. . Wir haben sogar Gedankenfreiheit g"habt, insofern wir dje Gedanken bei uns behalten haben. Es war nämlich für die Gedanken eine Art Hundsverordnung. Man hat s'haben dürfen, aber am Scnürl führen!-Wie man s' loslassen hat, haben s' einem s'erschlagen. Mit einem Wort, wir haben eine Menge Freiheiten gehabt, aber von Freiheit keine Spur. (GN-V., $72 f f$.

Hyperbolisch stellt Nestroy die Zensurverordnungen dar, welche den Menschen in seiner Sprechfreiheit einengen. In einem ironischen Glejchnis wird der Untertane durch diese Beschränkung als Hund betrachtet. Trotz all der Freiheiten gab es trotzdem keine wirkliche Freiheit.

Auch nach der Revolution von 1848 griff. Nestroy die Unzulänglichkeiten in der Politik an. In dem "Schicksals-Couplet" der Posse Höllenangst heißt es:

Und doch hab' i auf d'Reichstäg ka rechte Fiduz;

"In medio virtus'-In der Mitte is das Recht"--

Das Sprichwort sagt.klar, was an d'Rej.chstäg is schlecht.

Ober- und Unterhaus haben $\mathrm{s}^{*}$, aber kein Mittelhaus, Drum geht 's drunter und druiber, aber Rechts kommt nix heraus.

$$
\left(G W-V_{0}, 712\right)
$$

Nestroy erkent in dem adeligen Oberhaus, aber auch in dem ständischen Unterhaus, Mängel. Aus seinem Vissen um Maß und Mitte fordert er ein "Niittelhaus". Der satiri. sche Angriff gilt den nicht so ausschlieBlich für das wohl der Untertanen sorgende Regierungssystem. 
In einem Couplet greist der politische Schneider. Heugeig'n (Lady und der Schneider) den Gesinnungswechsel nach der Revolution an.

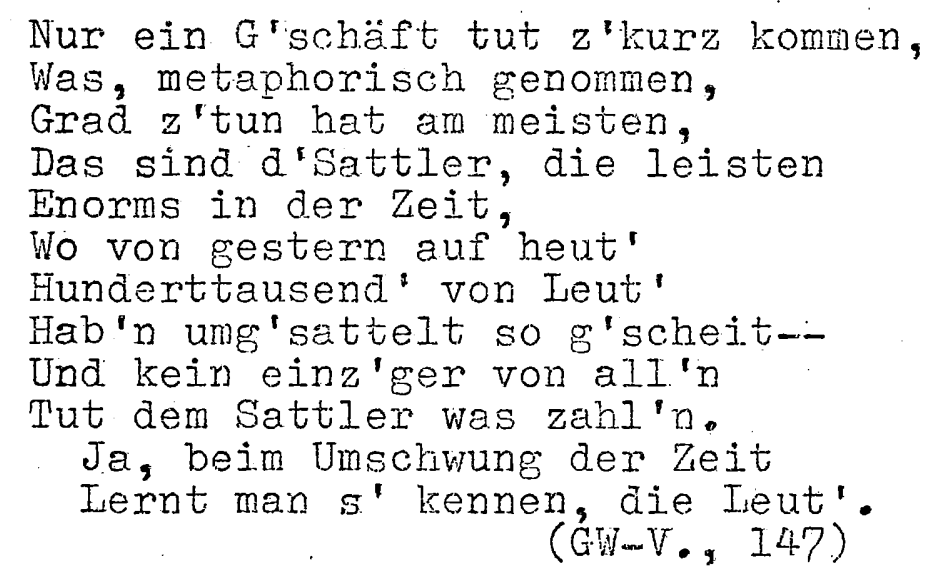

Durch die Doppeldeutigkeit von"unsatteln". und. "Sattler", greift Nestroy das Umsatteln aus politischen Motjven an. Ironisiert wird hier die "G'scheitheit" der vielen Leute, die ihre politischen Überzeugungen einsach über Nacht wechseln und mit jedem System sympathisieren.

Zu den gesetzlichen Folgen einer Revolution äußert sich der Gutsbesitzer Kern, in der von der Zensur verbotenen politischen Posse Der alte Mann mit der jungen Frau.

Nach Revolutionen kann 's kein ganz richtiges Straf-ausmaß geben. Dem Gesetz zufolge verdienen so viele Hunderttausende den Tod...natürlich, das geht nicht; also wird halt einer auf lebens]änglich erschossen, der andere auf fünfehn Jahr' ejng'sperrt, der auf sechs Wochen, noch ein anderer kriegt a Medaille-und im Grund haben $s^{\prime}$ alle das närnliche getan. $(G \forall-V \cdot, 366)$

Eine Revolution steht außerhalb des Gesetzes, sie widerspricht der Ordnung, die durch das Gesetz errhalten wird. Fs ist ironisch, daß man das Gesetz in so willkürlicher Weise anwendet, wenn Huderttausende das Gleiche getan haben. 
Das Überspannte einer Zeit, in der plötzlich biedere Kleinbürger politische Ieidenschaften entwickeln, verspottet Nestroy in der Posse Iady und der Schneider.

Heugeig'n: Opposition muß sein. Aber nur Geduld: (Mit Begeisterung) Sie miissen mich noch wo an die Spitze stellen, sei's Bewegung oder Klub, Iiberal, legitim, konservativ, radikal, oligarchisch, anarchisch oder garkanarchisch, 1 das is mir alles eins, nur Spitze:

(GV-V., 154)

- . Ich kann heut' nacht noch der Mann des Tages werden. Morgen steh' ich nachher schon wo an einer Spitze, und über-morgen bin ich vielleicht der, von dem's abhängt, ob Europa eine pennsylvanische Provinz oder ob Nordanerika eine Vorstadt von Frankfurt werden soll. (GW-V. 170)

Bieglscheer (Sdneidergeselle): Der Herr Heugeig'n hat ihnen versprochen, wie er einmal an der Spitze steht, so is's Arbejten das erste, was er abschafft. (GT-V., 180)

Mit burlesker Ubertreibung bis zum Unsinn wird dex Drang: des politischen Phantasten Heugeig'n nach einer "Spitze" dargestellt. Der satirische Angriff trifft die vielen Partejen, die um 1848 entstanden, den Größenwahn und den erhofften schnellen Aufstieg. Mit hyperbolischen Mitteln wird die Phantasterei satirisiert. Das Versprechen des Schneiders Heugeig'n, die Arbeit abzuschaffen, sobald er an der "Spitze" stehe, bringt eine koraische Entlastung.

Das Streben Nestroys nach einem Mittelweg wird durch den Techniker Edelschein, in einem Couplet ausgedrückt (Die Anverwandten): "Die Freihejt is Iicht, und durchs Licht wird dann Tag, Doch, wie beim Naturprozess, nur nach und nach." (GH-VI., 68I).

I Wiener Dialekt: gar-mein-archisch. 


\section{e. Schicksal}

Mit dem Begriff "Schicksal" hat sich Nestroy zeitlebens beschäftigt und es geradezu herausgefordert. Es widerspricht seinem rationalen Denken, eine willkürliche Macht jenseits aller Vernunft anzunehmen. In einem Aphorismus heiBt es: "Kaum ist die Ernte der Erfahrung glücklich eingebracht, wird der Acker von Schicksal neu gepflügt." (GW-VI., 573). Dem Unberechenbaren des Schicksals versucht Nestroy die menschliche Erfahrung entgegenzusetzen.

Vom Schicksal sind GIück und Unglück abhängig, sie können nach Verdienst oder Willkür ausgeteilt wercen. "Das Schicksal nimmt manchmal, um nicht zu schrecken, die läunige Miene des Zufalls an." (GW-VI., 572). Nestroy (und seine Figuren) wissen aber auch um die Gefährlichkeit, Ungerechtigkeit und grausame Ironie des Schicksals. Für den Ausdruck Schicksal wird manchmal auch Vorsehung gebraucht.

Wendelin: Die Vorsehung hat mit die Reichen, mit die Gliicklichen zu viel zu tun, fïr die Armen bleibt ihr ka Zeit. . . Warum sitzt der reiche Wucherer in der Equipagi, während seine Opfer hinter der Scheibtruhen gehn? Varum kleid't die reiche Fundsmutter ihre Lieblinge in atlaswattierte Schabrakerln, während die arme Menschenmutter für ihre Kinder nix anz'legen hat? . . man sieht's zu deutlich, die Vorsehung hat abg'wirtschaftet.... (GII-V., 269/70)

Hier, in der Fosse Hölenangst, klagt Wendelin die ungerechte Vorsehung an. Selten erreicht INestroy eine so 
scharfe Invektive wie in der Antithetik zwischen der "reichen Hundsmutter" und der "armen Menschenmutter". Eine spottende Ansicht über das Schicksal äußert Nestroy auch in einem Aphorismus, "Schicksalstandelmarkt, denn jedes Schicksal war schon da". (GV-VI., 581, Aphorismen aus den Konzeptblättern). Der unauflösbare Widerspruch der das Wesen des Schicksals charaktexisiert, macht es dem Menschen schwer, das Schicksal richtig zu erkennen. Der fleikige Schlicht in Mein Freund sieht alle seine Vorhaben fehlschlagen, ein Freund betrügt ihn und seine Braut heiratet einen andern. Daraufhin klagt er das Schicksal an: "Da sagt man nur: "Und deine Blitze leuchten nicht?"--macht sejnen Wolken-G'horschamerdiener vor'n Schicksal und gratuliert ihm zur neuen Blamage. Es is wirkljch Iuxus vom Schicksal, daß es Pfeile schleudert; an seinen Fügungen sjeht man ohnedem, dak es das Pulver nicht erfunden hat." (GW-V., 493). I Schlicht spottet über das Schicksal und wirft ihm Blindheit vor. Der Vergleich mit Pulver und Pfeil weist auf die primitiven Angriffsmittel des Schicksals hin. Der Spott steigert sich zum Fohn. In einer früheren Fassung heift es: "Und's is noch was in mir, was ein Triumphgeschrej aufschlagt grad' dann, wenr's mir recht schlecht geht, das j.st mein Schicksalshaß." Der Haß auf das Schicksal macht

${ }^{I}$ Die Zensur sah darin Atheismus, Beleidigung des christlich-religiösen Gefühls, gesteigert durch die scheinbare humoristische Ruhe (Abdruck des Zensuraktes, SW-XV., $373 f f)$. 
Schlicht jedoch stolz.

Nicht immer werden menschliche Handlungen für die Verkehrtheit der Welt verantwortich gemacht. Vom Sozialen kommt Nestroy bis zum Metaphysischen--die irdische Regierung kann nicht allein für die Ungerechtigkeiten verantwortlich sein. ". . Revolutionärs stürmen in der Regel gegen die irdischen Regierungen. an. Das ist mir zu geringfügig, ich suche das tbel tiefer oder eigentlich höher, ich revoltiere gegen die Weltregierung, das heißt gegen das, was man eigentlich Schicksal nennt. . . "I Hier gelangt Nestroy zu einer rejnen Kritik des Schicksals.

IEntwurf zu dem "Schicksals-Monolog", Hölenangst, (GW-..., 704 , Anhang)。 
Wenn wir tiefer in die Possenwelt Nestroys dringen, erscheint uns der Mensch darin wie eine Marionette, die von unsichtbaren Fäden bewegt wird. Wir erleben. den Menschen in der Spannung zwischen Schein und Sein, Es war Nestroys Ziel, mit seiner Satire durch die Hiille zum Kern zu gelangen. Aus einem Wissen um MaP und Mitte ist seine Kritik erdgebunden. Es ist das Geheimnis von Nestroys Kunst, daß er uns Wahrheiten lachend zu sagen vermochte. 


\section{BIBIIOGRAPHIE}

Johann Nestroy. Sämtliche Herke. Historjsch-kritische Gesamtausgabe, herausgegeben von Fritz Brukner und Otto Rommel, 15 Bände. Wien: Schroll Verlag, 1924-1930.

- Gesammelte Werke. Herausgegeben von Otto Rommel, 6 Bände. Wien: Schroll Verlag, 1948-49. - Johann Nestroy, Die Welt steht auf kein" Fall mehr lang. Eine Sammlung von Couplets und Monologen herausgegeben von Hermann Hackel. Wien: Forum Verlag, 1962.

- Des wüsten Iebens fliucht'ger Reiz. Ausgewäht mit einem Nachwort von Heinz Politzer. Frankfurt/ Main: Insel Verlag, 1961.

- Liberty Comes to Krähwinkel. The Tor Play Series edited by Eric Bentley. The Tulane Drama Review IV, Summer 1961. New Orleans: Tulane University.

Alker, Ernst. Die deutsche Iiteratur jm 19. Jahrhundert, 1832-1914. Stuttgart: Alfred Kroner Verlag, 1961.

Allemann, Beda. Ironie und Dichtung. Ffullingen; Günther INeske Verlag, 1956.

Arnold, Robert F. Das deutsche Drama. Minchen: C.H. Beck"sche Verlagsbuchhandlung, 1925.

Arntzen, Helmut. Deutsche Satire des 20. Jahrhunderts. Heidelberg: Wolfgang Rothe Verlag, 1964.

Satirischer Stil, zur Satire Robert Musils im "Mann ohne Eigenschaften." Abrandiungen zur Kunst, Musik und literaturwissenschait Bard. 9. Bonn: Verlag H. Bouvier \& Co., 1960.

Battaglia, Otto Forst de. Johann Nestroy. München: AJbert Langen-Georg Mülier Verlag, 1962.

Baum, Georgiana. Humor und Satire in der bürgerlichen Ästhetik. Berlin: Rütten und Leoning, 1959. 
Bietak, Wilhelm. Das Iebensgefühl des Biedermeier in der österreichischen Dichtung. Wien-Leipzig; 1931.

Böckmann, Paul. Formgeschichte der deutschen Dichtung. 2 Bände. Hamburg: Hof Smann und Campe Veriag, Bd. I. 1949).

- Stil-und Formprobleme in der Literatur. VorEräge des VII. Kongresses der internationalen Vereinigung für moderne Sprachen und Iiteraturen. Herausgeber Paul Böckmann. Heidelberg: Carl Winter Universitätsbuchhandlung, 1959.

Boor, Helmut de und Newald, Richard. Geschichte der deutschen Iiteratur. 6 Bände. Mïnchen: C.H. Beck'sche Verlagsbuchhandlung, $1949 f$.

Borow, Jurij. Über das Komische. Berlin: Aufbau Verlag, 1960 .

Burger, Heinz Otto (Hrsg.). Annalen der deutechen Iiteratur. 2. Auflage, 1. Lieferung. Stuttgart: J.B. Metzlersche Verlagsbuchhandung, 0.T.

Catholy, Eckehard. Das Fastnachtspiel des Spätmittelalters. Tübingen: Max Niemeyer Verlag, 1961.

Dietrich, Margret. Europäische Dramaturgie im 19. Jahrhundert. Graz-Köln: Herman Böhlau Nechfolger, 1961.

Dürrenmatt, Friedrich. Der Besuch der alten Dame (Anmerkung). Zürich: Verlag der Arche, 1956.

- Theaterprobleme. Zürich: Verlag der Arche, 1955.

Ehrismann, Gustav. Geschichte der deutschen Iiteratur bis zum Ausgange des Mittelalters. 4 Bände. Múnchen: C.H. Beck'sche Verlagsbuchhandlung, 1955.

Elliot, Robert C. "The Definition of Satire: A Note on a Method," Yearbook of Comparative and General Literature No. II (1962). Indiana University.

- The Power of Satire: Magic, Ritual, Art. Princeton: Princeton University Press, 1960.

Feinberg, Leonard. The Satirist, His Ternperament, Wotivation and Influence. Ames: Iowa state University Press, 1963.

Flemming, Willi. Die deutsche Barockkomödie. Band 4, Deutsche Literatur in Fntwicklungsreinen, Reihe Barock, Barockdrama. Wili. Fleming (Hrsg). 
Darmstadt: Wissenschaftiche Buchgesellschaft, 1965.

Das Schauspie] der Wanderbihne. Band 3 , Deutsche Literatur in Entwicklungsreihen, Reine Barock, Barockdrama. Wilii Flemming (Hrsg). Darmstadt: Wissenschaftiche Buchgeselischaft, 1963.

Eormkräfte der deutschen Dichtung vom Barock bis zur Gegenwart. Vorträge gehalten im Deutschen Haus Paris 1961-62. Göttingen: Vandenhoeck \& Ruprecht, 1963.

Friedell, Egon. Wozu das Theater. Essays, Satiren, Humoresken (Nestroy Artikel p.108-112). Herausgegeben von Péter Haage. München: Verlag C.H. Beck, 1965.

Fuerst, Norbert. The Victoxian Age of German Iiterature. University Park \& London: The Pennsylvania State. University Press, 1966.

Gibian, George. "The Grotesque in Russian and Western Iiterature" in Yearbook of Comparative and General Literature No. 13(1964). Indiana University.

Gregor, Joseph. Geschichte des österreichischen Theaters. Wien: Donau Veriag, 1948.

Greiner, Martin. Zwischen Biedermejer und Bourgeoisie. Göttingen: Verlag Vandenhoeck \& Ruprecht, $0 . T^{\text {T. }}$

Grimm, Jakob und Wilhelm. Deutsches Wörterbuch. Ireipzig: Verlag von S. Hirrel, $1854 \mathrm{f} f$.

Guthke, Karl S. Geschichte und Poetik der deutschen Tragikomödie. Gottingen: Vandenhoeck und Ruprecht, 1961 .

Haecker, Theodor. Opuscula. München, 1949.

Hämmerle, Alphons. Komik, Satire und Fumor bei Nestroy. Freiburg: Dissertation, 1947.

Hantsch, Hugo. Die Geschichte Österrejehs. 2 Bände. Grazw Wien-Köln: Verlag Styria, 1962.

Hartmann, Nicolai. Kleinere Schriften. 2 Bände. BerIin: Walter de Gruyter \& Co., 1955.

Hauser, Arnold. Sozialgeschichte der Kunst und Jitera.tur. 2 Bände. Mïnchen: C.H. Beck'sche Terlagsbuchhandlung, 1958. 
Hermand, Jost. Iie literarische Formenwelt des Biedermeiers. Giessen: Wílnelm Schmitz Verlag, 1958.

Highet, Gilbert. The Anatomy of Satjre. Princeton: Princeton University Fress, 1962.

Hinck, Valter. Das deutsche Iustspiel des 17. und 18. Jahrhunderts und die italienische Komodie. Stuttgart: J.B. Metzlersche VerlagsónchhandJung, 1965.

Holl, Karl. Geschichte des deutschen Iustspiels. Leipzig: $\overline{1923 .}$

Kayser, Wolfgang. Das Groteska, seine Gestaltung in Malerei und Dichtung. OIdenburg: Verlag Gerhard Staling, 1957.

- Das sprachliche Kunstwerk. Bern-Minchen: Francke Verlag, 1964.

Kernan, Alwin B. The plot of Satire. New Haven \& London: Yale University Press, 1965.

Knoche, Ulrich. Die römische Satire. Göttingen: Vandenhoeck und Ruprecht, 3957.

Kohlschmidt, Werner. Geschichte der deutschen Iiteratur vom Barock bis zur KIassik, Bana II in Geschichte der deutschen Literatur von den Anfängen bis zur Gegenwart. Stuttgart: Philipp Reclam Jun., 1.965.

Kraus, Karl. Auswahl aus dem Werk. Mïnchen: Kösel Verlag, $1 \overline{957}$.

Kutscher, Artur. Stilkunde der deutschen Dichtung. Bremen-Horn: Walter Dorn Verlag, 1952. 2 Bände.

Lazarowicz, Klaus. Verkehrte Welt, Vorstudien zu einer Geschichte der deutschen Satire. Tübingen: Max Niemeyer Verlag, 1963.

Leib, Frymet. Die Gesellschaftssatire bei Nestroy. Wien: Dissertation, 1931 .

Iiepe, Wolfgang. Mensch und Gesellschaft im modernen Drama. Beiträge zur literatur und Geistesgem schichte. Neumünster: Wachboltz Verlag, 1963.

Mann, Otto. Geschichte des deutschen Dramas. Stuttgart: Aifred Kröner Veriag, 1963.

Martini, Fritz. Deutsche Iiteratur in bürgerlichen Realismus 1848-1898. Epochen der deutschen literatur 
V/2. Stuttgart: J.B. Metzlersche Veriagsbuchhandlung, 1962.

- Forschungsbericht zur deutschen Iiteratur in der Zeit des Realismus. Stuttgart: J.B. Netzlersche Verlagsbuchhandlung, 1962.

Mautner, F.H. "Johann Nestroy und seine Kunst" in Johann Nestroy, Ausgewählte Werke. Wien: Otto Lorenz Verlag, $0 . \bar{J}$.

- "Nestroy, Der Talisman" in Benno von Wiese, Das deutsche Drama vom Barock bis zur Gegenwart, Band. Disseldorf: Verlag Bagel, 1958.

"Nestroys Kunst und unsere Zeit" in Schiller Jahrbuch 1963. Stuttgart: KIett Verlags, 1963.

Meuer, Friedrich und Stroh, Friedrich (Irsg). Deutsche Wortgeschichte. Berlin: Verlag walter de Gruy ter \& Co., 1959.

Meyer, Richard M. Die deutsche Literatur des 19. Jahrhunderts. Berlin: Georg Bondi, 1900.

Mïller, Gottfried. Die Theorie des Komischen. Würmburg: Konrad Triltsch Verlag, 1964.

Muschg, Walter und Staiger, Emil (Hrsg). Festgabe für Fritz Strich zum 70. Geburtstag. (p.15-38) Bern: Francke Verlag, 1952 .

- Tragische Iiteraturgeschichte. Bern: Francke Verlag, 1948.

NagI, I.W., Zeidler und Castle. Deutsch-Österreichische Iiteraturgeschichte. 3 Bände. Wien: Veriag Carl Fromme, 1914.

Pfeiffer, Johannes. Utber das Dichterische und den Dichter. Hamburg: Richard Meiner Verlag, 1956.

Reallexikon der deutschen literaturgeschichte. Band I, 2. Auflage 1958ff. Band III., 1928/29. Berlin: Verlag Walter de Gruyter.

Reimann, Paul. Hauptströmungen der deutschen Literatur 1750-1848. Beitrage zu ihrer Geschichte der Kritik. Beriin: Dietz Verlag, 1963.

Rommel, Otto. Die Altwiener Volkstomödie. Ihre Geschichte vom Barocken Welttheater bis zum Tode Nestroys. Wien: Schroll Verlag, 1952. 
Rommel, Otto, (Hrsg). Barocktradition im österrejchischbayrischen Volkstheater. 6 Bände. Leipzig: Reclam Verlag, $1935-38$.

- (Hrsg). "Unbekannte Couplets von Johann Nestroy" in Jahrbuch der Gesellschaft für Hiener Theaterforschung (1951752). Wien: Verlag A Sexl.

Rose, Ernst. A History of German Iiterature. New York: K. Praeger, 1960 .

Rotermund, Erwin. Die Parodie in der modermen deutschen Iyrik. Müchen: Eidos Verlag, 1963.

Schiller, Friedrich. Schillers Werke. Weimar: Herman Böhlau Nachfolger, 1943 ff.

- Uber naive und sentimentalische Dichtung. StutEgart: Philipp Reclam Jun., 1962.

Schmidt-Hidding, Wolfgang. Europäische Schlüsselwörter, Band I., Humor und Witz. Wortvergleichende und wortgeschichtliche Studien. Minchen: Max Hueber Verlag, 1963.

Schneider, Ferdinand. Die deutsche Dichtung der Aufklärungszeit. 2. Auflage. Stuttgart: J.B. Metzlersche VerlagsbuchhandIung, I.948.

Schweizer, Werner R. Der Witz. Bern \& Mïnchen: Francke Verlag, 1964.

Schwietering, Julius. Die deutsche Dichtung des Mittelalters. Darmstadt: Herman Gentner VerIag, 1957.

Seidler, Herbert. Die Dichtung. Wesen-Form-Dasein. Stuttgart: Alfed Kröner Verlag, 1959.

Sengle, Friedrich. Arbeiten zur deutschen Literatur $1750-$ 1850. Stuttgart: Metzlerscher Verlag, 1965 .

Smeall, J. I. English Satire, Parody and Burlesque. Exeter: A. Theaton \& Co.: Ltd., 1952 .

Speidel, Luäig. Kritische Schriften. (Nestroy Artikel. p. 99-105). Herausgegeben von Julius Rütsch. Stuttgart \& Zürich, Artemis Verlag, 1963.

Staiger, EniI. Grundbegriffe der Poetik. Ziirich: Atlantis Verlag, 1951.

Stammler, Wolfgang (Hrsg). Deutsche Philologie im Aufriß. 3. Bände. Berlin: Wrich Schmiat Verlag, 1952 ff. 
Stammler, Wolfgang. Won der Mystik zum Barock in Epochen der deutschen Literatur, Band II/I. 2 . Auflage. Stuttgart: J.B. Metzlersche Verlagsbuchhandlung, 1950.

Stephan, Joachim. Satire und Sprache, Zu dem Werk von Karl Kraus. Munchen: Anton Pustet Verlagsbuchhandlung, 1964.

Straubinger, 0. Paul. "The Reception of Raimund and Nestroy in England and America" in Osterreich und die Angelsächsische Velt. Hrsg. Otto Hietsch. Wien \& Stuttgart: Wilhelm Braumiller (Universitäts) Verlag, 1961.

Sutherland, W.O.S. Ir. The Art of the Satirist. State University of Texas, 1965.

Viëtor, Karl. Gejst und Form. Bern: Francke Verlag, 1952.

Vulliany, C.E. The Anatory of Satire. Iondon: Michael Joseph Lita., 1950 .

Wellek, René. Geschichte der Literaturkritik 1750-1830. Stuttgart: Hermann Luchterhand Verlag, 1959.

Wicke, Günter. Die Struktur des deutschen Iustspiels der Aufklärung. Bonn: H. Bouvier, 1965.

Wiese, Benno von. Friedrich Schiller. Stuttgart: J.B. Metzlersche Verlagsbuchhandiung, 1963.

Wilpert, Gero von (Hrsg). Sachwörterbuch der Iiteratur. Stuttgart: Alfred Kröner Verlag, 1964.

Worcester, David. The Art of Satire. 2. Auflage. New York: Russel \& Russel, 1960.

Battaglia, Forst de. "Nicht Phjlosoph sondern Moralist," Forum, IX (Mai 1962), 208-210。

Berger, Kurt. "Die Dichtung im Zusammenhang der Künste," Deutsche Vierteljahresschrift für literaturwissenschaft und Geistesgeschichte, XXI. (1943), 232-51.

Enzinger, Moriz. "Das österreichische Barocktheater," Osterreich in Geschichte und Jiteratur, $4 \mathrm{Jg} ., \mathrm{H} .1$ p. 18-24. (FIrsg. Institut Iür Osterreichkunde, 1960).

Görlich, Ernst J. "Der geistige Raum der österreichischen Iiteratur," Österreich in Geschichte und Iiteratur, 2. Jg., (1957) H. 4, p.175-180。 
Hadamowsky, Franz. "Die Commedia delı'arte in Österreich und ihre Wirkung auf das Wiener VoIkstheater, Maske und Kothurn, 1957, H. 4, p.312-316. Vierteljahrsschrift für Theaterwissenschaft.

Höllerer, Walter. Eine Rezension iber Beda Allemann, Ironie und Dichtung in Zeitschrift für deutsches Altertum und deutsche Literatur, Bd. 68.(1957), p.127-135.

Kindermann, Heinz. "Nestroy--Revolutionär und Bürger," Maske und Kothurn, 9. Jg. (1963), H. 2, P.132-152. Vierteljahrsschrift fur Theaterwissenschaft.

Kluckhohn, Paul. "Die Arten des Dramas," Deutsche Vierteljahrsschrift für Literaturwissenschaft und Geistesgeschichte, Bd. XIX (194I), p.240 ff.

Kraus, Karl. "Nestroy una die Nachwelt" Die Facke1, No. $349 / 50$ (1912), p.1.-23.

Mack, Maynard. "The Muse of Satire," Yale Review, 1951, p. 80-92.

Magill, C. P. "Austrian Comedy," German Iife and Letters, IV (Okt. 1950), p.3I-4I.

Majut, Rudolf. "Das literarische Biedermejer. Aufrip und Probleme," Germanisch-Romanische Monatsschrift, $\mathrm{Bd}$. XX $(193 \overline{2}), \mathrm{p} .40 \mathrm{~J}-424$.

Mühlher, Robert. "Die Iiteratur zur Zeit der Aufklärung in Österreich," Österreich in Geschichte und Iiteratur, 8. Jg. (1964), H. 5, . .289-297.

Petsch, Robert. "Zwei Pole des Dramas, "Deutsche Vierteljahrsschrift fïr Iiteraturwissenschaft und GeistesEeschichte, Bd. II (1924), p.193 fi.

Reichert, Herbert W. "Some Causes of" the Nestroy Reraissance in Vienna," Monatshefte, vol. 47 (1955), p.221-230.

Riewald, J. G. "Parody as Criticism," Neophilologus, vol. I (1966), No. I, p.125 ff.

Rollet, Edwin. "The Laughter of Johann Nestroy," The American-German Review, vol.XXIX (1.962), ño. I, p.19-39.

Rommel, Otto. "Komik und Iustspiel theorie," Deutsche Viertel jahrsschrift für literaturwissenschaft und Geistesfeschichte, BO. XXI. (1943), p.252-286. 
Rommel, Otto. "Die wissenschaftichen Bernühungen um die Analyse des Komischen, "Deutsche Vierteliahrsschrift fü Literaturwissenechaft und Geistesgeschichte, Bd. KXI $(1945), 0.161-195$.

Schumann, Willy. "Wiederkehr der schelme," PMIA, vol. IXXXI (1966), no. ?, p.467-4.74.

Schweizer Nusikzeiturg. "Der Zerrissene." Urauffuhrung von Gottfried von Einems Nestroy-Oper an der Hamburgischen Staatsoper. Jg. 104 (1954), p.377-379.

Spalding, K. "A Philological Note on Abraham a Sancta Clara," German Iife \& Letters, vol. IJI (1949), no. I, p.64-70.

Staiger, Emil. "Das Problem des Stilwandels," Fuphorion, Bd. 55 (1.961), H. 3, 0.229-241. Zeitschrift fur Iiteraturgeschichte, Heidelberg.

Steinmetz, Horst. "Der Harlekin, seine Rolje in der deutschen Komödientheorie und Dichtung des 18. Jahrhunderts," Neophilologus, I (1966), no. I, p. 95-106.

Tscherpel, R. M. "Die Funktionen der Sprache in der dichterischen Form, "Deutsche Vierteljahrsschrift fur Ijteraturwissenschaft und Geistesgeschichte, $\overline{\mathrm{B}} \mathrm{d} .29(1955), \mathrm{p} .76 \ldots 98$.

Weimarer Beiträge. Begrüdet von $I$. Firirnberg und $H$. $G$. Thalheim, Berlin Ost. 1966, H. 2, p.302 ff.

Wölfel, Kurt, "Epische Welt und satirische Weltw-zur Technik des satirischen Erzählens," Wirkendes Wort, Jg. 10 (1960), $0.85-98$. 